University of Rhode Island

DigitalCommons@URI

Open Access Master's Theses

1959

\title{
The Construction of a Mathematical Manual to Serve Secondary Schools with Particular Reference to Those of North Kingstown
}

Leroy Edwin Algren

University of Rhode Island

Follow this and additional works at: https://digitalcommons.uri.edu/theses

\section{Recommended Citation}

Algren, Leroy Edwin, "The Construction of a Mathematical Manual to Serve Secondary Schools with Particular Reference to Those of North Kingstown" (1959). Open Access Master's Theses. Paper 983. https://digitalcommons.uri.edu/theses/983

This Thesis is brought to you for free and open access by DigitalCommons@URI. It has been accepted for inclusion in Open Access Master's Theses by an authorized administrator of DigitalCommons@URI. For more information, please contact digitalcommons-group@uri.edu. 
THE CONSTRUCTION OF A MATHFMATICAL MANUAL TO SERVE

SECONDARY SCHOOLS WITH PARTICULAR

REFEREHTCE TO THOSE OF

MORTH KINGSTOWN

BY
LEROY EDWIN ALGRENN

A THESIS SUBMITTED IN PARTIAL FULFILLMENT OF THE

REQUIREMENTS FOR THE DEGREE OF

MASTER OF SCIENCE

IN

EDUCATION

ONIVERSITY OF RHODE ISLAND

1959 


\section{MASTER OF SCIENCE THESIS}

OF

LEROY E. ALGREN

\section{Approved:}

Major Proressor to pon peltan

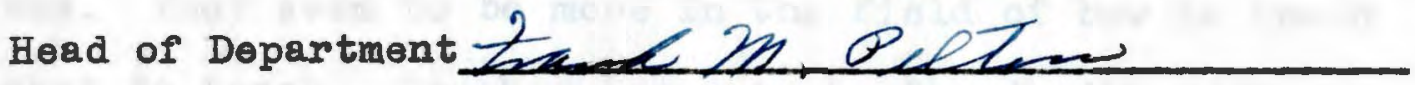

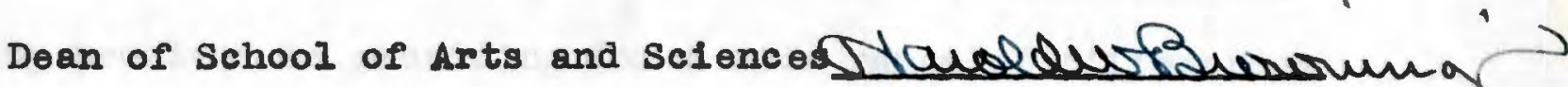

Director of Graduate studies Laten LWL Pellew

University of Rhode Island

1959 


\section{ABSTRACT}

This is not a course of study, and it is not intended as a directive which tells teachers what they should teach in their day by day routine in the classroom. It is designed as a resource for teachers and others who pistr to develop mathematics materials and to work effectively for and with their pupils. It must be acceptable in both theory and practice if it is to be used in the secondary schools of North Kingstown. Much thought has been given to the problems of teachers and the types of materials needed to solve some of these problems. They seem to be more in the fleld of how to teach than what to teach. Teachers seem to be faced with such continuing problems as providing for a wide range of differences in pupils within a group, handling large groups, overcoming the handicap of inadequate materials, and applying their knowledge of the learning process to the education of children. This guide to the development of curriculum materials in arithmetic and mathematics provides a flexible framework of content and procedures. The nature and meaning of arithmetic and mathematics as an essential part of everyday life are stressed in many ways within the reach of each pupil and within each section of the manual. There are included many suggestions as to the inter-relationship of the skills, abilities, and competencies of arithmetic and mathematics with other subjects of 
the curriculum.

As teachers use this manual to give direction and provide suggestions in the building of arithmetic and mathematies curricular materials to meet the needs of pupils, they will find certain areas of emphasis projected for careful consideration. The skills, abilities, and competencies of arithmetic and more advanced mathematics are necessary to the total development of pupils. The place of drill in learning, the use of the textbook in teaching, the principles for evaluation, and many other aspects of teaching have been included. It may well be said that this manual is designed in organization and content to aid teachers in the preparation of curricular materlals that will help pupils in the dally use of skills, abilities, and competencies in the fleld of both arithmetic and mathematics in general.

No time limits have been specified for teaching of various phases of the subject, thus allowing for greater flexibility on the part of the teachers. The intent here has been to guide the teacher into the requirements of the various courses. Such standard courses as General Mathematics, FirstCourse Algebra, Plane and Solid Geometry, Second-Course Algebra, and Trigonometry have been included in this study and will be found in detail within this manual. 
TABLE OF CONTENTS

Chapter

Page

I. INTRODUCTION . . . . . . . . . . 2

II. CRITICAL REVIEW OF LITERATURE '. . . . . 6

III. THE MANUAL FOR SECONDARY SCHOOL TEACHERS

OF MATHEMATICS ............ 16

Introduction . . . . . . . . . . 16

A Statement of Philosophy and Objectives. . . 20

Suggestions for Teaching Effectively . . . . 26

THE MANUAL

General Mathematics: Grades 7, 8, and 9. . 32

First Course Algebra . . . . . . . . . 55

Plane Geometry ........... . 72

Second Course Algebra. . . . . . . 88

Trigonometry .............. 122

Solid Goometry . . . . . . . . . . 139

IV. DISCUSSION . . . . . . . . 153

V. RECOMMENDATIONS FOR THE PREPARATION OF

A MANUAL . . . . . . . . . . 159

ACKNOWLEDGMENTS. . . . . . . . . 164

BIBLIOGRAPHY . . . . . . . . . 165 


\section{CHAPTER I}

\section{INTRODUCTION}

This is a mathematics manual designed for teachers of secondary grades with particular reference to the schools of the town of North Kingstown. The need for, such a manual or guide has grown out of the study of mathematics, particularly that of recent years. Revision and scope have been so greatly extended that, as a result, many teachers find themselves in a quandary when trying to determine what topics will be adequate at any given point in the mathematics sequence.

The purpose of this manual is throe-fold: first, to be of use in a helpful and gulding sense to inexperienced, experienced, and training teachers, both in North Kingstown and elsewhere. Such a manual can be of much value to all. There are oftentimes questions in the minds of now teachers as to proven methods, as well as to acceptable suggestions. It is hoped that both may be found in the body of this manual under the desired subject heading. Also, there are questions as to what material should be covered and to what extent, and whether or not a specific topic should be taken up at a certain grade level. These are sincere questions in the minds of new teachers.

Experienced teachers can find valuable use here. New suggestions for various units might alter and brighten a 
routine which has become overused and, thus, border on boredom. The varied and ample supply of suggestions in each topic under the various subject headings can be of much value to such teachers. The manual is so constructed that any part of a topic can be singled out, as well as its accompanying suggestions. Training teachers will doubtless find the manual an indispensable aid with its valuable suggestions as well as subject content coverage. The answers to many of their questions can be found to the ir own satisfaction.

For adequate teaching of mathematics there needs to be a definite plan. This study was concerned with the development of such a sequence of courses integrated around mathematics to be presented in usable manual form. It must not only be acceptable in theory but also in practice. There is need for building some type of manual that will incorporate the best methods of mathematics teaching so as to give experienced, as well as inexperienced, teachers assistance when needed. In conclusion, the need for such a manual has grown out of the study and increased scope of mathematics in more recent years. The material included in this manual has grown out of a careful study of various reports which have been made on the subject of mathematics revision. The organization of the material has resulted from twenty-one years of experience on the part of the writer in teaching mathematics in secondary schools to all levels of students. Furthermore, the suggestions as to methods and aids result largely in the same manner. 
From one's experience as a teacher of mathematics, there can be seen a need for such a manual which will serve the above-mentioned groups and do specifically the following three things:

1. Organize carefully subject matter at the proper grade level;

2. Offer helpful suggestions for clear, easy, and acceptable presentation to classes;

3. Integrate subject matter with other subjects wherever and whenever possible.

With this in mind, the following manual has emerged. This has been the very purpose of the entire study and contribution.

Prior to this study, no organized syllabus in mathematics has been in evidence in the secondary schools of North Kingstown. It is anticipated that the inftiation of such a program at this level, and at this time, will present no problem not usually associated with such a task but rather, as has been stated, serve as a manual for teachers as they feel the need for such a reference.

This manual has emerged from a philosophy which has guided the very preparation of the curriculum itself. A statement of this philosophy serves as an introduction to the manual as It will be used in the secondary schools of North Kingstown. The outline form was chosen purposely as it facilitates the extraction of any material a teacher may wish to use or the 
adition of further material.

While the very purpose in writing this work was to

serve primarily the teachers in the aforementioned town, this should not be misconstrued with the belief that it cannot serve other teachers. Mathematics teachers in any school system can, without a doubt, find valuable aids and suggestions for their own peace of mind in studying this manual. 
CHAPTER II

\section{CRITICAL REVIEW OF LITERATURE}

Some research in mathematics tends to focus on word counts, objective tests, and other elements which are subject to quantitative handling. However, the, current trend is to place less faith in these statistical studies and more in judgments of value. Carr, Wesley, and Murral conclude that current research is concerned with: (a) identification and measurement of intangible outcomes, (b) certain aspects of social learning and the development of conception through both direct and non-direct experience, (c) efficacy of equipment, particularly visual aids, and (d) development of a great diversity of courses of study, units, and curricula. This study falls into the latter category and its contents are certainly the results of judgments of value.

Research never determines objectives. However, it does make analyses of social trends and purposes, syntheses of opinions, and classifications of educational purposes. In this study, the objective of meeting the needs of children has been sought. Inclusion of certain items in the guide were placed there through personal judgment. However, many articles

IE. R. Carr, H. B. Wesley, and W. F. Murra, Social Studies, Encyclopedia of Educational Research, ed. Walters. Nonroo (1950), p.1215 
of contemporary literature on this subject or in this field have been studied and have had their influence.

Articles on guidance, teaching methods, and supervision have been examined as an ald in determining a philosophy and the objectives for organizing the manual. From such reading one concludes that an awareness of the needs of children because of the unsettled times in which they live is comon to nearly every article regardiess of the field with which they are primarily concerned.

According to Cox, Duff, and McNamara in Basic Principles of Guidancel, the fifth basic principle of guidance reads :

because of:

The need for guldance is particularly acute today

a) Increased complexity of our social organization

b) Rapidity of changes in our social organization

c) The changing character of sanctions as determined by

1.) The home

2.) The community

3.) The church

d) The industrial situation

e) The economic situation

f) The demands of life in a modern democracy

In the foreword of Curriculum Planning ${ }^{2}$ by Krug, the Educational Policies Commission is quoted as stating:

1P. W. I. Cox, J. C. Duff, and N. McNamara, Basic Principles of Guidance (Now York: Prentice-Hal1, Inc.1949), p. 75

${ }^{2}$. A. Krug, Curriculum Planning, (New York: Harper and Brothers, 1950), p. 1x. 
culum program in a local school system, are considered of sufficient importance to list here:

1. Start the problems with an emphasis on real problems of teaching and school life.

2. Don't dawdle over philosophy or objectives.

3. Place stress on materials and activities used in classroom teaching. As soon as possible, the curriculum discussions should get down to cases in terms of what teachers can do in the classroom.

4. Don't gibe at subject matter.

5. Emphasize needed changes and improvements in content of instruction,

6. Avold sweeping demands for structural reorganization.

7. Recognize and build on individual differences in teachers.

8. Utilize as much as possible diversified tools of instruction and learning activities.

9. Recognize and provide for emotional needs involved in group process.

10. Recognize the time problem and try to make provision for it. 1

of the experience method, Featherstone says:

In order to avoid the artificiality, formalism, and aimlessness that often come from trying to teach skills, appreciations, or knowledges separately or by direct and special methods, it is necessary to teach all these skills within the matrix of the total situation in which they operate; i.e., to teach them in the context of situations, problems, and activities that have an obvious and convincing resemblance to the patterns of actual daily living, emphasizing those elements of knowledge, skill, and attitude which are clearly necessary for dealing effectively with the situation at hand.?

Thus, Featherstone's statement has exercised consider-

IIb1d., pp. 218-236

2W. S. Featherstone, A Functional Currioulum for Youth, (Now York: American Book Company, 1950), p.230 
able influence in the decision to outline the subject matter and objectives by subject rather than to construct a series of suggested experience units.

Many appropriate textbooks and courses of study were reviewed to determine current practice in this field. Noticeable were one or more seeming weaknesses in their compilation. This faut has been given due attention in this manual. Oftentimes, the very size is considered a handicap when it interferes with the easy location of material which is to be used in instruction.

A weakness common to most manuals is the lack of concrete alds and suggestions for teachers. Such aids and suggestions are essential particularly for new and inexperienced teachers. However, their use must be so concelved by teachers as not to limit free selection of materials, free adaptations of suggestions, or the inclusion of other materials which might be pertinent to the topic under study. In this sense a manual can be of real value to imaginative and creative teaching. As a result of the use of the manual it is hoped that additional aids and suggestions can be incorporated in 1ts body.

Another weakness common to most manuals of this type Is the lack of suggestions to the teacher that the child needs to be assisted in finding his particular role or function in the class. Instruction seems incomplete when it does not assist the child in finding what his contribution may be to the success of home, school, or community groups. In his search 
for security, the child wants to know what he can do now, not In the future, to become an important member of his group, at the same time contributing to its success.

The improvement of teaching in mathematics, as in other subjects, depends to a large degree on the extent to which conclusions from research find their way into the classroom. Vital questions to the teacher of mathematics today might be: What does research say about the, effective ways of teaching and in what areas of mathematics education has considerable research been carried on? On the secondary school level, readings in mathematics teaching seem to emphasize considerably the need for students to understand. Much investigation is going on at present in regards to the extent to which physical aids and methods are able to contribute to attaining that goal. Experiments with introducing "modern" mathematics concepts to high school students reflect the desire of frontier thinkers in mathematies education to restudy the entire mathematics program.1 Mathematies today as a science or discipline is an entirely different subject than It was a generation ago. New flelds have been added: mathematical logic, mathematical statistics, topology, information theory, and others. Applications of mathematics have been extonded into many new fields. Psychology, economics and even soclology are now using mathematical concepts and techniques

lModernizing the Mathematics Curriculum, Commission on Mathematics of the College Entrance Board, (New York. 1958) 
in much the same way that physicists and engineers used mathematics at the turn of the century.

Devices themselves seldom teach, but in the hands of skillful teachers they can serve as aids to instruction. Investigation has concluded that the chalkboard is the most frequently used aid in mathematics teaching. However there is increasing emphasis placed upon the use of models, filmstrips, and the like. Lecture-recitation still leads as the most popular method of teaching. I

There is some considerable activity of late in the study of the content of high school mathematics courses. This varles from a mere listing of some practical problems for a given course to a controlled experiment in developing a mathematical sequence of topics in which mathematics teachers have themselves become involved. Such experiments have falled to produce any definitive results as to what should be included, although there is great activity in what the schools should do in the mathematical sequence. For implementation to take place, research will need to determine what specific changes can be put into effect with the present teachers. There are problems with reference to what each school system can do, such as how much, which "modern" mathematics can present teachers incorporate in their classes, and how much change can be made in the content of high school courses and still give

IUnited States Department of Health, Education and Welfare, Analysis of Research in the Teaching of Mathematics 1956 and 1957 (Washington: U.S.Government Printing Office,1958). 
security not only to the teachers but to the parents. These and simllar questions remain unanswered.

The Commission on Mathematics indicates that a combination of scores on an aptitude test and an achievement test, when considered with courses taken in mathematics previously, are a good predictor of success in high school mathematics. However, while this may be so, there has not been much to show what motivates students to pursue courses in advanced mathematics.1 There are indications that often secondary school mathematics teachers have been a dominant force in causing high school pupils to carry on such a study. But there is no evidence to show why these teachers were outstanding in their ability to influence pupils.

The Mathematics Commission emphasizes that mathematics should be taught as though it were a language. 2 Numerals are only the names one uses for numbers. In addition, equations are merely statements about numbers that are true, if the correct names are inserted.

New topies, many of which are not taught except to advanced college students, have been added to the current development of mathematics. Intuitive geometry has made vast atrides to find a place in the curriculum, as well as many of the previously mentioned advanced topics. New methods have

\section{Ib1d. p. 27. \\ I Ibid. p. 31.}


been substituted for old. Consolidation has taken place and mathematics has been re-evaluated. Curricular revision is necessary because mathematics is a different subject today than 1t was a generation ago, its applications are vastly more extensive, and its essential nature is now considered to be entirely different. Thus, it had been a growing concern of mathematics examiners that the standard curriculum in the secondary schools was outmoded and outdated. As a result the Comission on Mathematics of the College Entrance Board was appointed in 1955 to study the situation and make recommendations for a more up-to-date and functional mathematics. As has already been stated, mathematics should be taught creatively in terms of structure and pattern rather than through tricks and "gimmicks." On the premise that it does little good to devise a program so strange and unfamiliar that teachers are unable or unwilling to teach it, it is recommended that a modification of, rather than an outright substitution for, the existing curricula be the aim.

What is needed is a careful revision in point of view. Algebra must st1ll be taught, but teachers of mathematics agree that it is more important to teach the student to understand the fundamental ideas and concepts of algebra and their application, than to train the student in a certain number of basic skills, such as the use of parentheses, factoring, solution of Iinear equations and operations with fractions.

A process of elimination and consolidation in determining what should be taught in mathematics must be evolved, 
since topics of greater importance than the classic ones have been developed and are suitable for presentation to high school students.

Just to plan a new curriculum is not enough. It should be recognized that the new curriculum could rapidly become as out-dated as a present one and that mathematics must be taught as a vital force in our lives in which the mathematician must not be afraid to change the rules as new developments make them obsolete. 
CHAPTER III

THE MANUAL FOR SECONDARY SCHOOL TEACHERS OF MATHEMATICS

\section{INTRODUCTION}

There are many ways in which the mathematics taught to pupils in grades 7 through 12 may be organized and presented. This manual is not intended as an instrument by which these raried practices may be reduced to one standard practice. Nevertheless, it has become apparent that a program of mathematics for the secondary school level, which may be considered sound and feasible, should be studied and developed for a given school system in which the plan is to operate. In the light of situations as they exist in the secondary schools of North Kingstown, a program of mathematics has been developed and presented in this manual. Its presentation is in terms of content that can be reasonably expected to be taught in the various levels such as:

1. All teachers of grades 7 and 8 would turn substantially to the same body of content from which to teach mathematics in these grades. This content would be what is usually called general mathematics. It would certainly include a redevelopment and extension of the concepts of arithmetic taught in the earlier grades. It would also include those aspects of geometry and algebra which are simple enough to be comprehended by pupils at this age level and which are applicable in the lives of most people.

2. In grade 9 a dual of fering was assumed. Some pupils would be guided into another year of general mathematics. In the main, these would be pupils who are not likely to need extensive study 
of mathematics in their future plans. Other pupils would be guided into first-year algebra. These would be the pupils who anticipate further study of mathematics because they have an aptitude for and an interest in it, and because it is necessary for their plans.

3. Most of the pupils who take general mathematics in grade 9 would take only one more year of mathematics in high school. This would be a course called Senior General Mathematics. It was assumed that such pupils would usualiy take this course in grade 11 or 12 when their maturity would make the topics studied of first-hand Importance to them. The mathematics (mainly arithmetic) of buying, budgeting, (saving, investing, and the like will be studied by those pupils with an enthusiasm that comes from an awareness of the immediate relationship of such topics to their daily living.

4. Many of the pupils who successfully complete first-year algebra in grade 9 would continue with plane geometry in grade 10, second-year algebra in grade 11, and the solid-geometry-trigonometry course in grade 12. Advanced students would complete their second course in algebra in the first semester of grade 11 thus allowing time during that year for trigonometry and thus leaving open their twelfth year for solid geometry during the first semester and the more advanced work in analytic geometry and the calculus during the latter half of this jear.

Algebra would be treated as a study of mathematical structure, rather than merely the development of manipulative skill in one particular mathematical system. The study of inequalities as well as equations, and of expressions involving the concept of absolute value should be added to the syllabus. Provision should be made for experience in deductive reasoning in algebra as well as in geometry. The introduction of this point of view will require that teachers familiarize themselves with certain concepts not 
ordinarily included in their college training, in particular the notions of set, statements, variable, relations and functions, as these are formulated in modern mathematics. Geometry should bulld a sound understanding of the nature of deductive reasoning, a more adequate knowledge of geometric facts, and an experience in mathematical creativity on a lovel appropriate for each student. Subject matter of Euclidean geometry may include exercises sufficiently easy for almost any student to have the experience of discovering something for himself, but also problems sufficiently complex to challenge the brightest minds.

Existing courses do not always meet these objectives; Instead they include distressingly long lists of theorems to be proved, exclusive use of synthetic methods, and rigidly formalized proof's. Meaningless memorization by rote is often substituted by less able students for any attempt at creative understanding. In this manual there will be found a greatly curtalled list of required theorems, as well as every opportunity to develop spatial conoepts in addition to the concepts of plane geometry.

In the past the emphasis in trigonometry has been on the computational aspects of the subject, particularly the solution of triangles. Today, the problems of trigonometry involve vectors and their components rather than the solution of triangles. The "trigonometry of angles" presently emphasized can be reduced to a much small compass than is now devoted to it. Therefore, certain topics can be completely 
discarded; certain topics can be included in the second year algebra course; and the remainder to constitute the trigonometry program.

It is not recommended here that the inclusion of a course in calculus be a part of the normal high school curriculum. The average student cannot be adequately prepared for such a course in three years, and anything less than a full course will ordinarily be time wasted, since it will not Iit Into any typical college program. A course in calculus deals with ideas that are mathematically quite sophisticated, and mathematical maturity is absolutely essential. There is no value in a course in calculus that merely sets forth rules for calculation and formulas for solving certain types of problems without adequate attention to conceptual difficulties. However, it is not the desire here to close the door on the study of calculus for as the program moves along there could conceivably be a place for the course. Even then high schools should offer calculus only to able students who have found it possible to complete a full four-jear program in three years, and then should be sure that it is taught on a college level with college standards. 


\section{A STATEMENT OF PHILOSOPHY AND OBJECTIVES}

At present, teaching methods generally employed in the secondary schools of North Kingstown are tradition-centered. However, they have progressed to a transitional stage because some changes in methodology have been made ,by individual teachers. These changes fortunately are often concerned with newer and better ways of presenting subject matter material; others are innovations for handing some specific aspect of mathematics by experienced teachers.

Certainly the sincerity and ability of the present faculty are not to be questioned. However, as newer demands are made upon the teaching of mathematics there remains constant need for reevaluation to keep mathematics meaningful. If there is a fault to be found with present methodology, it may be found primarily because it is subject-centered. Teachers who use this subject-matter method of approach generally recognize this inadequacy. Often they are heard commenting that children today are subject to too many distractions and upsetting influences and are, therefore, unable to cope with them. Also, there is danger in stagnation. This will inevitably occur in any school system where active study and experimentation are not both encouraged and practiced.

The transitional stage between traditional teaching and more modern concepts of teaching certainly cannot progress 
until a majority of the teaching staff has a true appreciation of the meaning of child-centered teaching based on a child's interests, ablities, needs, and experiences. When this appreciation has been acquired, methods change rapidly until the desired goal or level in teaching is attained.

Teachers are fully cognizant of the fact that they must concern themselves with the "whole" child which includes his pecial interests, needs, and experiences while they teach the subject material. The difference in concept which is desired is that, while teaching the "whole" child, teachers must be positive that the child is acquiring the necessary basic skills and subject matter. It is then a question of emphasis, which in turn may alter to a very high degree the teaching methods employed. The child is taught the desired sk1lls, attitudes, appreciations, and understandings by his own experiences in a well-planned, meaningful situation.

Certainly a requirement for bringing about a change in teaching methods is the awareness of the teachers that present methods are inadequate. Changes in curriculum content and method become effective as the result of cooperative effort on the part of the entire staff. This effort, in turn, must be stimulated and coordinated to produce concrete results.

Because of the many changes in the world of the child, brought on by profound social, political, and economic trends, there is an increasing need for alertness on the part of teachers in recognizing opportunities for guidance.I There is

IP. W. L. Cox, J. C. Duff, and N. McNamara, Bas1c Prin1ples of Guidance (New York: Prentice-Hall, Inc., 1949), p. 15. 
noed for close personal guidance on the part of teachers. This need is often brought about by the immediate unsettled environment of the child, caused by broken homes, working mothers, and, in some cases, fathers in the Navy or in some other branch of the service.

Better than fifty percent of the secondary school population of North Kingstown are transient. These children are from families of civilian or service personnel connected with the Quonset Naval Air Station. Through necessity, they often follow the father from one assignment to another. Close friends and familiar places are abandoned on short notice. As can easily be seen, these children need speclal attention; yet they, in return, have many cultural contributions to offer because of their background of travel. School is becoming increasingly important to all our students. It compensates for the many threats to their security and the many causes for emotional instability. Thus, the school becomes a second home. Teachers and parents are becoming increasingly aware of the pressure of political factions in our society which wish to influence our thinking. Consequently, the need becomes greater for opportunities to practice analytical or critical thinking in our schools. Our youth need to learn to examine controversial issues with intelligence and forethought, and to reserve opinion and judgment until evidence has been carefully welghed.1 Our schools must provide opportunities for our youth

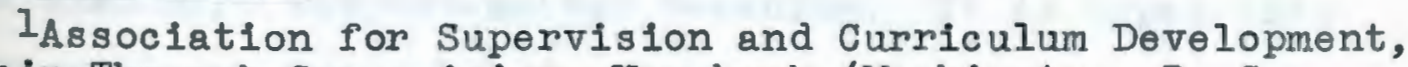
1946) pp. $1-16$. 
to exercise their judgment. They need to be guided through learning situations in such a way that it becomes habitual for them to meke up their minds and decide issues, basing their judgments on the merits of the case or the truths involved rather than to make their decisions because of special group pressures.

Thus, it can be seen that much more is required of the school than was formerly. Tradition cannof be the sole basis for ming decisions on what is important in the school program. And this does not mean discarding the basic tools of reading, writing, and arithmetic. Rather, it means developing a high skill in using these tools, and, at the same time, taking responsibility for new levels of understanding and behavior.

It would be folly to assume that teachers could accept these responsibilities and still keep all the old content of gchool experience. The increasing complexity of demands on the schools forces many decisions. A redistribution of both time and effort then is necessary.

The necessary shift away from subject-centered teachIng cannot be abrupt. The shift in emphasis is slow, since both teachers and pupils must understand, accopt, and have a desire for, as well as contribute to, the change. It is the Intent that this manual may assist teachers who use it, in planning experiences for their students which will prove more adequate than mere subject-matter teaching. It is hoped that It may assist in the development of learning situations which 
w11 provide more opportunities for guidance, and chances to learn desired skills, attitudes, and appreciations.

Skills are taught most effectively when students find that they have a need for them during the work of the unit. When such a need arises, teachers use the opportunity to teach the skills at once. Basic skills must be maintained, whether or not they are related to a unit; thus, one keeps his teaching traditional to some extent by scheduling periods of study in the required basic skills.

This manual will contain ideas and suggestions for experience units with recomendations for their use. No teacher 1s limited by the material in the manual; she may use it as she sees fit by extracting or altering some material or by using her own 1deas. However, the desired skills or competencies should remain the goal, no matter whose ideas are used. Granted that a plan may prescribe the focal points around which the activities of a group are to be developed during a designated period of time and it may indicate the competencies which such activities should advance, there are many equally acceptable alternatives for developing the activities and attaining the specifled competencles. Featherstone says:

If you do not like any of these suggestions and can think of others that are just as good, or better, for achieving the designated purpose, you are free to develop your own plan. You should, however, undertake to make a suitable record of what you do so that your plan can be added to the collection of suggested ways of working. Other people can profit from your exper1ence as well as you can profit from theirs. 1

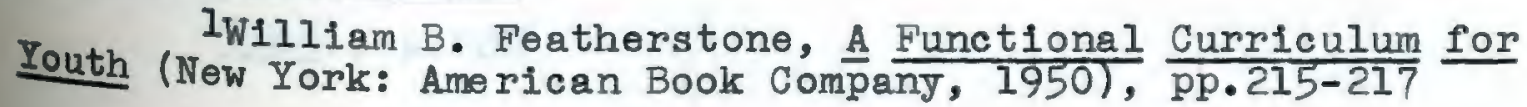


School subjects are a hindrance to creative education only when subjects are looked upon as ends in themselves, and loarning is regarded as a process of passively absorbing subject matter. Subjects are capable of being taught in a highly creative and functional way. Certainly, teaching a subject need not be a mere matter of expounding what has already been learned nor does learning need be a mere matter of absorption. It is possible to use the experience method in the teaching of highly organized subjects.

The problem of determining what curriculum materials to assign to each year has not been solved by research. I The experience of North Kingstown teachers, not unlike others elsewhere, have given them many varying opinions concerning the grade placement of the curricular material. There should be provision for the orderly sequence of the experience units presented and assignment of content material to a year level in terms of the level of abilities, interests, and experience of the pupils.

In this manual developed for the secondary schools of North Kingstown, units and materials presented are suggestions only and teachers are free to use them or any part of them, or to develop their own units which may fulfill the desired objectives. These units do not need to be used necessarily at the grade level suggested. It is possible to repeat a unit at a later level if it provides new experiences and higher lovels of accomplishment. 
SUGGESTIONS FOR TEACHING EFFECTIVELY

It is well for teachers to refresh themselves on some of the salient points in teaching. The answer, in the final analysis, is obvious; teach the child in a way that he learns best. This requires an understanding of the way in which growth, development, and learning occur.

Some of the most important factors to be kept in mind regarding the nature of learning are:

1. An individual learms best when he is guided by his own purposes or goals. Purpose determines what he learns and the degree to which he learns.

2. Chlldren grow physically, mentally, and sooially at different rates. While there are many growth curves which apply generally to children at a given age, many children deviate from these curves in various ways.

3. Learning is a continuous process. It begins in the home before the child enters school and continues both in and out of school throughout his adult life.

4. Behavior is caused and learned. Individuals react to the various forces of their environment in ways that have been learned as a result of the influences of the culture in which they live.

5. A child grows through experiences which provide both security and challenging adventure. A balance in such experiences is needed. Many times all new experiences become overwhelming to the child and cause frustration. On the other hand, the absence of challenge discourages exploration, retards development, and prolongs dependenc $\theta$. 
6. Each individual is unique. Fach child needs conditions and surroundings which will provide for the fullest development of his potentialities in ways which are suitable for his stage of growth and development.

7. We learn what we live. Learning is real only when it is acquired through actual living or through close relationship to former experiences already lived and learned.

8. Individuals learn many things at the same time. The good school provides the kinds of learning situations in which knowledge, skill, and attitudes may be learned simultaneously.

9. Children learn many things through example. The pattern of living predominant in the school is reflected in the attitude and behavior of the child.

It should be remembered that no one of these factors in learning operates separately; they are interrelated in a total instructional program. Learning will take place most offectively when these factors are characteristic of the development of a program for children at any level in the educational system. The test of their applicability often occurs when teachers analyze their classroom practices.

Since every child needs new experiences and at the same time the feeling of security that comes from working with 1deas, people, and things that are familiar to him, the teacher in thinking over the development of any particular child should ask herself: Am I providing a balance between new experiences and the use of old experiences for this child? Does this child face enough new problems to keep him stimulated? On the other hand, does he have opportunities to use his previous experiences often enough to bulld relationships 
and learn from them? Has the child opportunities to grow and develop in all areas of social living within the limits of his ability? Should he have more opportunities to think for himself and to question statements of others? Are the experiences that the child is having in school making a contribution to his development as a person? Are there situations existing through which he can develop those attitudes, understandings, and practices involved in the production and distribution of goods and services, communication, transportation of goods and people, the expression of aesthetic and religious impulses, the conservation of life and property and an adequate recreational life? If the school has helped the child to have meaningful experiences that are appropriate for him in all these areas, its program is contributing to balance in his life.

Every child needs to participate in group activities and at the same time he needs opportunities to work by himself. Some pupils work best in group situations, others do better when working alone, but all children need experiences in both situations. The teacher should analyze the activities of any individual and those of the class as a whole to see whether she is providing for balanced living in this respect.

All children need the recognition that comes from having their contributions to the group accepted as valuable. Every member of the group needs to be recognized for what he is or can contribute and each member of the group needs to be able to recognize others. Therefore, if each pupil's life is to be balanced there must be times when he recognizes others 
and is recognized himself. When the teacher is reviewing the mperiences of any chlld in her group, she should ask herself thether recognition is constantly given to a few or whether each child is having opportunities to lead and to make his iaximum contribution to the group. A child needs to acquire, wthin the limits of his ability, the skills which are inrolved in living a satisfactory life in an increasingly complex soclety. These should be developed when children reach a level of maturity at which they would normally have use for them. In a well-balanced program not all children are expected to develop the same skills nor to develop any one skill to the same degree of proficiency. The teacher who is re-examinIng her efforts to develop skills may ask herself: Is the ohild developing skills which he can use and which have meaning for him? Am I providing for different degrees of academic achievement? Am I challenglng the child to the limit of his capacity? Am I fitting the program to each child or am I fitting the child into a ready-made program?

Children learn in many different ways--by observing, constructing, examining, experimenting, talking, listening, collecting, seeing pictures, reading, and problem solving. To determine whether the teacher's program is balanced with respect to the kind of learning situations that are provided for the chlldren, she can ask herself: Am I giving each child an opportunity to learn by using different media or are his classroom activities confined to one or a few of the possible arenues for learning? Am I using a variety of instructional maperials? 
These are the princlpal ways in which the school program can be viewed in order to see whether it helps pupils to develop well-rounded personalities. This type of analysis should be made for the individual child. Teachers can use the same procedure when analyzing the program as a whole. In making this analysis it is essential that the teacher never lose sight of these facts: (1) that living can be balanced or unbalanced in many different respects; (2) that what cpnstitutes balanced living is different for each individual; and (3) that the task of developing a balanced program is less difficult when teachers take children into their confidence and use them in planning their school program. 
and

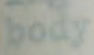

grouk

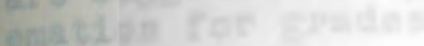

suggentint ang and

bopion b

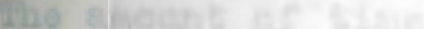

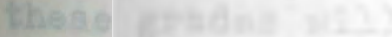

of the pathat

95

some
THE MANUAL 
GENERAL MATHEMATICS: GRADES 7, 8, AND 9.

\section{INTRODUCTION}

It is expected that pupils who come to grades 7,8 , and 9 will come with varying degrees of ability and understanding of the basic arithmetic principles and skills. Thus no body of content may be regarded as equally, appropriate for all groups of pupils in these grades. Hence, the following topics are suggested only as a workable breakdown of the scope of mathematics for grades 7 through 9:

I. Maintaining and deepening the understanding of the fundamental processes.

II. Percentage.

III. Direct measurement.

IV. Home and personal problems.

V. Graphs and tables.

VI. Informal geometry and the formula.

VII. Preview of algebra.

VIII. Indirect measurement.

IX. Mathematics of the school.

$\mathrm{X}$. Mathematics of the community.

XI. Travel and communication.

XII. Government income and expenditures.

No specific classification of these topics by grade is suggested in this manual but rather it is recommended that all topics be partially developed in each of the grades listed. The amount of time to be devoted to each topic in any one of these grades will depend upon two things: the need and readiness of the pupils.

It should be observed that general mathematics in grade 9 is not regarded as a course to precede first-year algebra. It is the intent here that both courses be offered in grade 9 with some pupils taking algebra and others taking general mathematics.

\section{Mathematical Needs of Pupils}

The mathematical needs of all pupils are, for practical purposes, set forth in the Guldance Report of the Commission on 
post-War Plans of the National Council of Teachers of Mathematics. These

1. Computation. Can you add, subtract, multiply, and divide effectively with whole numbers, common fractions, and decimals?

2. Per cents. Can you use per cents understandingly

3. Rat10. Do jou have a clear understanding of ratio?

4. Estimating. Before you perform a computation, do you estimate the result for the purpose of checking your answer?

5. Rounding numbers. Do you know the meaning of significant numbers? Can you round numbers accurately?

6. Tables. Can you find correct values in tables; e.g. Interest and income tax?

7. Graphs. Can you read ordinary graphs: bar, line and CIrcle graphs? the graph of a formula?

8. Statistics. Do you know the main guides that one should follow in collecting and interpreting data; can you use averages (mean, median, and mode); can you draw and interpret a graph?

9. The nature of measurement. Do you know the meaning of a measurement, or a standard unit, or the largest permissible error, of tolerance, and of the statement that "a measurement is an approximation"?

10. Use of measuring devices. Can you use certain measuring dovices, such as an ordinary ruler, other rulers (graduated to thirty-seconds, to tenths of an inch, and to millimeters), protractor, graph paper, tape, callper micrometer, and thermometer?

11. Square root. Can you find the square root of a number by table or by division?

12. Angles. Can you estimate, read, and construct an

13. Geometric concepta. Do you have an understanding of point, IIne, angle, parallel lines, perpendicular lines, triangles (right, scalene, 1sosceles, and equilateral), parallelogram, (Including square and rectangle), trapezoid, circle, regular poljgon, prism, oylinder, cone, and sphere? 
14. The 3-4-5 relation. Can you use the Pythagorean Felationship in a right triangle?

15. Constructions. Can you with ruler and compass construct a circle, a square, and a rectangle, transfer a line segment and an angle, bisect a line segment and an angle, copy a triangle, divide a line segment into more than two parts, draw a tangent to a circle, and draw a goometric figure to scale?

16. Drawings. Can you read and interpret reasonably woll, maps, floor plans, mechanical drawings, and blueprints? Can you find the distance between two points on a map?

17. Vectors. Do you understand the meaning of a vector, and can you find the resultant of two forces?

18. Metric system. Do you know how to use the most important metric units (meter, centimeter, millimeter, kilometer, gram, kilogram)?

19. Conversion. In measuring length, area, volume, welght, time, temperature, angle, and speed, can you shift from one commonly used standard unit to another widely used standerd unit: e.g., do you know the relationship botween yard and foot, inch and centimeter, etc.?

20. Algebraic symboliom. Can you use letters to represent numbers; 1.0., do you understand the symbolism of algebra--do you know the moaning of exponent and coefficient?

21. Formulas. Do you know the meaning of a formula--can Jou, for examplo, write an arithmetic rule as a formula, and can you substitute given values in order to find the value for a required unknown?

22. Signed numbers. Do you understand signed numbers and can you use them?

23. Using the axlons. Do you understand what jou are doing whon you use the axloms to change the form of a formula or when you find the value of an unknown in a simplo equation?

24. Practical formulas. Do you know from memory certain widely used formulas relating to areas, volumes, and interests, and to distance, rate and time?

25. Similar triangles and proportion. Do you understand the meaning of similar triangles, and do you know 
how to use the fact that in similar triangles the ratios of corresponding sides are equel? Can you manage a proportion?

26. Trigonometry. Do you know the meaning of tangent, sine, cosine? Can you develop their meanings by means of a scale drawing?

27. First steps in business arithmet1c. Are you mathematically conditioned for satisfactory adjus tment to a first job in business; e.g., have jou a start in understanding the keeping of a simple account, making change, and the arithmetic that 1llustrates the most common problem of communications and everyday affairs?

28. Stretching the dollar. Do you have a basis for dealing intelligentiy with the main problems of the consumer; $\theta .8 .$, the cost of borrowing money, Insurance to secure adequate protection against the numerous hazards of 11fe, the wise management of money, and buying with a given income 80 as to get good values as regards both quantity and quality?

29. 'Proceeding from hypothesis to conclusion.' Can you analyze a statement in a newspaper and determine what is assumed and whother the suggested conclusions really follow from the given facts or assumptions?

TOPIC I--MAINTAINING AND DEEPENING THE UNDERSTANDING OF THE FUNDAMENTAL PROCESSES

Content

4. Koaning, origin, and use of numbers

1. Roman

2. Arab1c

B. Place value

o. Origin and use of sero

D. Bounding numbers

\section{Teaching suggestions}

Arouse interest through use of the origin of numbers, by having students bring in newspaper clippings and have the pupils read the numbers.

Emphasize importance of place value as well as development of zero. This may be done by solving problems on an abacus and on an adding machine. Students might make an abacus. Then contrast the old methods with the new Improved methods.

Contrast Roman and Arabic systems of numbers, pointing out the difficulties 
E. Yoaning of the rundamental processes, whole numbers, fractions (common and docimals), and donominate

numbers

1. Adding whole numbers, fractions, and denominate numbers

2. Subtracting whole numbers, fractions, and denominate numbers

3. Multiplying whole numbers fractions, and donominato numbers 4. Dividing whole numbers fractions, and denominate numbers met in performing the fundamental operations with the use of Roman numbers.

Place value should certainly recelve attention at this level. It should not merely be a review with excessive drill but rather, the emphasis should be on the redevelopment and extension of meanings.

Stress importance of decimals in every day affairs as well as the meaning of the decimal.

Fractions continue to trouble many pupils here. The difficulty usually arises from lack of understanding of the nature of fractions and operations with them. Charts and othor learning aids, made and used by pupils, are helpful in reteaching meanings. It is important that time bo found for this redorelopment.

At this time the reasons for many of the rules can be easily shown. When pupils roly upon rules for placing the decimal point in quotients and products, often absurd answers result. Hence, pup1ls should be taught to think about the reasonabloness of their answers. This will be done if they learn to place the decimal by estimate before they use the rules, e.g.,

$$
\text { .6) } \longdiv { 6 . 3 6 }
$$

Here pupil should estimate before any work sterts that the quotient will be something more than 6 because he is dividing by less than 1 . This might avold such incorrect answers as 1.6 or even 16.

Money matters and measurements should furnish many practical problems in the uses of decimals.

\section{Evaluation:}

Have the pupils gained a clearer insight into the nature of the Hindu-Arabic number system, and the four operations with whole numbers?

Have the pupils increased their speed and accuracy in 
performing the fundamental operations of integers and fractions?

Do the pupils have a thorough understanding of the decimal number system since many of the concepts and operations in this unit depend upon this understanding? (Use of very small and very large numbers will give some indication of this mastery).

Do pupils exhibit a high degree of sklll in locating the decimal point in products and quotients not only by using the rules but by the application of common sense?

Are the pupils able to use the four fundamentel processes with denominate numbers?

Are pupils able to change fractions, from common to decimal form and vice versa?

TOPIC II--PERCENTAGE

\section{Content}

A. Extension of meaning of per cent

B. Changing fractions and decimals to per cents and vice versa

c. Finding the per cent of a number

D. Finding what per cent one number is of another

E. Finding the whole number when a part of it is knoum

F. Rounding off per cents

G. Short cuts in per cent

H. Applications of per cent

\section{Teaching suggestions}

Have a bulletin board display of 1llustrations showing uses of per cent.

Ermphasize that the $\%$ sign is a symbol for expressing fractions with denominators of 100 .

Present flgures of sales for a paper route and compute the commission with the class.

Discuss bargain sales and buying on discount.

Find per cent of profit earned on a hot-dog sale. Estimate percentage of time devoted to various activities at home.

Make a bar graph to show percentage of qualified voters in a community who cast ballots; use per cents in sports: finding per cents and interpreting batting averages, team standings, etc.

Find per cent of tax money allotted locally for transportation, instruction, maintenance, and other items in the local school program. Find what per cent of the total cost of education is paid by state funds and what per cent 
is paid from local taxes.

Develop the formula $p=$ br and solve problems using it.

Eveluation:

The pupil should know:

That the per cent sign is only a substitute for the denominator 100; have an understanding of percentage through knowledge of common and decimal fractions; have a working knowledge of per cent in solving problems of simple interest, comnission, trade discount, per cent of increase and decrease, and what per cent one number is of another; appreclate the uses of per cont in -reryday affairs such as advertising, discount in buying, borrowing or lending money, interpreting newspaper articles using per cent, te.; and be able to find the whole number when a part of it is lnown.

TOPIC III--DIRECT MEASUREMENT

Content

A. Origin, need, and meaning of measurement

1. Common units of measurement

B. Kotric system-roaning, use, relation to the English system

c. Jnglish system-denominate measures, linear, liquid, dry, wolght, money, time, temperature, etc.

D. Tature and computation with aproximate numbers.

B. Procision in moasurement
Teaching suggestions

Have varlous pupils report elther in writing or orally about the history of measurement.

Create display of as many measuring devices as the pupils can assemble.

In order to motivate interest have the class list the measurements necessary in cooking, in sewing, in taking a trip, etc.

Discuss the Bureau of Standards and its value as a public safeguard.

Interview a mechanic, a carpenter, an industrial arts teacher etc., on the value of accuracy in measurement.

Measure your classroom and various articles in 1t and then examine, discuss, and use a variety of measuring devices to determine the degree of accuracy.

Read the gas, light, and water meters at your home at different intervals; get the rates on such utilities, and compute the bill. 
Interview a merchant to see how the public is protected against inaccurate welghts when buying.

Make a list of all units of measure involved in operating your home.

Make estimates of helghts and weights of a number of your friends, then check by actual measurements. Retest jourself with different people.

Compare the English and metric systems of measurements and solve practical problems with both, at the same time stressing approximation.

Show advantages of the metric system over our system of weights and measures.

Have ample practice in changing one unit of measure to another unit.

Give pupils practice in estimating and measuring langths to show that all measurements are approximations.

\section{Evaluation:}

Do your pupils measure with any degree of accuracy?

Do your pupils have a reasonably clear understanding of the relationship of the metric system to the English?

in this unit?

Do your pupils show a workable knowledge of the vocabulary

Are the pupils famlliar with all the units of measures such as linear, Ilquid, weight, time, money, etc.?

Are the pupils able to read light and gas meters, and to solve such prectical problems as finding the amount of covering nooded for a floor?

TOPIC IV--HOME AND PERSONAL PROBLEMS

Content

A. Bank services

1. Savings accounts
Teaching suggestions

Practice using the bank forms.

Discuss types of bank accounts. 
2. Chocking eccounts

3. Ioans

4. Sefety deposit box

B. Borrowing money

1. Banks

2. Individuals

3. Loan agencios

4. Insurance policies

c. Budgeting

1. Time

2. Money

D. Buying

1. Installment buying

2. Mall order buying

3. Cash purchases

4. Chargo ac counts

B. Inves tments

1. Government bonds

2. Savings

3. Real estate

4. Stocks and bonds

5. Losn associations

6. Home projects

P. Insurance

1. Life

a. Ordinary IIfe

b. Iimited payment

c. Bndowment

d. Term

2. Health and accident

3. Hospitalization

4. Property

a. P1re

b. Personal
Follow the travels of a check.

Write checks and complete the stubs.

Find the answers to such questions as: What rate of interest does the bank pay on savings accounts? What rate did it pay 10 years ago? What use does the bank make of the money deposited in savings accounts? How does one open a savings account?

Set up a class bank and conduct the ordinary bank transactions.

Discuss advantages and disadvantages of borrowing money from the varlous agencles.

Assign such problems as: Which 18 more economical, to buy an automoblle through a finance company or to borrow the money from a bank? On what kinds of insurance policles may money be borrowed?

Compare actual interest rates of small companies with bank rates.

Make a personal and a household budget for time and money.

Plan a monthly or yearly family budget and make a graph to show wise distribution of income. Elther a bar or a circle graph may be used.

Have class keep records of personal income and expenses and make a graph of this material.

Discuss advantages and disadvantages of the various kinds of buying.

Solve typical problems associated with buying food, constructing an addition to the home, etc.

Discuss the ways of investing one's savings and bring out any possible advantages and disadvantages. The following list may suggest ways: savings and loan assoclations, savings banks, resl estate, postal savings, U. S. Government Bonds, and shares of stock. 
property
c. Automobile

G. Sholter
1. Buying
2. Ronting
3. Up-keep
D1scuss such problems as the differences between investment and speculation; elements of risk in all investments; differences between mortgages, stocks, and bonds; and the varled types of investments.

Study tables which show rodemption values of Unlted States Savings Bonds of all denominations.

Study various kinds of insurance recognizing adrantages and disadvantages of each.

Discuss benefits of Iife insurance to the individual insutred and to his family not only as a protection but as a means of savings.

Iist yearly expenses involved in owning or renting a home.

Treivation:

Does the pupil know:

The services offered by banks; how to use the ordinary forms used in banking procedures; institutions which lend money and the routine by which it may be borrowed; the various rates of Interest and how to compute them; the differences between interest-bearing and non-interest-bearing notes; the value of a personal budget; what per cent of the income should be set aside for each item in the budget; how to set up a sensible budget; how to keep an expense account; the advanteges and disadvantages of the various kinds of buying; how to compute the rate of interost paid for goods purchased on the instaliment plan; the value of consumer credit; how to figure the cost of owning a home, an automobile, etc.; how to compare the cost of renting and owning a bome; the value of systematic savings or wise investment; how and where to make investments and the risks involved in investment; types of insurance--life, fire, automobile, health, otc.; and, anong many other important factors, the cautions to be observed when purchasing insurance.

TOPIC V--GRAPHS AND TABLES

Content

4. Roading graphs found in news papers
Teaching suggestions

Have students bring to class as many kinds of graphs and tables as can be found in newspapers and magazines. 
B.

Making graphs

1. Rounding numbers

2. Selecting scales

3. Selecting appropriato lind of graphs

C. Bar graph

D. Circle graph

B. Iine graph

F. Pictograph

G. Making and using tables
Make bar, circle, and IIne graph which use statistical data that have meaning for the cless, such as: number of pupils In different grades, expenditures of income, variations of temperatures, growth of school populations, accident and death rates, and pupil drop-out by grades.

Have pupils interpret completed graphs.

Know what a table is and be able to make one from know facts.

Stress tmoptance, of rounding numbers.

Check completed graphs for neatness and acouracy.

When teaching circular graphs drill on finding the number of degrees in fractional and decimal parts of a circle.

Many kinds of tables are used today, among which are: interest, cost, nileage charts, and tables showing the amount of antifreeze to use in a radiator. Pupile should collect and learn to read a variety of such tables.

\section{Evaluation:}

\section{The pup1l should:}

Be able to read and interpret the tables which he uses; be able to construct, read, and interpret pletograph, bar, 1ine, and circle graphs; be able to round off numbers to use in the construction of graphs and tables; be able to name and draw each type of graph that the teacher has demonstrated; be able to make graphs neat, Interesting, well-spaced, casily read, and adapted to the material at hand; be able to criticize a graph which misrepresents the facts.

TOPIC VI--INFORMAL GEOMETRY AND THE FORMULA

Content

A. Geometric concepts

1. Meaning and measurement of angles
Teaching suggestions

Have class bring in pictures of geometric flgures whlch we see dally in order to reestablish an understanding of geometric Ilgures. 
2. Recognition

of kinds of:

a. Iines

b. angles

c. plane and solid

Pigures

B. Basic constructions

1. Bisecting an angle

2. An angle equal to a given angle

3. Perpendicular to a line from a point outside the IIne

4. Perpendicular bisector

c. Construction and properties of geometric figures

1. Perpendicular and parallel lines

2. Angles

3. Triangles

4. Squares, Rectangles, Parallelograms, hexagons, etc.

5. Circles

D. Development and application of geometric formulas

1. Perlmeters of plane figures

2. Areas of plane figures

3. Surface area and volume of solid flgures

4. Angle and triangle rolationships a. Sum of the
Develop skill and accuracy in the use of drawing instrunents such as the compass, protractor, rule, etc.

Practice measuring many angles with the protractor.

Name the angles formed by the hands of the clock.

Develop the meaning of volume by placing blocks of uniform dimension into a rectangular box in which they fit.

Draw diagrams of a football field, tennis court, baseball field, etc.

Allow time for making original designs involving the use of circles and regular polygons.

Construct a square inch and a square foot.

Develop formulas experimentally to holp with understending, such as,

a. To find the area of a rectangle, cut a number of one-inch squares from paper and with these form as many rectangles as possible;

b. To find the area of a given triangle, cut another triangle of equal size to form a parallologram.

Measure and compute perimeter and area of the rloor, blackboard, basket-ball court, etc.

Measure $a$ bin and estimate the number of tons, for example, that it will hold and chock by computation.

Find number of cublc feet of air per pupll in the classroom.

Have pupils measure the circumference and diameter of various wheels, lamp shades, cans, etc. and divide to find 


\section{angles of triangle \\ b. Congruent triangles \\ c. triengles}

a the value of pi.

Bring out relationship between the cylinder and $\operatorname{con} \theta$, using one of each of equal base and helght.

Introduce meaning of complimentary and supplementary angles, giving practice in their construction.

Discuss meaning of pairs of equal angles when parallel lines are cut by a transversal.

Construct similar triangles. Cut them out and campare them.

Run an experiment showling that in similar triangles the corresponding angles are equal and the corresponding sides have the same ratio.

Use figures cut from paper to show the meaning of congruence.

Use protractor to measure angles of various sizes and kinds of triangles to discover that the sum of the angles equals 180 degrees.

In like manner, have pupils discover that the sum of the angles of $a$ quadrilateral equal 360 degrees.

Encourage pupils to create original designs.

\section{Evaluation:}

\section{The pupil should:}

Have a working imowledge of the rocabulary of the topic; be his own critic of his own accuracy in measuring; be able to make with great accuracy standard constructions; have an aware. ness of geometric forms in the world about him; recognize the commonly used geometric flgures; know the relationships of one, two, and three dimensions; recognize the varied application of formulas and be ablo to apply a formula to a situation; demonstrate understanding of congruence, similarity, symmetry, size, and nature of angles, etc. 
JOPIC VII-REVIEW TO ALGEBRA

\section{Content}

1. IIgebra as general number

B. Language of algebra

C. Directed numbers

1. Nature

2. Computation

D. Computation with imple literal numbers

B. Equations

\section{Teaching suggestions}

Elementary algebra is basically the mathematics of general number. Therefore, it is a poor comparison to teach that arithmetic uses the ten digits and algebra uses letters.

To help develop the "unknown" number concept have puplls erase the letter and replace it by 1 ts numerical value.

Translate verbel expressions into general number form such as:

a. If pencils cost $5 \&$ each, discuss the method of finding the cost of various numbers of pencils.

b. Percentage equals base times rate.

c. Circumference of a circle equals pi times the diameter.

Introduce the four ways of showing number relationship--graph, table, rule, and formula.

In order to 11lustrate positive and negative numbers and to help develop rules for the fundamental operations use:

a. Temperatures above and below zero, number scales, spending and saring, locations above and below sea level, propit and loss, overwelght and underwe1ght.

Euphasize zero as a position to help in understanding directed numbers.

Develop the concept of balance in equations by comparing with scales used in a candy store.

Also the meaning of the word equation may be developed from its base word EquAL. 
Present equation through its close relationshlp to the formula and show that the equation is an expression of equality involving an unknown quantity.

Constantly remind pupils that the letters actually represent numbers. Translate verbal statements as follow into equations using $X$ to represent the unknown number:

a. Some number divided by $s i x$ equals two.

b. The sum of a number and four 1s elepron:

c. A certain number decreased by nine is one.

When solving equations, use the following principles, better know as axioms:

a. Adding the same number to both sides

b. Subtracting the same number from both sides

c. Multiplying both sides by the sama number.

d. Dividing both sides by the same number.

Transposing should not be taught since It is a mechanical device and lacks meaning. In solving an equation, it is always best to use the four basic axioms listed above.

This may take more time but the results in pupil understanding will bo worth the effort.

Avold such expressions here as "crossmultiplying".

It is important also to have the pup1l check his equations.

This topic is not intended to prepare pupils for further study of algebra. Rather it is intended to take from alge- 
bra those basic 1deas which should be a part of any person's general oducation. Most of the pupils who take general mathematics in these grades will take only one more mathematics course in high school--senior general mathematics.

\section{treluation:}

Can the pupil think more clearly and organize his material botter whon solving word problems?

Does the pupil use his knowledge of equations to solve other word problems?

Can the pupil use formulas with greater ease and efflcleney?

Does the pupil have a clear understanding of the meaning and importance of positive and negative numbers?

Has the pupil increased his interest in mathematics?

Can the pupil add, subtract, multiply, and divide signod aubers accurately?

Does the pupll thoroughly understand that the letters used in algebra actually represent numbers?

TOPIC VIII--INDIRECT MEASUREMENT

Content

1. Scale drawing

B. Similar triangles

C. Rat10

D. Proportion

B. Properties of right triangle

B. Square root (by table and diviaion)

\section{Teaching suggestions}

Make all constructions with compass and stralghtedge.

Measure height of the school flagpole, a tree, a church spire, etc., by using similar triangles, and scale drawing. Show results on paper, makling all drawings to scale.

Solve problems in ratio and proportion. Give ample problems in measuring distances indirectly.

Make a scale drawing of a baseball diamond. Then, how far is 1t from home plate to second base?

Draw to scale on squared paper. 
Use scales on maps and blueprints.

Decide upon a trip and figure the distance covered from a map.

Illustrate the rule of Pythagoras by constructing the square on each side of a right trianglo.

Individual pupil and class projects in outdoor measurements recommended.

Evaluation:

Does the pupil have the ability, to find the ratio of two 1tems?

Does the pupil understand that a proportion is the equality of two ratios? Can he make and solve a proportion?

Can the pupil make, read, and interpret scalo drawings?

Does the pupil recognize similar and congruent triangles and their parts?

Can the pupil use similar and congruent triangles to make indirect measurements?

TOPIC IX--MATHEMATICS OF THE SCHOOL

Content

A. Operational cost

i. Transportation

2. Fuel

3. Electricity

4. Janitorial service

5. Cafeteria

6. Bullding

7. Repairs

8. Care of grounds

9. Water

B. Attendance

1. Average da1ly attendance

2. Drop-outa
Teaching suggestions

Have a group of pupils secure information concerning the cost of operating the school. Use this information to work up averages, graphs, and per cents.

Find the per cent of attendence for the class and the school.

Compare the attendance records by graphs.

Find out the cost per pup1l and use the figures to compute the cost of fallures.

Compute the per cent of failures.

Make anple use of statistics and graphs here.

Set up tables showing the standing of 
C. Cost of failures

D.

tra-curricular

activities

1. Athleties

2. Clubs

3. Class parties, otc.

B. Physical propertles of the school plant

1. Square and cubic foot space per pupil

2. Height, length, etc.. of buildIngs and grounds

3. Heal thful conditions of heat, light, and sefety athletic teams.

Lay off atbletic fields and make scale drawings of same.

Measure the floor space and alr space of the classroom in terms of square and cubic units-per pupil and total.

Learn to read thermometers and be able to check the temperature in the classroom occasionally. Show this information graphically.

Measure the treads and risers of stairways in relation to safety regulations.

\section{Eiveluation:}

Are the pupils able to compute the average daily attendance each month for their class?

Are the pup1ls able to keep accurate accounts of their sehool expenses by the month and year?

Are the pupils aware of statistics in the cafeteria, athlotic department, in solving problems involving sales, cost of goods sold, cost of lunches served, margin or gross profit, oporating expenses, net profit?

\section{TOPIC X-MATHEMATICS AND THE COMMUNITY}

\section{Content}

A. Supporting the community

1. Local and state taxation

a. Where money

\section{Teaching suggestions}

This topic should be easily coordinated with social studies since its background is the community.

Have the pupils find ways the community serves 1ts people and how these services are supported through taxation. 
comes from

b. How it is spent

B. Utilities

C. Occupations

1. Trades-carpenter, plumber, machinist, mason, beauty parlor operator, sales clerk, etc.

2. Professions law, teaching, ministry, medicine, nursing, etc.

3. Occupations typical to the local commun1ty-agriculture, fishing, manufacturing, etc.
Make problems and graphs based upon above information.

Make use of special community projects such as construction of public buildIngs, water systems, parks, roads, etc.

After teaching reading of meters, have each student read meters at his home for a perlod and figure the cost of the utility.

Have elther individuals or groups select an occupation of personal or local interest; by investigation find out and list the mathematical kmowledge needed; 1llustrate by the use of problems from real life.

From newspapers, magazines, or other sources collect examples of what would be suitable for a bulletin board display on the subject, "Mathematics in Leisure l'ime Activities".

Evaluation:

Are the pupils able to use community resources as a means for problem making and problem solving?

Have the pupils shown an interest in studying occupations in the local community and are they able to interpret and use information found?

Have the pupils shown further improvement in their use of the fundamentals of arithmetic?

TOPIC XI--TRAVEU AND COMMUNICATION

Content

A. Travel

1. History of travel where mathematics is used

2. Ways of travel
Teaching suggestions

Trace the development of travel from early days to the present. Compare the time and expense of trips.

What advantages and disadvantages of each method of travel would you 
a. Private automob1le

b. bus

c. Train

d. Plane

- Boat

3.

Services for

travelers

a. Time tables

b. Maps

c. Rates

d. Reservations

๑. Methods of carrying money

B. Communications

1. History of communications where mathematics is directly used

2. Means of communication
a. Tele- phone
b. Telo- grams
c. Mail
services
d. News- paper
- Radio
f. Tele- vision

consider before you made a trip?

What factors would determine the type of transportation?

Compute the approximate cost of a trip by plane, train, and bus.

Collect timetables, meps, and other information from raliway offlces, bus torminals, etc.

Make maps of time zones in the United States.

Find answers tq such typical questions as :

What time is it in each of the time zones when it is 8 o'clock in your home?

If you need \$1000 for a trip, how would you carry this amount safely? How much extra would it cost?

What types of reservations can you make when you travel by train. plane, or bus? How are these reservations made? What 18 the cost of such reservations?

Collect information on communication such as the cost of long distance telephone calls to varlous places from your home. Show this information graphica11y.

Ilst all ways of communication ava11able to you, comparing them as to speed, cost, efflclency, convenience, rellability, and extent of use.

Collect information from the U. S. Post Orfice and make tables of rates. Then develop formulas for first and second class ma11.

What is the relative cost of sending each kind of telegraph message?

Discover opportunities for employment offered boys and girls of your age by the press, radio, telephone, and tele- 
graph companies. What preparation in mathematics is needed?

Evaluation:

The pup1l should:

Be able to use a scale of miles in map reading to find distances botween towns; compare timo and cost of air travel with those of train, bus, or boat; know the advantages and disadventages of each means of travel; be able to figure the appreximate cost of trips by car, train, bus, or plane; be able to read and interpret time tables; be familiar with all the vices rendered by the post office; know how'we can be sure that a package or letter reaches the person to whom it is sent.

TOPIC YII--GOVERNMENT INCOME AND EXPENSES

Content

A. Texation

1. Direct and indirect

a. Distinc tion mado

b. Examples

2. Local and state taxes

a. Real and personal property

b. State income

c. H1ghway taxes

d. Foes, Iines

Q. Ut1lity taxes

1. Dog, poll vohicle, otc.

B. Gevernment expen808

1. Local and state governments

2. Police and
Teaching suggestions

The toacher might introduce this topic by such a question as follows:

Do your parents or the community in which you live buy the food and pay the rent for your family?

What things in jour community are not bought directly by your family? How are such goods and services paid for?

What are taxes? Explain the difference between direct and indirect taxes and give examples of each.

Draw out the reasons for taxes by a group discussion.

Study community to find ways it best serves its people.

Make use of local community projects such as public buildings, water system, parks, roads, etc.

Learn how assessments are made by studying the real estate in your community. 
fire departments

3.

sanitation Publ1c wel-

fare

5. Highways and

6. Library and recreation

7. Principal and debts

8. Public works

9. Public education

C. Federal (National) texes

1. Where money comes from

a. Income taxes

b. Internal revenue

c. Soc1al

Security. retirement, and unomployment funds

a. Cus toms

- Miscellaneous recelpts bridges interest on

Study types of l1censes issued in your community.

Study the amount of tax money spent for schools, roads, etc.

study spendings for publlc welfare.

Compute the amount of gasoline tax paid by an individual on a long trip.

Learn the direct tax on gasoline in Rhode Island and the amount of Federal tax. Study and f111 out tax forms.

What power did the. $\$ 1 x$ teenth Amendment of the Constitution $81 v e$ Congress? How long ago did 1 t become a law?

Bring in tax recelpts for class to study.

Help pup1ls develop a clear understanding of where the tax money comes from. Include in this such indirect taxes as: gasoline, amusement, tobacco, inberit. ance, Ilcenses, sales tax, etc.

Find out how Rhode Island spends her tax money for administration (government), education, highways, parks, publ1c welfare, conservation, etc.

Have pupils make graphs showing the sources and distribution of the tax dollar in Rhode Island.

1 tures

a. National defense

Compare money spent for education, highways, and recreation in Rhode Island

b. Pensions and benefits for veterans

c. Relief and recovery expenditures

d. Interest on federal debt

- Insurance for veterans with money spent for same in other states.

f. Agriculture 

Department
8. Social Secu- rity and
retirement
h. Retired
workers

Eveluation: purposes of taxation?

Do pupils demonstrate a working lnowledge of the vocabulary used in the unit?

Do pupils lnow what agencies levy tiaxes and the uses made of tax money? Group or individual reports might be used.

Do pupils understand the difference between direct and indirect taxes?

Have pupils become conscious of the three taxing agencies: lcosl, state, and federal?

Are pupils able to compute simple tax problems? For instance, rate when the amount of tax and assessed valuation are kovn, or amount of tax when assessed valuation and rate are lonorn.

Changes in the growth of pupils during the entire unit such as interest, work habits, evidences of thinking, cooperation, etc. should be noted. 
FIRST-COURSE ALGEBRA

\section{INTRODUCTION}

It is herewith recommended that students who plan more work in mathematics be encouraged to take First-Course Algebra. This further study of mathematics may be necessary for future vocational or professional aims or it may be studied for the pleasure to be derived from the study of mathematics.

Certainly the skills, ideas, and principles of algebra need to be taught carefully. Skill alone in the mechanical manipulation of algebraic symbols is a seriously inadequate outcome of the teaching of such an important branch of mathematics. skill without understanding is so likely to produce the temporary learning of the subject which so many teachers complain of and which plagues a pupil who enters college and studies mathematics at this level. nine topics:

In this manual, First-Course Algebra will be divided into

I. Introduction to algebra.

II. The equation.

III. Signed numbers.

IV. Fundamental operations in algebra.

V. Equations of the first degree in two unknowns.

VI. Spocial products and factoring.

VII. Fractions and fractional equations.

VII. Finding square roots and using radicals.

IX. Quadratic equations,

TOPIC I_-INTRODUCTION TO ALGEBRA

Content

A. Why study algebra?

B. How to study algebra?
Teaching suggestions

List and discuss professions for which algebra is needed. Help students find out the mathematics requirements for his proposed vocation or for the college 
c. origin of algobra

D. The nature of genaral number

E. The nature and use of the formula

F. Terms, coefficient, and porrer

G. Combining $11 \mathrm{k} \theta$ and unl1ke terms

H. Malding formulas from verbal statoments

I. Evaluation of and substitution in a cormula

\section{Supplementary Work}

A. Interpreting the moaning of more complex literal axpressions

B. Expressing more complicated verbal data algebraically

c. Preparing booklets or reports on history of our modexn symbols or on the works of great men who contributed to the atudy of algebra he intends to enter.

Study the origin of algebra and point out the historical development of the subject. Find out what men made contributions to algebra.

Present algebra as a language and tool of mathematics.

Pretest to estimate the present ability of the class with reference to:

a. The ability to interpret simple algebraic expressions.

b. The ability to express simple verbal statements symbolically.

c. The ability to combino literal numbers.

d. The ability to interpret and ovaluate simple formulas.

Then, the class should be ready for grouping for practico. Each group should proceed at 1 ts own rate, recelving help when needed.

Al1 pupils should complete the work listed in content, except that marked supplementary which is to be assigned as enrichment material.

Briefly review the use of symbols to indicate sum, difference, product, and quotient.

G1ve some drill in combining terms and the substitution of values in formulas; take the rest of the time in making formulas from verbal statements, tables, and graphs.

The Idea that algebra is the study of general number needs to be thoroughly taught. This means that many examples of universal number relations w111 be derived by pupils and expressed in algebraic language. Tables which pupils build and from which they discover a relationship serve this purpose well. 
Here the formula is used as a toplc to provide a ready transition frow arithmetic to algebra. Any uninteresting review is to be avolded here. Instead, the formula is used as a familiar toplc through which the general number idea of algebra is taught.

Pupils should be given drill material in terms of their noeds-oither in groups or Individually through the use of the blackboard, dictated exercises, or mimeographed sheets.

Allow enough drill on each now concept to develop accuracf and efficlency in Its use and application. However, drill should be used only after the process 1s understood.

Demonstrations and explanations made by the teacher should, in so far as possible, be exercises within the experiences of the pupils.

Rules are of value only when they summarize a process already learned and understood. These rules should be developed by the class in class discussions whenever possible.

Orten pupils begin the study of algebra with arithmetic dericiencles. Research has indicated that it is futile for a teacher to try to correct these at the boginning of his algebra courso before getting into the content of the subject. This can much better be done incidental to the study of the new topios of algebra.

\section{Ereluation:}

Cheok list for PUPIL of things to be remembered:

Algebralc numbers, formulas, factor, general numbers, like terms, coefflcient, algebraic expression, unlike terms, and power.

Important sk11ls:

Student should bo able to ldentify like terms; add like terms; subtract like terms; multiply and diride algebrale numbers; translate rules into formu- 
1as; and translate verbal statements into algebraic language.

Observation check list for teachers:

a. Does pupil understand how and why letters are used to represent general numbers?

b. Does pupil know the meaning of words used?

c. Can pupil make and apply simple formulas?

d. Can pupil collect similar terms?

- Can pupil ovaluate simple formulas and algebraic expressions, etc.?

TOPIC II--THE EQUATION

\section{Content}

A. Hature of equations

B. Hature of a solution to an equation

c. Roviewing the solution of equations by the four axioms

D. Translating verbal problems into equations and solving

B. Chocking equations

\section{Surolementary work}

1. Solving more complex literal equations

B. Solving more advanced problems
Teaching suggestions

Give a brief test at the beginning of the unit to measure the present ability of the pupils with reference to:

a. Knowledge of terms used in working with equations.

b. Ability to solve linear equations of the simplest form.

c. Ability to select pertinent data from a stated problem and form an equation.

A set of platform balances will help to develop an understanding of equations. Be sure that the student sees that there is still a balance when the same amount is added or subtracted from both sides or when each side is multiplied or divided by the same number.

Emphasize orderly arrangement and sequential steps in solving an oquation.

Go over the four axioms for solving an equation( in the boginning it is a good Idea to have the students writo out the axiom used in solving an equation).

G1ve amplo dr111--always keeping before the class the Idea of on equation boing a balance.

Short cuts are apt to be mechanical de- 
The equation cannot recelve too much emphasis. Algebra The majority of the units studied in alseba receive an applicathon in the solution of equations. Inportance that the student recelve basic principles of the equation. Thus larly present the pupils with problems and then to make use of the basic ideas of the equation.

IOPIC III--SIGNED NUMBERS

\section{Content}

1. Neaning of signed numbers

B. ldding signed numbers

C. Subtracting signed numbers

D. Multiplying signed numbers

5. Dividing signed numbers

\section{Teaching suggestions}

It is important that the teacher find out the extent to which her students have acquired an understanding of signed numbers and operations with them in the previous course. She could spend much time in useless repition. Should the teacher decide that this unit should be taught in this class the following suggestions are offered:

A thorough understanding of signed numbers must bo established. A number scale seems basic to this understanding.

Once the scale is understood, pupils can place on it temperature readings, altitudes above and below sea level, profits and losses, and the like. All of this teaching should precede any attention to the four operations.

The teacher must make clear the distinction between the use of + and - to Indicate addition and subtraction and to indicate signed numbers, e.g., the two minus signs below have different meanings:

$$
3-(-7)=?
$$

When teaching the four operations with signed numbers a fine opportunity presents itself for developing an understanding of the process before the rule is introduced. For example, the pupils may use the number scale to discover how to add signed numbers. Then they may express it in their own words, comparing it with the rule found in the text. Thus it becomes their rule for adding signed numbers. 
Eveluation:

Do the pupils have an understanding of the nature of Igned numbers? Do they have an ability to add, subtract, multi-
plJ, and divide signed numbers on the number scale and by rule?

Teachers should not wait for a complete mastery of the objectives of this unit before going on to the next; there are any uses of signed numbers throughout the first course in alsobra, consequently there will be many opportunities for retoraching if it is needed.

TOPIC IV- FUNDAMENTAL OPERATIONS IN AIGEBRA

\section{Content}

1. Four operations with simple literal numbers

1. Adding, subtracting. multiplying, and dividing monomials and polynomials

B. Use of fundamental processes in solvIng

1. Equations

2. Verbal problems

a. Nunber relation

b. Perimeter

c. Motion

d. Age

C. Symbols of grouping

1. His torical background for use of grouping symbols

2. Purpose of symbols of grouping

3. Placing terms within symbols

4. Uses of symbols of grouping
Teaching suggestions

Allow for plenty of practice in fundamental operations with monomials, including fractional and decimal coofficlents to both increase skill in handling them and to increase the understanding of the meaning of each operation.

Show that exponents indicate a short form of multiplication much as multiplication itself indicates a short form of addition.

Help students discover for themselves the laws of exponents in multiplication and division, allowing for ample practice in the application of these laws.

Teach the solution of equations as the tools necessary for solving verbal problems using, in so far as possible, those which have real life meaning and which will interest pupils to develop the power to reason.

Develop the skill needed in performing the four fundamental operations with monomials and polynomials.

Have sufflclent practice with sgmbols to insure mastery.

Compare arithmetic multiplication and division with that of polynomials.

Use some division exercises that have 
remainders as well as those in which terms need rearranging.

Show that parentheses and other symbols of grouping are used to indicate a unity of the quantity enclosed. The removal or insertion is possible only by some law of operation as addition, subtraction, or multiplication.

Removal of parentheses preceded by a positive or negative sign may be taught as addition or subtraction of a quantity and as multiplication. For example, - (4y - 7) could mean subtract giving $-4 \overline{7}+7$. or It might mean $(-1)$ times $(4 \mathrm{y}-7)$, which also gives $-4 y+7$.

At this time complicated exercises involving more than two sets of symbols of grouping might be avolded. Seldom does a pupil find use for anything more than parentheses and brackets.

\section{Evaluation:}

The pup1l should:

a. Be able to add, subtract, multiply, and divide monomials and polynomials;

b. Be able to prove the lavs of exponents in multiplication and division;

c. Understand the meaning of parentheses and be able to insert or remove them from an algebraic expression or equation.

TOPIC V--FROATIONS OF THE FIRST DEGREE IN TWO UNKWOWNS

Content

A. Nature of Iinear

B. Yoaning of a solution of a linear cquation in two unlanowns

c. colution of simultaneous linear oquations in two valnowns
Teaching suggestions

In so far as possible, use problems within the reach of pupil that will illustrate equations with two unknowns, such as:

a. How many candy bars at $5 \&$ and 7 each can be bought with $\$ 1.20$ ?

b. There were 1200 persons watching a ball game. The adults paid 65 for an admission ticket and the children paid 10\%. if 
1. Graphing

2. Elimination by addition or subtraction

3. Substitution

D. Terms needed:

1. Horizontal axis

2. Verticel axis

3. origin

4. Abscissa

5. Ordinate

6. Coordinate

7. Point

8. Variable

9. Simul taneous equations

10. Independent equations

11. Dependent equations

E. Vorbal-problem solving

1. Mixture

2. Number-relations

3. Inves tment

4. Others the total receipts amounted to $\$ 516.00$, how many adults and how many chlldren saw the game?

Pupils will noed practice in plotting points and graphing single equations bofore graphing systems of equations.

Explain carefully and 1llustrate the construction of a graph of an equation.

Make tables of values used in drawing graphs. Stress the function concept by emphasizing that one of the variables depends on the other to which values have been assigped.

Show that the graph of an equation of the first degree having two variables is a stralght line, explaining that a inear equation having two variables has an indefinite number of solutions.

Allow for sufficient practice for graphical solution of linear equations.

Have pupils plot two linear equations on the same set of axes.

Euphasize that if a point lies on the graph of two different lines, its coordinates must satisfy each equation, and the coordinates of this point are the roots of the system of equations.

Prove by substituting values in the equations.

Allow for some equations to be graphed that have no common solution or all common solutions and thus bring in independent and dependent equations.

Discuss the need for algobraic solutions of simultaneous equations because the answers then are exact and require less time than the graphic solution.

Start verbal problems involving two unknowns. 
Observation check 11st:

2. Is the pupil familiar with terms used?

b. Does the pupil understand and appreclate the value of two variables in the solution of problems?

c. Does the student understand what is meant by the common solution of a set of equations from both the algebraic and geometric points of viow?

d. Can pupils graph reasonably fast and accurately?

Can the student solve sets of equations:

a. By graphing?

b. By elimination, by addityon, or subtraction?

c. By substitution?

Is the student able to reason out a verbal problem and solve 1t?

TOPIC VI--SPECIAL PRODUCTS AND FACTORING

Content

A. Terms used:

1. Monomial

2. Binomial

3. Trinomial

4. Square

5. Cubo

6. Prime factor

B. Finding the square of a monomial and binomial by insection

c. Factoring by romoring common factor

D. Pinding the product of two binonials of the form $(a x+b y)(c x+d y)$

E. Finding product of sum and differonce of two terms

F. Factoring perfect square trinomials
Teaching suggestions

If spocial products and factoring are developed together, pupils will more easily grasp the meaning of such forms as:

$$
a^{2}-b^{2}=(a-b)(a+b)
$$

Determine the present ability of the pupils with reference to:

$$
\begin{aligned}
& \text { a. Knowledge of meaning of factor- } \\
& \text { ing; } \\
& \text { b. Recognition of similarity be- } \\
& \text { c. Kneen division and factoring; } \\
& \text { Knowledge of terms used. }
\end{aligned}
$$

Discovor special ways of obtaining products mentally:

$$
\begin{aligned}
& \text { a. Polynomial by monomial; } \\
& \text { b. Binomial by binomial; } \\
& \text { c. Product of sum and difference; } \\
& \text { d. Square of binomial. }
\end{aligned}
$$

Discuss the meaning of the word factor and define what is done when an expression is factored. This can be easily brought out in arithmetic; the factors 
of type $a x^{2}+$

B.

Finding principal factors of algebraic expressions of 24 are: 1 and $24 ; 4$ and $6 ; 3$ and 8 . Here prime factors can well be introduced.

Lead pupils into the understanding that factoring grows out of multiplication.

Present simple applications as:

a. Removing common monomial factor.

b. Solving the trinomial form: $a x^{2}+b x+c$.

c. Difference of two perfect squares.

d. Perfect square trinomial.

Dr111 through 111ustrations and appl1cations to specific examples involving both 11 teral and numerical terms. Include nonfactorable expressions as well.

Use quadratic equations only as an example of factoring.

Jse ample verbal problems.

\section{Braluation:}

Does the pup11:

a. Understand the meaning of the word factor? Does he indicate this understanding in factoring rather than a moaningless, mechanical oporation devold of meaning?

b. Find special products mentally with reasonable speed and accuracy?

c. Have the ability to select the type to which certain problems in factoring belong? Then can he factor the expression readily?

d. Understand why each factor is set equal to zero in a quadratic equation?

TOPIC VII--FRACTIONS AND FRACTIONAI EQUATIONS

Content

A. Bxplanation of terms to be used in the topic of iractions

B. Reduction of

\section{Teaching suggestions}

Here is an excellent opportunity to enlarge the general number ldea of algebra. For example, pupils should be taught how algebraic fractions are the generalized equivalents of the arithmotical fractions with which they are 
eractions to 10west terms

c. Finding a common nominator of soreral fractions

D. Multiplying and dividing fractions

E. Lding and subtracting fractions

F. Solving fractional cquations

G. ranlyzing problems that involve eractions and forming and solving equations

Supplomentary work

A. Ldding and subtraoting complex Iractions

B. Nultiplying and diviaing complex Iractions already familiar. Also, operations with algebraic fractions follow the laws as arithmotical fractions. For example:

$$
\begin{aligned}
& \frac{1}{2}+\frac{1}{3}=\frac{2+4}{(2)(4)} \\
& 1 / a+1 / b=\frac{a+b}{a b}
\end{aligned}
$$

Begin with simple arithmetical fractions and proceed in gradual stops to literal fractions.

Test to measure the fresent ability of the pupils with references to the following:
a. A knowledge of terms such as equivalent, numerator, denominator, etc.;
b. ability to reduce fractions to lowest terms:
c. ability to find a common denominator:
d. ability to add, subtract, multiply, and divide fractions from arithmetic:
- ability to solve simple fractional equations.

Review meaning of fractions by using some idea within the everyday exporience of the pupils. Erample: if you spend 60 \& you spend $60 / 100$ of a dollar which 1s $6 / 10$ or $3 / 5$.

Make sure that terms used are definitely understood. Operations with fractions should receive special attention and thorough treatment.

Practice finding a common denominator.

Pupils should understand the basic principle of fractions, namely, that the value of a fraction is not changed if both the denominator and numerator are multiplied or divided by the same number.

When solving fractional oquations, pupils should see that they apply the four axioms to reduce a fractional equation to 1 ts 
equivalent without fractions.

Consider multiplication and division first because of their similarity in treatment to reduction to lowest terms. However, attention should be called to the following:

Factors, not terms, are divided out. Use divide rather than cancel.

When all the factors in both numerator and denominator have been divided out, the result is 1, not zero.?

Have one or two pupils demonstrate processes on the board, giving help only when needed.

Addition and subtraction of fractions will necessitate considerable emphasis.

Exercises in addition and subtraction of fractions may be checked by numerical substitution, however do not use numbers that will make any denominator zero.

Review finding a common denominator with arithmetic fractions in demonstration of addition and subtraction of fractions.

Have arill in these fundamental processes after the process has been understood.

Pupils should understand that in fractions three signs are present, elther expressed or 1mplied: the sign of the numerator, of the denominator, and of the fraction itself. Practice changing signs to assure clear understanding of this process.

In reducing mixed expressions to improper fractions, the rule of arithmetic may be applied or the exercise may be considered one of addition or subtraction.

With complex fractions, two methods should be pointed out:

Reduce numerator and denominator to simple 
fractions and divide, or

Multiply both numerator and denominator by a common multiple of all the denominators.

Present simple fractional equations.

Demonstrate process of changing a fractional equation into one of a simpler form. Help pupils diacover the principlo involved. Provide drill in solving and checking simple fractional equations.

Include solution of verbal problems involving fractfonal equations.

\section{Evaluation:}

Check list for pupil of things to be remembered: The numerator tells how many. The denominator tells what kind. The line separating the numerator and the denominator means divide.

Algobralc fraction; signs of a fraction; common denominator; like and unlike fractions.

Important skills to develop are:

Making equivalent fractions; multiplying fractions; adding like and unlike fractions; subtracting like and unlike fractions; dividing fractions; changing signs of a fraction; solving fractional equations.

Observation checkliat for teachers:

a. Are the pupils familiar with the common terms us ed?

b. Can pupils add and subtract, multiply and divide fractions with reasonable speed and accuracy?

c. Do pupils understand how by changing signs tho fraction is simplified?

d. Are pupils able to select and organize data in preparing to solve fractional equations?

e. Do pupils understand how to reduce fractions to lowest terms?

f. Do pupils understand that, in adding or subtracting fractions, they must have a common denominator, but to multiply or divide they do not require a common denominator? 
IOPIC VIII-FINDING SQUARE ROOT AND USING RADICALS

\section{Content}

A. Computing arithmotical squaro roots

B. Finding square root by table

c. Becoming familiar with common terms used in working with square root such as:

1. Radical

2. Square

3. Factor

4. Radicand

D. Bimplifying radloul.

E. Adding, subtracting, multiplying, and dividing radicals

F. Rationalizing a binomial surd in the denominator

G. Solving equations containing radicels

\section{Supplementary work}

A. Bxtracting square root of numbers by use of the slide sule

B. Hore complex problems of types bove

1. Multiplication or division of radicals of different order

2. Square roots of binomial surds
Teaching suggestions

Test to measure the present ability of pupils with reference to:
a. Abllity to recognize squaros of numbers from 1 to 15.
b. Abllity to find square roots of numbers.
c. Understanding of the terms: square and square root.

Emphasis should lcome in the understanding of square roots, radicals, and radical equations. Complicated problems here are seldom used.

Introduce the unit by calling attention to the scientist's uses of squares and square roots as in the formula for the distance for falling bodies,

$$
s=\frac{1}{a} b t^{2}
$$

Show that both time and energy in computation can be saved by the use of radicals. It should also be shown that this unit is a foundation for further study in both mathematics and science.

Discuss what is meant by "radical expression."

Discover any historical facts about the radical sign.

The following should receive attention:

a. Any positive number has two square roots. The positive one is called the principal root.

b. The coefficient of the square root of $x$ or of 6181 .

c. The radical should be treated as a term in algebra.

Bring out the reason for rationalizing a fraction with radicals in the denominator-facility in evaluating the fraotion. 
Introduce the squaring of both sides of an equation as Axiom Five in the solution of equations. Still, the pup1l should recognize this as the equivalent of the multiplication axiom. He should be cautioned to check all roots as extraneous roots may be introduced.

A clear distinction should be made between square and square root as pupils often are confused on the two.

The following skills and concepts should be emphasized in this unit by demonstrations, pxplanations, and drills:

$$
\begin{aligned}
& \text { a. Understanding of terms used. } \\
& \text { b. Addition, subtraction, multi- } \\
& \text { plication, and division of } \\
& \text { radicals. } \\
& \text { c. Square roots by computations } \\
& \text { and tables. } \\
& \text { d. Solution of equations involving } \\
& \text { radicals. }
\end{aligned}
$$

Pupils should make a list of fields of studies and vocations that require a knowledge of the material of this unit.

After the process is understood, provide ample drill.

\section{Eveluation:}

Check list for pupil of things to be remembered: Base, power, radical, radicand, square root, and square.

Important skills to develop are:

Finding the square root of a number; simplifying a radical; solving equations involving radicals.

Observation checklist for teachers:

a. Can pupils find squares and square roots with reasonable speod and accuracy?

b. Do pupils understand the meaning of the concepts and terms used?

c. Are pupils acqualnted to some extent with the history and origin of squares and square roots?

d. Are pupils familiar with the fundamental principles governing the simplification of radicals? 


\section{Content}

1. Hature of quadratic equations B. Troomplete quad-

1. Solved by square root method

2. Solved by graphing

c. oomplete quadretios

1. Solved graphically

2. Solved by factoring

3. Solved by completing square

\section{Teaching suggestions}

Introduce the study of quadratic equations by graphing a quadratic oquation that has no real root; one that has equal real roots; and one that has unequal real roota. Bramples are as follows:

$$
\begin{array}{cl}
\text { a. } x^{2}+4 x+5=0 & \text { no real roots. } \\
\text { b. } x^{2}+4 x+4=0 & \begin{array}{l}
\text { equal real } \\
\text { roots. }
\end{array} \\
\text { c. } x^{2}+5 x+6=0 & \begin{array}{l}
\text { unequal real } \\
\text { roots. }
\end{array}
\end{array}
$$

Thus show what it means for a quadratic equation to have real roots and why any particular quadratic may have not any, one, or two real roots.

Factor some quadratics as was done in prevlous units and then present one that cannot be factored. Now apply the basic axiom for the solution of equations and lead to the solution by the method of completing the square.

Use such familiar formulas for the square method as:

and problems as:

$$
A=(p 1) r^{2}
$$

Find the side of a square whose area is 64 square inches.

The derivation and use of the quadratic formula is to bo left to Second-Course Algebra. 


\section{PLANE GEOMETRY}

\section{INTRODUCTION}

Logical proof is the crux of a course in plane geoThis means that the ability to state and prove independentif a theorem of geometry is a primary purpose of this course and implies an understanding of the relationship of assumptions, definitions, hypotheses, and conclusions to proors. Ho doubt of equal importance is the ability to apply the method of proof used in geometry to non-mathematical situations. Then too there are these other purposes: an awareness and appreciation of geometry in art, nature, industry, and architecture; kill in the use of instruments for making geometrical measurements and constructions; and knowledge of the basic facts and rolationships of geometry.

It is to be left with each teacher and her group to decide how many theorems will be formally proved. In general, she will select enough to develop a thorough understanding of the nature of a mathematical proof as well as the ability to make an original proof. Constructions, corollaries, and applications will be used extensively, though formal proofs will not be required of all of them.

Teachers should find valuable the laboratory method of teaching that employs many models and other learning alds. Through the use of models, charts, etc., pupils may be led to diacover geometric relationships which they can state as theorems to be proved in words which they understand. In this way reality may be introduced to plane geometry for pup1ls, part1eularly the slower ones. In addition, pupils will be stimulated in this manner to develop proofs which differ from those found in the textbook.

The teacher of plane geometry must remember that her puplls have most likely learned some facts and relationships of geometry in earlier courses in general mathematics. However, in these earlier courses conclusions were reached inductively through experimentation and measurement. Now in plane geometry, pupils must learn the difference between a conclusion established inductively and one establish deductively through a formal mathematical proof. This transition 
from what has been called the "intuitive geometry" of general wathematics to the demonstrative geometry course of the tenth grade is, therefore, of primary importance.

This course in plane geometry has been planned around eleven topics:

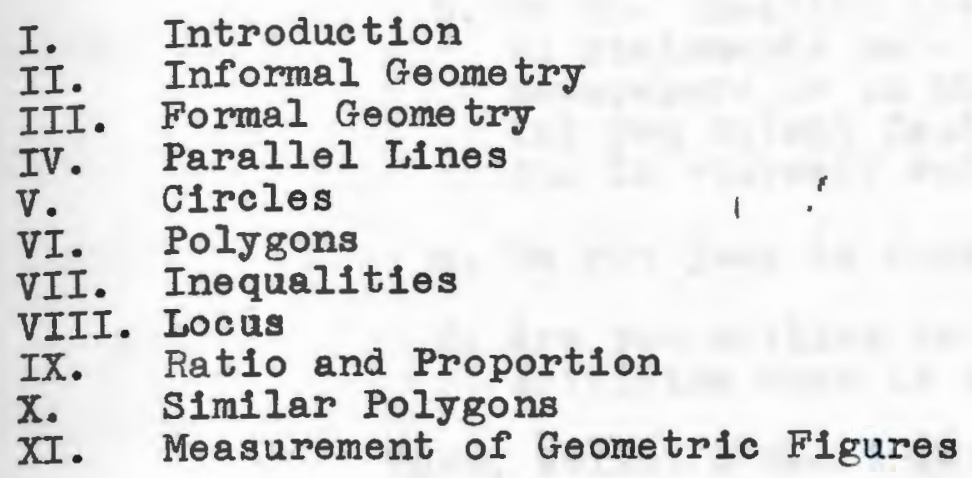

TOPIC I--INTRODUCTION

\section{Content}

A. The origin and early use of geometry

1. Contributions made by great mathematiclans and nations

2. Egyptian ropetretchers

B. temetry found in our urroundings

1. Nature

2. Science

3. Industry

4. Art

5. Architecture

\section{Teaching suggestions}

Pupil should read about Thales, Pythagoras, Plato, Euclid, and others. After a general discussion, have essays written or reports given on the life and work of important mathematic ians.

Allow pupils an opportunity to list and bring to class geometric figures observed on way to school in order to point out the elements of symmetry.

Have pupils find out in what ways geometry directly or indirectly enters into the pursuits of various occupations.

Have pupils construct original designs as used in wall paper, fabrics, or linoleum.

Have on display a number of optical 
c. Hoed for, and nature of logical thinking

1. Habits of correct thinking

2. Assumptions and dofinitions illusions to show the danger of basing conclusions on appearances.

Have pupils make an anlysis of their thinking by rating themselves --sometimes, always, or never on such questions as:

a. Do you exaggerate?

b. Do you question the validity of statements made in the newspapers or on the radio? Can you detect faulty reasoning in yourself and others?

c. Do you jump to conclusions?

d. Are you willing to accept criticism when it is valid?

Then, select a few traits for which improvement is necessary.

Give pupils several statements, such as, "It always rains when the sun does not shine. The sun is not shining" to illustrate the fact that, if a single exception can be found, the conclusion is false.

Have pupils make similar statements and see what conclusions they can draw from each.

Encourage pupils to look for errors in reasoning in advertisements and in other sources familiar in their dally experiences.

Draw from pupils reactions as to how to avoid faulty reasoning.

Discuss with pupils the meaning of definitions, how definitions are made, the necessity of leaving certain terms undefined, the use of definitions in proving simple geometric exercises, and the importance of definitions in non-mathematical situations.

Point out that a good definition is 
reversible and places the object in the smallest known class and gives the characteristics which makes it different from the other objects in the same class.

Develop inductively an understanding of axioms and postulates as they are needed.

TOPIC II--INFORMAL GEOMETRY

\section{Content}

A. Basic constructions

1. Bisect an angle

2. Bisect a line segment

3. An angle equal to a given angle

4. A perpendicular to a Iine from a point on the Iine.

5. A perpendicular to a ine from a point not on the line

\section{Teaching suggestions}

Check to see how many pupils understand how to do the basic constructions as taught in general mathematics.

Allow for further attention to these constructions if this check reveals the necessity.
Content

A. Nature of deductive proof

1. Contrast with conclusions reached by induction or experimentation

2. Relationship of definitions, axioms, and postulates to proof

\section{Teaching suggestions}

Have pupils draw two intersecting Iines and ask if the vertical angles appear equal. Have them check by folding the paper and by measurement.

Have pupils pick out the "1f" "then" clause in any number of statements so they will see the condition and the conclusion.

Help pupils discover the postulates and definitions needed in a formal 

B. Proofs of simple theostraight lines intersect, the vertical angles are equal

1. Systematic arrangement of proofs

2. Identifying hypothesis and conclusion in theorems

3. Representing hypothesis in a rigure

C. Congruent theorems

1. Definitions and as sumptions

2. Theorems

3. Applications

D. Proof of basic constructions proof that vertical angles are equal. Have pupils write out the formal proof. Point out that measurement and observation alone were not used in the formal proof of the equality of vertical angles.

Give pupils several examples from the text that will require simple proofs; for example, supplements of the same angle are equal.

Develop the meaning of altitude, median, etc., of a triangle by using models.

Have pupils construct triangles when SSS; SAS; or ASA are given. Then construct three triangles equal to them, cut out, and place one on the other to 1llustrate the three congruent theorems.

Proof of the triangle congruence theorems is hard for beginners to understand. Therefore, it might be advisable to postulate these theorems at this point and proceed with other proof more easily understood. If this is done, it should be cleariy indicated what this means for subsequent proofs based on these theorems .

Have pupils prove exercises given in text using these three theorems.

Let pupils suggest congruency used in clothing, industry, and design.

Have pupils prove the basic constructions and explain why the constructions are possible.
TOPIC IV--PARALLET LINES

Content

A. Definitions

1. Parallel lines

\section{Teaching suggestions}

Have each pupil construct a model as suggested at the end of the unit and lead him by a serles of questions 
2. Transversal

3. Corresponding angles

4. Alternate interior angles

5. Altemate exterior angles

B. Theorems

1. Indirect proof

2. Converse theorems

3. Practical appl1cation

4. Theorems related to parallel lines to discover the theorems based on parallel lines. This procedure should help him understand the ifthen relationship for he knows that what is fixed on his model tells him what is given and what results as he moves the wires on his model tells him what he must prove. Have the pupil state his own definitions of angles and the propositions of parallel lines. Have the class polish the definitions and propositions and then have each pupil prove the propositions.

Introduce pupils to the indirect method of prodf by making use of non-mathematical situations involving indirect reasoning.

Have them list all the possibilities that may arise and show that all possibilities except one leads to a contradiction of the hypothesis so the remaining possibility is true.

Pupils are to write the converse and inverse of several theorems and decide which are true.

Cite examples of false conclusions which result from accepting the truth of a converse or an inverse statement in both mathematical and non-mathematical situations.

$$
\begin{aligned}
& \text { Ex.-The Hoover sweeper runs } \\
& \text { quietly. } \\
& \text { Con.-If a sweeper runs quietly, } \\
& \text { It is a Hoover. } \\
& \text { Inv.-If the sweeper does not run } \\
& \text { smoothly, it is not a Hoover. }
\end{aligned}
$$

Point out that this type of reasoning is a trick used by the propagandist.

Draw attention to the use of parallel lines used in mechanical drawing, architecture, interior decorating, costume designing, and engineering. 
Have pupils construct and cut out isosceles, scalene, right, and equilateral triangles. Cut off two of the angles and place them on elther side of the third to show that the sum of the angles of a triangle equals a stralght angle.

Now have pupils give a formal proof of this theorem by constructing a line parallel to the base through the vertex and by constructing a line through one of the base vertices parallel to the opposite side.

Help pupils make a table showing the sequence of theorems, definitions, and assumptions on which this theorem depends.

Suggest pupils read a detective novel. Study the logic and list the steps used in solving the case. Eliminate steps that were misleading.

Suggested model referred to at the beginning of the unit:

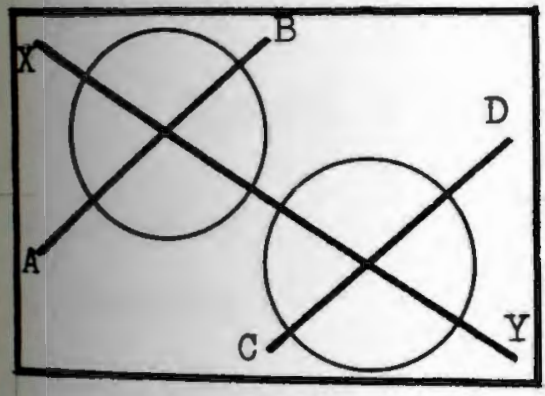

Cut a plece of cardboard 8" by $12^{\prime \prime}$. Notch the centers of four protractors and paste them on this board. Cut 4 pieces of wire from coathangers and sew them on this board to the center of the circles made by the protractors ( $A B$ and $C D$ ). Use buttons on back to hold wires securely.

TOPIC V--CIRCLES

Content

Teaching suggestions

A. Dofinitions Assumptions

B. thoorems

C. Brercises

Pupils are to review such terms as radiua, diameter, chord, etc. and develop an understanding and a definition of a circle by use of a globe. Through the discussion bring out the difference in size 
D. Angle measurement

1. Angles formed by tangents, chords, secants, and radil

B. Constructions

F. Applications of circles formed by longltude and latitude.

Through experimentation let pupils conclude that one and only one circle can be constructed through three points not in a straight line.

Using two circular cardboard figures, with a sector cut out of one, illustrate by placing one upon the other the idea that equal angles (central) have equal arcs.

Help pupils derelop a definition of tangeney (both internal and external) by rolling a coin along a line and by using rubber bands.

To help pupils review theorems draw on the board figures representing each one studied and ask pupils to state the theorem each drawing represents.

Have puplls solve several exercises involving the use of these theorems.

Have pupils construct designs using the knowledge they have obtained about circles and angle measurement. Ask them to complete a circle when an arc of the circle is given.

Discuss advantages of the circle over the stralght line as in the arrangement of seats in churches or amphitheaters.

Point out that civilization moves along on wheels (circles).

A project that could be developed for extra assignment is "Civilization on Wheels."

TOPIC VI--POLYGONS

Content

A. Definitions
Teaching suggestions

Pupils develop definitions for members of the polygon family. 
B. Constructions

C. thoorems

1. Angles of polygons

2. enadrilaterals, parallelograms, etc.

D. Practical applications
Construct polygons for a polygon $\operatorname{tre\theta }$.

Have pupils derive the theorem informally for the sum of the angles of any polygon, exterior and interior angles.

Definitions of quadrilaterals and theorems on parallelograms may be formulated by the pupil upon discovery of the relationship between the parts.

Point out to the pupil the many applications of the parallelogram of forces in aeronautics, physics, etc.

Use a plane table to show the location of points of intersection. Polygons are formed by joining the end points of the intersecting lines.

Pupils are to inscribe a pentagon in a circle by the method used in drafting.

TOPIC VII--INEQUALITIES

Content

Teaching suggestions

A. Axioms

Assist pupils in formulating the

B. Theorems

C. Applications

fundamental theorems of inequality of triangles, sides, and angles. The inequality of arcs and chords of a circle may be studied now.

Help pupils develop proof.

Illustrate from arithmetic for the inequality axioms.

Point out the circular reasoning involved in proving the proposition: If two sides of a triangle are unequal, the angles opposite these sides are unequal and the greater angle lies opposite the greater side, by the indirect method in 
which each one is made to depend upon the other.

Have puplls cite examples of circular reasoning from non-mathematical situations.

TOPIC VIII--LOCUS

Content

4. Definitions

B. Theorems

C. Examples

D. Applications

\section{Teaching suggestions}

Pupils are to define word locus.

Illustrate the definition by tacking a large piece of paper on the bulletin board on which are placed points and lines. Let pupils, supplied with a circle to roll, a line to move, or a ruler for measuring, carry out the required movements to develop the fundamental loci, using a thumb tack or colored crayon to mark successive positions of the moving point or line.

The result is a number of points which show the locus as a pattern traced by the moving point.

Remind pupils of the fact that when they were constructing graphs of equations they were really constructing loci.

Locate algebraically:

a. The locus of points equidistant from the points $(3,5)$ and $(-1,5)$;

b. The locus of points which are 4 units from the line whose equation is $Y=2$;

c. The locus of points at a given distance $R$ from the origin $(0,0) \mathrm{X}^{2}+\mathrm{Y}^{2}=\mathrm{A}^{2}$

The better pupils might extend this theorem to include the locus of points at a given distance from a 
given point whose coordinates are $a$ and $b$.

Solve any examples given in basal texts.

Call attention of pupils to the illustration of loci in "Treasure Island."

Have pupils locate points in a classroom and on the school grounds by use of a straight edge and string compasses.

Call attention to the fact that star paths are often studied by photographing their positions at various intervals with a fixed camera. Stars near the poles trace circular paths on the photographic plate while stars near the equator trace straight lines.

Locus in three dimensions might be introduced here.

TOPIC IX--RATIO AND PROPORTION

\section{Content}

A. Definitions

B. Exercises

C. Theorems and related constructions

D. Practical application

\section{Teaching suggestions}

Teach ratio as a fraction, and proportion as equal fractions.

Point the change in value as the numerator increases and denominator remains constant, or the denominator increases and the numerator remains constant.

Practice solving fractional equations and apply the axfoms of algebra.

Cut a triangle from ordinary notebook paper using a line as the base and the space between lines as the common unit of measure. Have pupils analyze and write out a proof for, "A parallel to one side of a triangle, intersecting the other two 
sides, divides the other two sides proportionally."

Emphasize the necessity of a common unit of measure.

Have pupils write the converse of this theorem and prove the examples in the text related to each.

Have pupils measure the classroom and make a scale drawing of same.

Solve several problems such as:

a. Given a 15 foot board, divide it in two parts which will have the ratio 2 to 3 .

b. Measure the length and width of two American flags of different sizes and determine whether they have the same ratio.

c. A brakeman pulls with a force of 125 pounds on a brake wheel 20 inches in diameter. The force is communicated to the brake chain by means of an axle $2 \frac{1}{2}$ inches in diameter. Find the pull on the brake chain.

Explain the use of ratio in determining the number of representatives in Congress.

\section{Content}

A. Definitions

B. Theorems

C. Practical application

D. Related theorems

1. Proportional segments in circles

\section{Teaching suggestions}

Have pupils construct a square $4 \times 4$, a rectangle $8 \times 2$, a square $5 \times 5$, and another square $4 \times 4$. Compare the four figures and point out the difference between similarity, equality, and congruence.

Have each pupil construct a triangle with one angle measuring 60 degrees and another measuring 80 degrees. 
2. Right triangle and mean proportional
Two pupils working together could compare the triangles and write out a proof for, "Two triangles are similar if two angles of one are equal respectively to two angles of the other."

It might be of help to point out that the combination of letters in the numerators usually indicates one triangle and those of the other by the denominators when the pupil is selecting similar triangles from a given proportion.

Another ald in indicating corresponding parts of similar figures is the use of colored chalk.

Use such examples as:

A photograph $3 \frac{1}{2}$ by $4 \frac{7}{2}$ is to be enlarged so that the width of the enlarged picture will be 9 in. Find the length of the enlarged picture.

Develop the theorem: "If two chords intersect in a circle, the product of the segments of one equals the product of the segments of the other" by measuring the segments and finding the product. Develop by similar method the theorem dealing with secants and tangents.

If chords $A B$ and $C D$ intersect at $B$ and $A B=10$ inches, $C E=4$ inches, $E D=4$ inches, find $A E$ and $E B$.

Solve any exercises in the text using these theorems. Also use numerical applications of students' choice to 1liustrate the meaning of these theorems.

It might be necessary to teach or re-teach radicals at this point. 
TOPIC XI--MEASUREMENT OF GEOMETRICAL FIGURES

Content

1. History

B. Definitions

c. Theorems

1. Polygons

a. Special triangles

b. Parallelograms

c. Rectangles

d. Rhombus

๑. Square

f. Regular polygon

g. Trapezoid

h. Any polygon

2. Exercises

3. Pythagorean

theorem

a. History

b. Proof

c. Exercises

d. Applications

4. Circles

a. Definitions and relationship

b. Theorems and constructions

c. Exercises and practical application

D. Numerical trigonometry (optional)

1. Definition

a. Trigonometric ratio

2. Application
Teaching suggestions

Have pupils do research on the origin and development of measurement. (The Nineteenth Yearbook of the National Council of Teachers of Mathematics has valuable help for the history and use of surveying instruments). Have pupils construct some of these and use them to lay off a baseball diamond, a football field, or survey the school grounds.

Emphasize the fact that area is measured in square units.

Also emphasize the difference between area and perimeter.

Develop an informal proof for the area formulas of the following:
a. Parallelogram
b. Triangle
c. Regular polygon
d. Trapezold

Have pupils solve the numerical exercises in the text giving special attention to the manipulation of formulas to solve for the missing terms.

Study and explain the history and use of the Pythagorean theorem.

Help pupils develop an understanding of the formal proof of this theorem using the square and encourage the abler pupils to experiment and develop proofs using the semi-circle or similar polygons in place of the square.

Have pupils solve a number of examples applying the Pythagorean theorem. 
3. Construction

a. A triangle equal to a given polygon.

b. A square equal to the difference of two squares.

c. A circle whos $\theta$ area is equal to the sum of two circles.
Have pupils construct geometric figures for the square root of 2 , 3 , etc. (The diagonal of a square, with the side equal to one inch is the square root of 2 . Use the length of this diagonal for one side of a rectangle and one inch for the other and the diagonal of this rectangle is the square root of 3 ).

By referring to the Seventeenth Yearbook of the National Council of Teachers of Mathematics have pupils point out the use of the Pythagorean theorem in locating foreign objects such as bullets, needles, or glass in a human body when $\mathrm{x}$-rays are made.

Develop the relationship between the circle, the regular inscribed and cireumscribed polygons, the apothem, and the radius.

Inscribe a triangle, square, pentagon, hexagon, octagon, in a circle to introduce the basic concept of the theory of limits.

Measure the diameter and circumference of a number of circles and divide each circumference by the diameter of that circle. If you are accurate, you will find that this ratio equals 3.14 .

Call attention again to the fact that geometry is a complete and interrelated system by having the pupils list the independent theorems in this unit.

Allow pupils to solve the numerical examples in the text using the special area formulas for triangles, the formulas for sector and segment to give practice in arithmetical and algebraic skills.

On a blackboard graph draw right triangles of different sizes and show the pupils how sine, cosine, and tangent change as the size of the angle changes. 
Teach pupils how to use the trigonometric tables.

Have pupils solve numerical exercises in the text using the trigonometric tables.

Have pupils use simple instruments they have constructed to measure helghts of objects around the school (trees, flagpole, posts, etc.).

\section{EVALUATION:}

Evaluation of any topic should include the following:

Demonstration of theorem proof;

Construction problem;

Objective questions to test vocabulary and facts;

One or more original problems to show application and to test ability to use what has been learned. 


\section{SECOND-COURSE ALGEBRA}

\section{INTRODUCTION}

Capable pupils should be encouraged to elect a second course in algebra, especially if they wish further training in mathematics or the sciences. The second course in algebra should belp the student to develop: (I) an advanced understanding of the number system through the study of irrational and imaginary numbers; (2) an understanding of the use of graphical representation; and (3) an understanding of the function concept through the study of tables, graphs, formulas, and equations. This course should also facilitate computation by giving the pupil the new computational tool of logarithms. It should help him acquire more advanced algebraic skills and the ability to apply them to wider fields as well as an increased understanding of the locus concept.

Often too much time is spent reviewing first-year algebra, eonsequently it is often difficult to complete the work of the second year. With this in mind, it is suggested that a review covering the fundamentals, factoring, fractions, first-degree equations in both one and two unknowns be completed in approximately six weeks.or less.

The new content of the second course should allow immediate follow-up, beginning with the unit on functional relations, and a short period of time be given along with the advanced topics for such reviews as are necessary to retain skills and oxtend the applications of the underlying principles.

In this way, a better comprehension of the entire course will be achieved. Second-Course Algebra is herewlth divided into eleven topics:

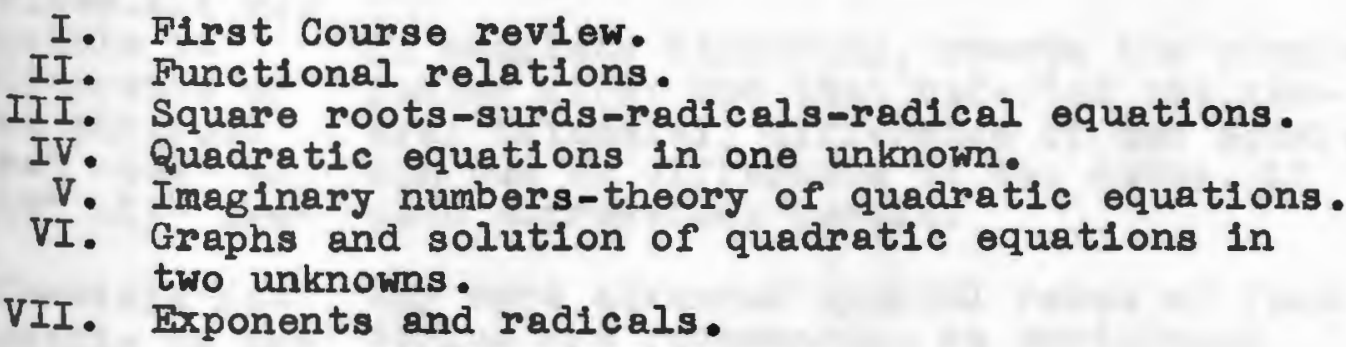


VIII. Iogarithms

IX. Numerical Trigonometry

X. Progressions

XI. Equations of higher degree

TOPIC I--FIRST-COURSE REVIEW

Content

Teaching suggestions

PABT I

Addition, Subtraction, Multiplication, and Division

A. Signed numbers

B. Yonomials

C. Polynomials

\section{PABT II}

Special Products and Factoring

A. Factoring trinomills of the type: $a x^{2}+b x+c$

B. Special cases of ractoring

1. By grouping: $a x+a y+b x+b y$ $a(x+y)+b(x+y)$

2. Polynomials reducible to difference of trio squares; $a^{2}+2 a b^{2}+b^{2}-c^{2}$ $(a+b)^{2}-c^{2}$

3. Trinomials reducible to difference of two squares: $16 a 4-12 a^{2}+1$ $\left(4 a^{2}-1\right)^{2}-4 a^{2}$

4. Binomials reducible to the
Allow for practice materlal to make sure that pupils understand the procedure. Follow this with a diagnostic test to determine individual pupil assignments.

Assign to each pupil related practice exercises that correspond to the exercises he was unable to solve in the test.

A reviow here will refresh the concepts. If all pupils do not achieve the goals, short reviews during the year will help more than too much time spent here.

Since this is a review, pupils will enjoy a new approach in which they seo all regular cases, except removing common monomials, as special cases of $a x^{2}+b x$ $+c$. For example, the usual separate cases, 1llustrgted with thes trinomials: $x^{2}+4 x+4 ; x^{2}-2 x-8 ; 3 x^{2}-13 x-10$ are all special cases of $a x^{2}+b x+c$.

Teach the multiplication of each type along with the factoring processes.

often the topic of factoring is given too much time in the review at the outset of second-course algebra. The teacher must bear in mind that further opportunity is provided to study factoring throughout the course.

In complete factoring, remove the simplest factor first and then refactor the general trinomial, difference of two squares, and sum or difference of two cubes, if such expressions remain.

Any more advanced special cases of factoring are recommended as enrichment 
difference of two squares: $4+4$ $\left(a^{2}+2\right)^{2}-4 a^{2}$

5. Sum or difference of like powers: $a^{n}+b^{n}$ $a^{n}-b^{n}$

PART III

\section{Frections}

A. Roduction of a fraction to Its lowest terms

B. Lultiplication and division of fractions

C. Sign of fractions

D. Addition and subtraction of fractions

E. Complex fractions

F. Mixed Iractions

PART IV

Firat-Degree Equations

A. Equations with one unlanown

B. Equations with two unknowns

C. Fractional equation

D. Verbal problems exprossing a firstdegreo equation

E. Equations with three unknowns (as onrichment material) material for pupils who need less time on review.

A short review of the fundamental 1deas of arithmetical fractions should help to increase understanding of algebraic fractions.

Relate the work in algebraic fractions to that of arithmetical fractions.

Require pupils to express the line separating the numerator and denominator of the fraction as "divided by."

Remind students of the three signs of a fraction, elther written or implied, 1.e., the sign of the numerator, the sign of the denominator, and the sign of the fraction.

Emphasize the fundamental law that only fractions with equal denominators can be combined.

At this level pupils should be encouraged to replace much step-by-step witten work with sound mental work. For example, many pupils should be able to eliminate writing down the invert step in division of fractions.

Briefly review the solution of equations with one unknown by use of the four basic axioms, 1.e., the same number may be added to or subtracted from both sides of an equation and both sides of the equation may be multiplied or divided by the same number.

Review equations involving parenthesis and fractions.

Graph the first degree equation in two unkowows. Use the graph to point out that such an equation has an infinite number of solutions since there are an infinite number of points on the line. Then try to develop the idea that there must be as many sets of data as there are unknowns. Problems in non-algebraic language should help clarify the presentation. Then proceed with the solution of 
first-degree equations in two variables.

Review methods of solution by elimination by addition or subtraction and substitution.

Apply the solution of linear equations by the use of verbal problems drawn from the experlences of the pupils, whenever possiblo.

The teacher should always bear in mind that the review of this work is to refresh and to extend the meaning of FIRST-COURSE ALGEBRA.

Evaluation:

The pupil should:

Understand the terminology used;

be able to carry out the fundamental operations with signed numbers, nonomials, polynomials, and fractions;

solve problems involving parentheses; solve equations using the basic axioms of addition, subtraction, multiplication, and division; translate verbal problems into equations and solve them; find special products mentally and factor all types completely; solve systems of equations by graphing, by elimination, by addition, by subtraction, and by substitution.

TOPIC II--FUNCTIONAL RELATIONS

Content

A. The function concept

B. Ways of expressing the functional relations:

1. The word-rule
2. The formula
3. The table
4. The graph

Teaching suggestions

Develop the concept of functional relations by discussing with the class the 1dea of one quantity depending upon another quantity. Some examples are:
a. Upon what will the total cost of a family's grocery order depend?
b. Upon what will the total distance a car travels depend?
c. Upon what do the total wages a man earns depend?
d. Upon what does the amount of taxes depend?


c. The meaning and use of the words:

1. Formula

2. Variable

3. Constant

4. Independent variablo

5. Dependent variable

D. Graphing by plotting points

B. Graphing by the intercept method

F. The lope of a line

G. Linding the slope of a line from its equation

H. Families of firstdegree functions

$$
\begin{aligned}
& \text { 1. Type } \\
& \text { 2. Type } m x \\
& y=m x+b
\end{aligned}
$$

I. Graphs of systems of first-degree oquations

J. Ratio and proportion

K. Variation

1. Direct

2. Inverse

3. Joint
Give many other examples from both pupils' and teacher's experience.

Show each of the four ways of expressing the functional relations, 1.e., the word-rule, the formula, the table, and the graph.

Show that many functional relationships cannot be expressed in mathematical terms.

Give and require of the class various examples of the use of the words in C. Dse the language in class discussions throughout the topic. and thereafter.

Given the word-rules, allow the pupils to write the formulas, prepare the tables, and plot the corresponding graphs.

Reteach the meaning of axis, origin, quadrants, abscissa, ordinate, co-ordinates.

Have class plot various points in each of the four quadrants.

Derelop concept that two points determine a traight line. A third point is located only as a check.

Explain meaning of x-intercept and j-intercept.

Present the intercept method of graphing as the easy way of locating two points through which a straight line can be drawn.

Explain meaning of the slope of a line. It can be defined as the ratio of rise to run.

Define positive and negative slope as follows:

$$
\begin{aligned}
& \text { a. If a line rises to the right, } \\
& \text { its slope is positive. } \\
& \text { b. If a line rises to the left, } \\
& \text { Its slope is negative. }
\end{aligned}
$$

The following teaching procedure 
should prove helpful in teaching the finding of the slope of a line from its equation.

a. Plot the graph of the equation $3 y=2 x$ and determine the slope of this line.

b. Solve the equation for $I$.

c. Compare the slope of the line with the coefficient of $x$.

d. Plot the graph of the equation $3 y=2 x+6$ and determine the slope of this line.

- Solve the equation for $I$.

f. Compare the slope of the Iine with the coefficient of $x$.

g. Compare the constant term with the $\mathrm{J}$-intercept. Hence, $\mathrm{m}$ is the slope of the line $\mathrm{y}=\mathrm{mx}+\mathrm{b}$, and $\underline{b}$ is the $I$-interoept.

The following procedure should prove helpful in explaining the equation $y=m x$.

Have the class graph the following equations on the same set of axes:

$$
\begin{aligned}
& \mathbf{y}=\mathbf{z} \\
& \mathbf{y}=-\frac{t}{x} \\
& y=\frac{1}{2} x \\
& y=-\frac{1}{8} x \\
& y=2 x \\
& y=-2 x \\
& y=4 x \\
& y=-4 x
\end{aligned}
$$

Be sure that student observes that:

$$
\begin{aligned}
& \text { a. All the graphs pass through } \\
& \text { the origin. } \\
& \text { b. As the value of } m \text { Increases, } \\
& \text { the graph of } \mathrm{J}=\mathrm{mx} \text { appears } \\
& \text { to rotate in a clockwise } \\
& \text { direction. The teacher may } \\
& \text { need to point out that the } \\
& \text { change in m from } \mathrm{t} \text { to }-4 \text { is } \\
& \text { a decrease in } m \text {. }
\end{aligned}
$$

The following procedure should prove helpful in explaining the equation $\mathbf{J}=\mathbf{m x}+\mathrm{b}$.

Have the class graph the following equations on the same set of axes: 


$$
\begin{aligned}
& y=x+2 \\
& y=2 x+2 \\
& y=3 x+2 \\
& y=-4 x+2 \\
& y=-2 x+2
\end{aligned}
$$

Notice that when $m$ changes and $\underline{b}$ remains constant, the graphs appear to rotate about the point $(0, b)$.

Have the class graph the following equations on the same set of axes:

$$
\begin{array}{ll}
y=2 x+1 & y=2 x+6 \\
y=2 x+4 & y=2 x+8
\end{array}
$$

Notice that when $m$ remains constant and $b$ changes, the graphs appear to be translated (moved so as to remain parallel to one another).

After these examplos have boen presented and observations made by the pupils, help the students to generalize concerning any first-degree equation of the form $y=m x+b$. Make sure the student understands that the coefficlent of $x$ alone determines the slope of a line when the equation of the IIne is in the form $y=$ $m x+b$, with the constant term $b$ determining the location of the line on a graph.

The student should now realize that either of the following sets of data determine a straight line:

$$
\begin{aligned}
& \text { a. two points, or } \\
& \text { b. one point and the slope of } \\
& \text { the line. }
\end{aligned}
$$

In graphing systems of first-degree equations, it is important that the student be able to recognize dependent, inconsistent, and independent equations. The following procedure will help:

Have the class graph the following 
types of pairs of equations:

$$
\begin{aligned}
& 2 x+4 y=2 \quad \text { Dependent } \\
& 4 x+8 y=4 \quad \text { equations } \\
& 3 x-2 y=6 \quad \text { Inconsistent } \\
& 6 x-4 y=8 \quad \text { equations } \\
& 4 x+3 y=6 \quad \text { Independent } \\
& 2 x+y=4 \quad \text { equations }
\end{aligned}
$$

Teach pupils to recognize each of the above types of equations:

$$
\begin{aligned}
& \text { a. If the equations are } \\
& \text { dependent, one equation can } \\
& \text { be derived from the other by } \\
& \text { multiplying by a constant. } \\
& \text { b. If the equations are incon- } \\
& \text { sistent, the ratio of the } \\
& \text { coefficients of } x \text {, and the } \\
& \text { ratio of the coeficlents } \\
& \text { of } 7 \text { are the same, but the } \\
& \text { ratio of the constant term } \\
& \text { is different. } \\
& \text { c. If the equations are inde- } \\
& \text { pendent, the ratios of the } \\
& \text { coefficients are not the same. }
\end{aligned}
$$

The student should recognize that there is no solution for elther dependent or inconsistent equations, but there is a solution for independent equations. The graphical representation of eacn should make this clear.

The concept of ratio as being a comparison between like quantities can be presented by a brief review of the slope of a Iine. Many other examples should be given so that the concept of ratio is clear.

Demonstrate to the class that a ratio is a fraction and obeys all the laws of fractions.

The student should understand that a proportion is a statement that two ratios are equal. Thus, a proportion is a fraction's equation. trate the concept of proportion and 
problems in indirect measurement of fer practical application.

Both the colon and the fractional forms of proportion should bo taught.

The main idea in this study of variation 18 an understanding of the three types of variation. The student will nood much practice in stating verbal problems involving variation into algobraic language.

\section{DIRECT VARIATION}

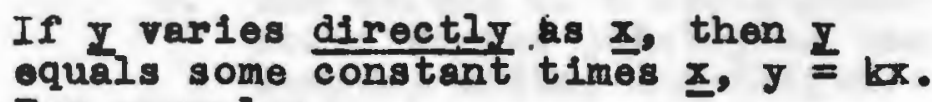
For example:

a. The distance a train travels at a uniform rate varies directly as the time. (The uniform rate is the constent.)

b. The amount of property tax, at a flxed rate, paid varles directly as the assessed value. (The tax rate is the constant).

c. The area of a circle varies directly as the square of the radius. ( $p 1$ is a constant term).

INVERSE VARIATION

If $I$ varies as the inverse of $x$, then I quals some constant times $17 x$, $\bar{y}=k l / x$. For example:

a. The volume of a gas in a container varies inversely as the pressure.

b. The number of revolutions made by a wheel rolling over a given distance varies inversely as the radius.

c. The resistance a wire offers to an electric current varies inversely as the square of the radius. 
If $I$ varies jointly as $x$ and $z$, then I equals some constant times $\overline{x z}, \bar{y}=k x z$. For example:

$$
\begin{aligned}
& \text { a. The area of a triangle varies } \\
& \text { jointly as the base and altitude. } \\
& \text { b. The total cost of a set of } \\
& \text { books varies jointly as the } \\
& \text { number of volumes and the cost } \\
& \text { of each volume. } \\
& \text { c. The volume of a rectangular } \\
& \text { solid varies jointly as the } \\
& \text { length, width, and heigth. }
\end{aligned}
$$

\section{Eveluation:}

The pupil should be able to:

Thlnk in terms of functions;

express, Interpret, and use functional relationships

in the form of words, formulas, tables, and graphs;

demonstrate and understand the concepts, vocabulary, and symbolism of the topic; compare changes in two related variables; recognize functional relations in life situations, some of which cannot bo expressed mathematically.

TOPIC III--SQUARE ROOTS--SURDS--RADICALS AND RADICAL EQUATIONS

Content

1. squares and square root

1. From a table

2. By approximation

3. By rule

B. Surds

1. Simplifi cation of:

a. Whole

b. necimal

c. Fractiona

2. Addition and subtraction
Teaching suggestions

Test to determine what should be included in this unit.

Have a brief drill on the use of the table to find both the square and square root of numbers. A clear distinction should be made hore as pupils often fail to distinguish the difference.

Pupils should memorize the squares of numbers from 1 to 25 and the cubes from 1 to 12 .

The students should be taught to use the square and cube of the sum and the difference of two numbers for 
3. Multiplication and division

c. Radical equations facility in squaring numbers, e.g.

$$
32^{2}=(30+2)^{2}=900+120+4=1024 .
$$

At this point teachers should give the algebraic explanation of the common rule for finding square root of 5184 . First let $t$ equal the tens in the square root and the u the units. Then

$$
\begin{aligned}
(t+u)^{2} & =t^{2}+2 t u+u^{2} \\
& =t^{2}+u(2 t+u)=5184
\end{aligned}
$$

Now $t^{2}$ must be 4900 and $t=70$ Then $u(2 t+u)=284$, but $t=70$, hence $u(140+u)=284$

But 140, the coefficient of $u$, is contained about 2 times in 284 . Substituting

$$
2(140+2)=184 .
$$

Therefore,

$$
\sqrt{5184}=72 \text {. }
$$

In simplifying surds, it is well to require a systomatic plan in the beginning such as:

$$
\begin{aligned}
& 5 \text { in. }+3 \text { in. }-2 \text { in. }=6 \text { in. } \\
& 5 x+3 x-2 x=6 x \\
& 5 \sqrt{2}+3 \sqrt{2}-2 \sqrt{2}=6 \sqrt{2}
\end{aligned}
$$

Multiplication and division of radicals should be introduced by a short review of products of binomials. Students easily transfer from

$$
\begin{array}{ll}
(5+x)(3-x) & \text { to }(5+\sqrt{2})(3-\sqrt{2}) \\
15-2 x-x^{2} & 15-2 \sqrt{2}-2
\end{array}
$$

This might be a good time to stress the fact that squaring a radical whose index is 2 removes the radical sign.

A review of the product of the sum and difference of two numbers will help the class to understand rationalization of 
binomial surd denominators.

Stress the 1dea that denominators are rationalized only to facilitate the evaluation of the fraction.

Apply the basic axiom that the numerator and denominator of a fraction can be multiplied by the same number. To rationalize the denominator, the numerator will be the conjugate of the donominator.

Begin the study of radical equations with very simple equations. Formulas might be used which ịvolve radicals.

For ease in solution and to avold introducing extraneous roots, the teacher should stress the idea that one radical expression should be the only term on one side of the equation as $\sqrt{2 \bar{y}}+4=5$ should become $\sqrt{2 y}=1$ before solution.

\section{Freluetion:}

Pupils should:

Be able to find squares and square roots with accuracy; be able to solve problems using the rule of Pythagoras that involves square and square root; know the language related to the content of the topic; simplify, add, subtract, multiply, and divide radicals;

be able to rationalize the denominator of fractions; be able to solve linear equations involving radicals.

TOPIC IV--QUADRATIC EQUATIONS IN ONE UNKNOWN

Content

1. Graphing quadratic oquations

B. Solution of quadratic oquations

1. Incomplete quadratics

\section{Teaching Suggestions}

Graphical representation of quadratic equations offers the best approach to quadratic equations because here the student can grasp the meaning of the equation and the roots of the equation.

A quadratic equation should be graphed. Then the teacher should point out that the roots of the quadratic are the values 
a. Square mothod

b. Factoring method

2. Complete quadratics

a. Factoring method b. Completing method

c. Formula method

$x=$

$=\frac{-b \pm \sqrt{b^{2}-4 a c}}{2 a}$

d. Graphic method

c. Fractional quadratic equations

D. Radical equations

F. Verbal problems

1. Numerical

2. Consecutive integer

3. Reciprocals

4. Numerator and denominator

5. Geometric

6. Distance

7. Pleture frame of $x$ where the curve crosses the $x$ exis. Have the students locate the points at which the quadratic equation crosses the $x$ axis and give the roots of the equation.

Plenty of practice should be given in the graphical solution of quadratic equations in which the roots are real, rational, and unequal.

Then present a quadratic in which tho roots are real, unequal, and irrational. This should bring out the inadequacy of the graphical solution and lead to the algebraic method pf solution.

A suggestion here is that a graphical representation of each type of quadratic equation be made before the algebraic solution is given. The reason for Imaginary roots is readily seen when a graph 18 dram.

Stress the fact that there are two roots to a quadratic equation.

Have students solve some incomplete quadratics as found in formulas such as the formyla for falling bodies, $s=g t^{2}$.

Use the method of factoring when the factors are readily seen.

The method of completing the square is Important as a background for the derivation of the quadratic formula.

After the derivation the student ahould memorize the formula.

Stress that the quadratic formula gives two roots to a quadratic oquation but that sometimes these roots are equal.

Solve many equations of varied types by the formula.

Have the students check some of all types of roots by substitution.

In radical equations, extraneous roots are sometimes introduced when both 
members of an equation are raised to a certain power. Thus, it is nocessary that the roots of all radical equations be checked.

Verbal problems often involve quadratic equations. The aim here should be that of developing the ability of translating the problems into equations.

Puplls need much belp with reading and analyzing. Teach pupils to write down and organize all relevant data with care.

Evaluation:

The pupils should:

Solve a quadratic of the form $a x^{2}+b x+c=0$ by:

a. Graphing 1t;

b. factoring, if possible;

c. completing the square;

d. the formula:

- solve vorbal problems leading to quadratic equations;

f. solve fractional and radical equations which lead to quadratic equations;

8. check roots always and discard inappropriate ones.

TOPIC V--IMAGINARY NUMBERS--THEORY OF QUADRATIC EQUATIONS

Content

1. Inaginary numbers

1. Simpli-

fication using

imaginary unit

2. Operations

with

Imaginary

numbers

a. Addition and subtraction

b. Powers of the Imaginary unit
Teaching suggestions

Show how imaginary nymbers come about. Graph the equation $x^{2}+2 x+3=0$. Show that the roots are imaginary. Then solve the equation by the quadratic formula to show how 1mag1nary numbers arise.

Point out the use of imaginary numbers in electricity in physics.

Explain the imaginary unit $\sqrt{-I}=1$ and powers as $-1=12$. Then show how every imaginary number can be expressed as a product of the real number and the Imaginary unit: $\sqrt{-36}=\sqrt{-1}$ or 61 . 
c. mult1plication and division

B. Gouplex numbers

1. Addition and subtraction

2. Multiplication and division

a. Conjugate complex numbers

3. Quadratics having imaginary roots

4. Character of roots as determined by

a. the discriminant

5. Relation between roots and coefficients

6. Forming oquations from given roots

a. Numerical and literal roots

b. Integral and fractional roots

c. Rational and irrational roots

d. Complex roots

7. Iiteral quadratics

8. Equations solved like quadratics
Here the teacher might explain that two of the three cube roots of 8 involve imaginary numbers. $\sqrt[3]{8}=2,-1+\sqrt{-3}$, and $-1-\sqrt{-3}$

Imaginary numbers are subject to all the normal laws of operation which are used with real numbers and thus may be added or subtracted as radicals are.

Set up the series $1,-1,-1,1$ for powers of 1 .

When studying complex numbers, use the law that only like, terms can be combined.

Use sufficient drill to insure confidence in working with these numbers.

By the use of the quadratic formula, have the students identify the roots of a quadratic equation as

a. Real or complex

b. Equal or unequal

c. Rational or irrational

After such identiflcations as were suggested above, develop a summary:

If $b^{2}-4 a c$ is The roots are

Positive and a

Real

perfect square

Rational

Unequal

Positive but not Real

a perfect square Irrational

Unequal

Real

Rational

Equal
Complex Irrational Unequal or Imaginary 
The teacher should point out that most complex roots are irrational.

Have students determine character of the roots by use of the discriminant and drill.

From the quadratic $a x^{2}+b x+c=0$, show that the sum of the roots is $=$, and the product is $\frac{c}{a}$.

Encourage the class to make up problems. Literal quadratics should be used as enrichment material. Any equation which' can be put in the form: $a()^{2}+b()+c=0$ may bo solvod as a quadratic. Examplos are:

$$
\begin{aligned}
& \text { a. } x^{4}-13 x^{2}+36=0 \\
& \text { b. }(5 x+12)^{2}-5(5 x+12)-6=0
\end{aligned}
$$

Eveluation:

The pupil should know:

The meaning of imaginary numbers and roots;

the nature of roots by inspecting the discriminant

$b^{2}-4 a c$; bow to form equations when roots are given

as well as solve the equations;

how to use and express the imaginary unit;

how to carry out the fundamental operations with imaginary numbers;

how to solve equations of higher degree that have the form of quadratic;

how to check by using relations between roots and coefficients.

TOPIC VI--GRAPHS AND SOLUTION OF QUADRATIC EQUATIONS IN TWO UNNKNOWNS

\section{Content}

A. Graphs of circles

$$
x^{2}+y^{2}=r^{2}
$$

B. Graphs of ollipses

$$
b^{2} x^{2}+a^{2} y^{2}=a^{2} b^{2}
$$

\section{Teaching suggestions}

Reviow graphs of first-degree equations. Emphasize that these graphs were straight lines. Explain why seconddegree equations are called conics. Use pictures of sections of cones to show the forms of the conics. 
c.

$$
\begin{aligned}
& y=a x^{2} \text { or } \\
& y=a x^{2}+b x+c \\
& x=b y^{2} \text { or } \\
& x=a y^{2}+b y+c
\end{aligned}
$$$$
\text { Graphs of parabolas }
$$
D. Graph of the hyper-

$$
\mathrm{IY}=\mathrm{c}
$$

I. quadratic equations with two unknowns

$$
\begin{aligned}
& \text { 1. One linear and } \\
& \text { one quadratic } \\
& \text { 2. Pairs of } \\
& \text { 3. Verbatics } \\
& \text { Verbal problems }
\end{aligned}
$$

\section{THE CIRCLE}

Using a sample equation such as

$$
x^{2}+y^{2}=49
$$

a. Solve for $y$ and show the the range of real values for $x$.

b. Solve for $x$ and show the range of real values for

c. Hake a table of corresponding values of $x$ and $I$.

d. Plot the points and draw smooth curve' through them.

- Go from this quickly to the use of the compass to draw the graphs without making a table of values.

f. Generalize concerning the nature of the equation of

a circle, 1.0.,

$$
x^{2}+y^{2}=r^{2}
$$

g. Point out that the circle is the basis of many fundamental geometric constructions and that it is the form of many objects around us.

As a proviow to analytical geometry, the circle may bo dorined as the path a point traces so that it is a given distance from a fixed point. Tho distance is the radius and the fixed point is the center of the circle.

\section{THE ELLIPSE}

Use the same steps as in a through d for circle graphs.

Study the equation of the ellipse, i. $0 .$,

$$
b^{2} x^{2}+a^{2} y^{2}=a^{2} b^{2}
$$

or

$$
\frac{x^{2}}{a^{2}}+\frac{y^{2}}{b^{2}}=1
$$


Explain the meaning of $x$ and $y$ intercopts, and major and miñor axis and arcs. Show how these graphs may bo sketched.

Point out the use of ellipses in orbits of planets and satellites, arches, auditoriums, bridges, designs, etc.

The ellipse may be defined as the locus of a point which moves so that the sum of the distances of this point from two fixed points is a constant. The two fixed points are the foc1 and the constant is the length of the major axis.

\section{THE PARABOLA}

Briefly review parabolas with the Y-exis as the axis of symmetry as they were studied in Topic IV.

Set up tables and graph the following parabolas:

$$
\begin{array}{ll}
x=y^{2} & x=1 / 4 y^{2} \\
x=1 / 2 y^{2} & x=2 y^{2} \\
x=-y^{2} &
\end{array}
$$

In so doing, note that:

a. All curves pass through the origin.

b. The axis of symmetry is the $x-a x 1 s$.

c. The graph opens to the right if $x$ is positive and to the left if $\underline{x}$ is negative.

Point out practical examples of the parabola as light reflectors, arches, etc.

The parabola may be defined as the locus of a point which moves so that the distance from a fixed point is oqual to the distance from a fixed line the directrix. 
When graphing the hyperbola, make a table of corresponding values for $x$ and I. Then plot the points and draw smooth curves through them.

Teach the meaning of asymptotes as well as their use.

Point out the applications in scientific formulas, sound ranging, etc., calling special attention to Boyle's Law $(p v=c)$.

Graphical representation of quadratics in two unknowns shouzd be made. This adds meaning to the solution of such equations and gives some inslght into analytical geometry.

The algebraic solution of one linear and one quadratic equation should be limited to the substitution method.

Pairs of quadratic equations may bo solved by the method of substitution or that of addition and subtraction.

Verbal problems should show the need for ability in solving systems of quadratics and give the pupil practice in choosing the method he considers best to use in each solution.

\section{Evaluation:}

Tho pupil should:

Recognize the following about graphs of equations:

$$
\begin{array}{ll}
a x+b y=c & \text { gives a straight line } \\
a x^{2}+b x=c & \text { gives the parabola } \\
a x^{2}+b y^{2}=c & \text { gives the ellipse } \\
x y=c & \text { gives the hyperbola } \\
a x^{2}-b y^{2}=c & \text { gives the hyperbola } \\
x^{2}+y^{2}=c & \text { gives the circle; }
\end{array}
$$

Solve quadratic systems and pair the answers correctly. Be able to graph tho systems of equations. 
BOPIC VII--EXPONENTS AND RADICALS

Content

A. Exponents

1. The fundamental laws of exponents

2. Fractional exponents

3. Negative exponents

4. The zero exponent

5. Application of exponents

B. Radicals

1. Simplification of radicals

a. Removing factors from the radicand

b. Simplifying fractional radicands

c. Reducing to a lower order

2. Addition and subtraction of radicals

3. Fundamental laws of radicals

a. Multiplication law

b. Division law

4. Rationalization of denominators

C. Radical equations
Teaching suggestions

Review with the class the work they have already had about positive integral exponents and powers of the same base. Explain that in this unit those fundamental laws are to be extended in order that meaning may be given to negative and fractional exponents and $z e r o$ as an exponent. Explain that to do this, we must choose definitions in such a way that the new exponents will obey the same laws as positive integral exponents do.

Allow for practice in the use of the fundamental laws of exponents with positive integers.

Operations with exponents involving whole numbers should become almost automatic. In order to gain this proficlency oral drill might be gainfully used.

Fxtend the fundamental laws of exponents to Include fractional exponents, negative exponents, and the zero exponent.

Emphasize the difference between the power of a root and the root of a power. When possible, the power of a root should be used in preference to the root of a power. Show the pupils the reason for this preference.

Here is a fine example of the many opportunities in algebra to advance the understanding of the nature of mathematical proof. For examplo, these steps const1tute good proof of $A^{\circ}=1$.

$$
\begin{aligned}
& A^{n} \div A^{n}=A^{n-n}=A^{0} \quad \text { (Law of expo- } \\
& \text { nents in division). }
\end{aligned}
$$

$A^{n} \div A^{n}=1$ (Any quantity divided

by 1tself).

Therefore $A^{0}=1$ (Quantities equal to the same quantity equal each other). 
In physies, chemistry, and astronomy, there is constant occasion to deal with very large or very small numbers. Exponents are often used to express these numbers.

Emphasize the fact that radicals heving the same index and the same radicand can be added or subtracted.

Emphasis should be placed on the fundamental laws of radicals. However, a high degree of skill of operation with radicals is rarely needed. Therefore, greater emphasis should be placed on understanding the process. It should bo enough if a pup1l'can work with radicals correctly if not speedily.

Stress the fact that radicals must be of the same index before they can be multiplied or divided.

Care should be taken to check roots. We often introduce roots that do not satisfy the equation as giren. Students should be shown how these roots are introduced.

Evaluation:

The pup1l should:

Know the meaning of the terms used.

Know the fundamental laws of exponents.

know the meaning of fractional, negative, and zero exponents.

Be able to operate with them as with positive integral exponents.

$\mathrm{Be}$ able to simplify radicals by using fundamental laws of exponents.

$\mathrm{Be}$ able to solve equations contalning radicals.

TOPIC VIII__LOGARITHMS

Content

4. Basic concept of logarithms

B. Exponential and logarithmic forms

\section{Teaching suggestions}

Present an effective over-view of this unit at the very outset. This can be done by using the accompenying miniature system of logarithms to base "2". 
c. Pinding the logarithm, the number, and the base

$$
\text { 2. } \begin{aligned}
& \log _{2} 4=x \\
& \log _{2} x=2 \\
& \text { 3. } \log _{x} 8=3
\end{aligned}
$$

D. Finding the characteristic and mantissa

E. Interpolation

F. Ant1logarithms

G. Operations with

logarithms

1. Logarithm of a product

2. Logarithm of a quotient

3. Logarithm of a power

4. Logarithm of a root

H. Cologarithms

I. Applications of logari thms

1. Formulas

a. Circle

b. Cjlinder

c. Cone

d. Sphere

- Cubo

f. Rectangular solid

8. Area of triangle

h. Trape$201 \mathrm{ds}$

2. Sclence formulas
Have this table on the side board and the following examples on the front board when the class comes in. Have the pupils in each row do one of the problems by arithmetic.

$$
\begin{aligned}
& \text { 1. } \frac{128 \times 512}{1024} \\
& \text { 2. } \frac{(512 \times 128)^{2}}{64} \\
& \text { 3. } \frac{\sqrt{65.536}}{256} \\
& \text { 4. } 1 / 4(32768)
\end{aligned}
$$

When the class has finished the exercises, write the answers from the table beside each example on the front board.

See if some pupils have the insight to tell how the teacher could write down the answers from the table.

Such a procedure can be used to convince the class of the efficiency of logarithms. Explain that this system is built to base 2, but that it would not be convenient for practical use. Show the advantage of use of number 10 as a base. Explain that the logarithm used hore is actualiy an exponent.

Emphasize that logarithms are merely exponents. The logarithm of a number is simply the power to which the base is raised to get the number.

Drill on the changing from the exponential to the logarithmic form. For explo, change from the exponential form $23=8$ to the logarithmic form $\log _{2} 8=3$.

In order to $11 x$ the concept of a logarithm, have pupils state orally the powers of 2 in logarithmic form. 
Drill on each of the three steps in exercise $C$ for finding $x$. It is very important that students are able to state such answers quickly by inspection.

When beginning the study of the characteristic, develop a table of the powers of 10, with spaces between the lines, from at least the third power to the minus third power, using both the exponential and logarithmic forms. For example:

$$
\begin{aligned}
& 10^{3}=1000 \\
& 10^{2}=100 . \\
& 10^{1}=10 \\
& 10^{0}=1 \\
& 10^{-1}=.1 \\
& 10^{-2}=.01 \\
& 10^{-3}=.001
\end{aligned}
$$

Have class understand that a logarithm consists of two parts, a whole number and a decimel. The whole number, or characteristic, is found by inspection. The decimal part, called the mantissa, is taken from tables.

From the table of powers of 10 the class should see that a given number greater than one has a positive logarithm, while a number less than one has a negative logarithm. At this point drill on finding the characteristic of the log of a number.

Explain that for convenience, to aroid negative logarithms, we use a positive logarithm followed by a -10 , thus if

$$
\begin{aligned}
& 10^{-1}=.1 \text {, then } \log .1=-1 \\
& \text { or } 10 \mathrm{~g} .1=9.0000-10 \\
& \text { if } 10^{-2}=.01 \text {, then } \log .01=8.0000-10
\end{aligned}
$$

When the student understands the meaning of characteristic and how to derive $1 t$, 
he should be taught the use of the table of mantissas. Practice with numbers of three digits should be followed by numbers of two, one, and four digits.

When beginning the study of interpolation, the students should be taught to obtain tabular differences by inspection and to interpolate without the use of proportional parts. After this fundamental method is well understook, four or five place tables giving proportional parts may bo explained and used.

Explain that the number corresponding to a given logarithm is called the antilogarithm of the logarithm.

Explain how to find antilogarithms with and without interpolation.

The following suggestions will prove helpful in the study of operations with logarithms:

All the operations with logarithms should be preceded by a brief review of operations with exponents.

"Set up" the problem before looking up any logarithms.

After the class has a good concept of the four operations with logarithms, the teacher should explain cologarithms, but their use is optional.

Before applying logarithms distinguish between:

$$
\begin{array}{ll}
\log (2 a)= & 2 \log a= \\
\because 2 a= & \because \log a= \\
\text { and } a= & \text { and } a=
\end{array}
$$

After logarithms have become understood, apply their use in mathematics, business, and science. 
Eveluation:

The pupil should:

Onderstand that logarithms are exponents;

be able to give the logarithms of numbers to bases other than base 10:

be able to use logarithms to facilitate arithmetic operations of multiplying, dividing, taking roots of numbers and raising numbers to certain powers; see and feel the need for logarithms in mathematics whout the foeling that logarithms are more time consuming and more difficult than the actuel arithmetical computation.

TOPIC IX--NUMERICAL TRIGONOMETRY

Content

A. Trigonometry as an aid in indirect measurement

B. The tangent of an angle

1. Tangent value

2. Problems

c. The sine of an angle

1. Sine value

2. Problems

D. The cosine of an angle
Teaching suggestions

Call attention to the very large number of measurements our modern life requires and lead pupils when listing some of these to see that two ways of measuring are used: direct and indirect. Then bring out the fact that trigonometry is especially helpful in indirect measurements in:

$$
\begin{aligned}
& \text { a. Navigation } \\
& \text { b. Astronomy } \\
& \text { c. Surveying } \\
& \text { d. Building, etc. }
\end{aligned}
$$

\section{TANGENT}

Review briefly ratio and similarity of triangles to link "the unknown to the unknown".

Have students measure carefully the sides and angles of right triangles and compute the numerical values of ratios representing the tangent.

Show the natural tangent values and then the logarithmic tangent values.

Clarify the angles of elevation and depression.

The teacher should make clear that the ratios of sine, cosine, and tangent 
are defined in terms of right triangles. Then he should point out that the trigonometric tables make it possible to obtain the value for any angle in the triangle.

\section{SINE}

A drawing is most helpful in problem solving. Follow a plan similar to finding the tangent, making cloar that the sine is simply another ratio obtalned by studying the relationship of the side opposite the angle to the hypotenuse.

\section{COSINE}

The cosine ratio may be derived in the same manner as the tangent and sine--showing both natural and logarithmic values. It 18 advisable to have pupils learn these three functions-tangent, sine, and cosine.

Much drill should be given the three common angles--thirty, forty-five, and sixty degrees.

Field trips in which these three functions are used such as to calculate heights of flagpoles, bulldings, etc., should prove most valuable as teaching alds.

\section{Eveluation:}

The pupils should:

Know how the tangent, sine, and cosine of angles are found:

memorize the definitions of the three functions-tangent, sine, and cosine;

understand the rocabulary of the unit;

bo able to apply the principles learned in solving practical problems by use of indirect measurement.

TOPIC X--PROGRESSIONS

\section{Content}

A. Progressions as on interesting and
Teaching suggestions

This unit helps us to see the rhythm, harmony, symmetry, and the pleasing 
useful device

of mathematics

D. Aritnmetic

progressions

1. The $\mathrm{n}$-th term

2. Aritnmetic means

3. Sum of $\mathbf{n}$ terms

4. Practical applications

C. Geometric

progressions

1. The n-th term

2. Geometric means

3. Sum of $\mathrm{n}-\mathrm{th}$ terms

D. Infinite geometric progressions

1. Sum to infinity

2. Repeating decimals

E. The binomial

theorem

F. Ixpanding

binomials

1. Writing the $r-t h$ term

G. Applications of the binomial theorem

1. Construction of compound interest tables

2. Problems in compound interest

3. The normal distribution curve

4. Law of

Probability

H. Negative and fractional exponents quality that mathematics possesses. This has already been observed in the conic sections and in the poljgons of geometry and further observation is made in the study of series. There is practical value in the study of serles. Installment buying, calculating annuities, insurance statistics, otc., are examples where series of one kind or another are used.

In applying for positions of various types after leaving school, pupils will likely be confronted with tests containing numerous problems based upon progressions. When they work certain practical problems they will find it necessary to deal with sequence of numbers in which each number is related in a definite way to the number which precedes $1 t$. Four kinds of serles are treated-arithmetic, geometric, infinite, and binomial.

Now develop with the class illustrations of different types of serles, such as:

$$
\begin{aligned}
& \text { a. } 5+10+15+20+=s \\
& \text { b. } s=1+8+27+64+ \\
& \text { c. } s=1+1 / 3+1 / 5+1 / 7+ \\
& \text { d. } s=x+2 x+4 x+8 x+
\end{aligned}
$$

Some of the pup1ls may be encouraged to compose some series of their own where the differences are negative, fractional, and decimal, and the ratios are integral, fractional, negative, irrational, etc.

\section{ARITHMETIC PROGRESSIONS}

Show the class how to derive the formula:

$$
1=a+(n-1) d
$$

Assign practice exercises using the formula. 
Have class insert one, two and then five arithmetic means between the numbers 4 and 16 , such as

\begin{tabular}{|c|c|c|c|c|c|c|}
\hline 4 & & 8 & & 12 & & 16 \\
\hline 4 & 6 & 8 & 10 & 12 & 14 & 16 \\
\hline
\end{tabular}

For the first series of numbers, show the class that

$$
\begin{aligned}
& M=\frac{A+B}{2}, \text { where } M \text { stands for the } \\
& \text { arithmetic mean and } A \\
& \text { and B for the first } \\
& \text { and last terms } \\
& \text { respectively. }
\end{aligned}
$$

For other series, point out that we may use the formula

$$
1=a+(n-1) d
$$

Develop the formula

$$
S=\frac{n}{2}(a+1)
$$

Practical applications of arithmetical progressions may bo show by falling bodies, interest and banking, the striking of clocks, potato races, salaries with regular increases, etc.

Progressions offer a rich opportunity to link mathematics with important social economic situations.

The following problem might be cited as an example of the above:

A man is offered a home at $\$ 9,500$ on the following terms:

$\$ 1,500$ cash, somi-annual payments of $\$ 500$, and, at the end of each half year, the interest at the rate of $5 \%$ a year on the debt during that half jear. 
(a) Prepare a table showing the interest and the total payment due at the end of each of the first three half years.

(b) What will his payments be at the end of the tenth year?

(c) What will be the total of his payments when he has completely paid for his home?

\section{GEOMETRIC PROGRESSIONS}

Show class how to derive the formula:

$$
1=a r^{n-1}
$$

Assign some exercises in which the student will need to resort to the use of logarithms.

Have class insert a geometric mean between 4 and 16. Then show them how the formula $x= \pm \sqrt{a b}$ may bo used to find geometric means. Prior to introducing the formula for the sum of $\mathbb{N}$ terms, the teacher may tell one of the following storles:

a. As I was going to St. Ives I met a man with seven wives, each wife had seven sacks, each sack held seven cats, each cat had seven kits. Kits, cats, sacks, man and wives, how many were going to St. Ives?

b. To reward a faithful minister a friend offered to gratify any wish made by the minister. Either to sober the king or to be malicious, the minister made this seemingly modest request: One grain of wheat for the first box on a checker board, two grains for the second box, four grains for a third box and so on, successively doubling the amounts until 64 boxes are exhausted. The king foolishly scoffed at what seemed to him 
a modest request, but, in reallty, tnere was not enough wheat in the whole world to meet the request.

Develop the following formulas:

$$
S=\frac{a-a r^{n}}{l-r} \text { and } S=\frac{a-r l}{1-r}
$$

INFINITE GEOMETRIC PROGRESSIONS

Derive the formula:

$$
\mathrm{S}=\frac{a}{1-r}
$$

Show by actual addition of decimals that the sum of $1,1 / 2,1 / 4,1 / 16$, etc. approaches 2 as the number of terms indefinitely increases:

$$
\begin{array}{r}
1.0000000 \\
.5000000 \\
.2500000 \\
.1250000 \\
.0625000 \\
.0312500 \\
.0156250 \\
.0078125 \\
1.9921875
\end{array}
$$

Have class change a number of fractions to decimals such as:

$$
\begin{array}{ll}
8 / 9=.8888 \ldots & 8 / 15=.5333 \ldots \\
5 / 11=.4545 \ldots & 1 / 7=.1427 \ldots
\end{array}
$$

Have class change repeating decimals back to fractions by use of the formula:

$$
S=\frac{2}{1-r}
$$

THE BINOMIAL THEOREM

Have pupils develop, by actual multiplication, the first five powers of $(a+b)$.

Arrange coefficients of the successive expansions of $(a+b)$ in the configuration known as "Pascal's Triangle." 


$\begin{array}{cc}1 & (a+b)^{0} \\ 11 & (a+b)^{1} \\ 121 & (a+b)^{2} \\ 1331 & (a+b)^{3} \\ 14641 & (a+b)^{4}\end{array}$

The student should note:

a. That the first and last numbers of each row is unity;

b. That each coefficient in this arrangement is equal to the sum of the two coefficients which are in the line above and nearest to the right and left of it;

c. That any coefficient of any term after the first term may also be determined by means of the coefficient of the term just preceding according to the following rule: Multiply the coefficient of the preceding term by the exponent of $A$ in that term and divide the product by the number of that term;

d. That the first term is $A^{n}$;

e. That from any term to the next following term, the exponent of $A$ decreases by 1 and the exponent of B increases by 1;

f. That the sum of the exponents of $A$ and $B$ in each term in the expansion is always $N$;

g. That the number of terms in the expansion of $(a+b)^{n}$ is n + 1;

h. That the coefficients of terms equidistant from the ends are the same;

1. That when $B$ is negative, the terms are alternately plus and minus. 
EXPANDING BINOMIALS

Write the expansion of $(a+b)^{n}$ where $\mathrm{N}$ has successive values as $6,7,8,9$, etc.

Substitute a number for either a or $\underline{b}$ and then expend.

Let $a$ and $b$ take on exponents and finalIy cöefficients.

Write the expansion of $(a+b)^{n}$, etc. Writing the $\mathrm{R}^{\text {th }}$ term:

a. Write the expansion of $(a-b)^{5}$

b. Write the first five terms of $(a-b)^{n}$.

c. Write the $\underline{x-t h}$ term of $(a-b)^{5}$.

Applications of the binomial theorem:

Develop a few such tables giving the compound amounts of $\$ 1$ at different rates of interest up to five years.

Show the difficulty of this calculation by arithmetic and the facility of it by the binomial theorem method.

Develop and apply the formula for compound interest,

$$
A=p(I+r)^{n}
$$

Applications of the binomial theorem to the normal distribution curves and probability is recommended as enrichment material.

Explain that the ordinates of the points on the normal distribution curve are the coefficients in the binomial expansions of $(a+b)^{n}$. 
Evaluation:

The pupil should:

Be able to find the law which is used to form

different serles.

Be able to solve accurately and rapidly problems based on arithmetical progressions.

Be able to solve accurately and rapidly problems

based on geometric progressions.

Be able to expand a binomial $(a+x)^{n}$ when $N$ is a positive integer.

Be able to find " $r$ ", any term in the expansion of a binomial.

Be able to change fractions to decimals.

Be able to change repeating decimals, back to fractions.

TOPIC XI--EQUATIONS OF HIGHER DEGREE

Content

4. Language

1. Rational

function

2. Integral

function

3. Degree

B. Remainder theorem

c. Synthotic division

D. The factor theorem

B. The cubic function
Teaching suggestions

Many second courses in algebra do not include this subject, but capable pupils should have an opportunity to learn to solve equations of higher degree. Reviow quadratic equations and equations that are quadratic in form.

Clarify the language and definitions to be used.

Practice on the use of the remainder theorem to find the remainder and prove it for a fow exercises by long division. The "short-cut" should be eagerly accepted by the students. Allow for further drill on the use of the theorem.

Show that synthetic division is a short form of division which can be used when the divisor is a binomial. A few examples worked by both long and synthetic division should arouse interest in the short form.

When pupils understand synthetic division and the remainder theorem, It should be easy for them to understand and use the factor theorem.

When studying the cubic function, the 
values of $Y$ may be found by direct substitution, but pupils should be encouraged to use synthotic division to make table of values. The generel shape of the graph of a cublc function should be clear to students. This may be a good time for a cumulative review of graphs of various functions, starting with the very simplest and building to this or even a quartic function as a climax.

\section{Evaluation:}

The pup1l should:

Understand the rocabulary involved; know and be able to use the remainder and factor theorems; be able to use synthetic division, computing mentally; recognize the shape and be able to graph the cubic and quartic functions. 


\section{TRIGONOMETRY}

\section{INTRODUCTION}

Trigonometry is a mathomatics course designed for such purposes and uses in engineering, physics, navigation, astronomy, etc. It is, therefore, not just anothor mathematics course as far as mathematics is concerned but it offers practical applications for many other courses and professions. Thus, it is intended to be an elective course for those pupils who have these purposes.

Since most colleges offer trigonometry, high schools who feel their mathematics curricula overcrowded or understaffed may afford to eliminate trigonometry from their programs. However, it is suggested that it be dropped only in schools where such a situation exists, because trigonometry is a good final course in high school. It requires extensive use of algebra and consequently provides a final review of algebra through trigonometry.

As in other mathematics courses, it is easy to teach here with much formalism. There is a possibility of many formulas and problems in the solving for angles. Yet, it seems much more important that the student grasp the fundamental meanings of trigonometry rather than a collection of formulas for solving "classroom problems." Extensive use should be made of field trips in which the principles of trigonometry are applied to everyday practical problems.

toples:

Trigonometry is divided into the following eight

I. The Language of Trigonometry

II. Solution of Right Triangles

III. Use of Tables and Interpolation--Solving

IV. Right Triangles by Logarithms

IV. Measurement of Angles

V. General Properties of Trigonometric Functions

VI. Graphs of Trigonometric Functions

VII. Identities and Equations

VIII. Solution of the General Triangle 
TOPIC I--THE LANGUAGE OF TRIGONOMETRY

Content

A. Historical sketch

B. The trigonometric functions

1. sine of an angle

2. $\operatorname{cosin} \theta$ of an angle

3. tangent of an angle

4. cotangent of an angle

5. secant of an angle

6. cosecant of an angle

C. Functions of special angles

1. functions of $0^{\circ}$

2. functions of $30^{\circ}$

3. functions of $45^{\circ}$

4. functions of 600

5. functions of $90^{\circ}$

D. Co-functional relations for acute angles

$$
f(A)=\begin{aligned}
\text { co-function } \\
(900-A)
\end{aligned}
$$

B. Inverse relations

$$
\text { 1. sine } A=\frac{1}{\operatorname{cosecant} A}
$$

Teaching suggestions

Make use of the library by having the students trace briefiy the development of trigonometry.

Point out clearly that a function of an angle is a ratio and can be expressed as a decimal fraction.

Have pupils use the complete definitions for the functions. After the complete meaning is under stood, abbreviations may be used to save time.

Students should be able to derive the value of the function of each angle of a 300-600-900 triangle and each angle of a 450-450-90 triangle.

It will become helpful to associate the $\sqrt{2}$ with a $45^{\circ}$ angle, and $\sqrt{3}$ with $30^{\circ}$ and $60^{\circ}$ angles. Then the student should memorize the value of the given functions but he should at all times be able to derive their values.

Study functions of the complement of the acute angle showing the co-functional relations:

$$
\sin A=\cos B=\cos \left(90^{\circ}-A\right) \text { etc. }
$$

Develop with the class the three Pythagorean relations. Have the students transform these equations into other forms.

Show how the function hexagon can be used to recall important relationships. 


$$
\begin{aligned}
\text { 2. } \operatorname{cosine} A & =\frac{1}{\sec a n t A} \\
\text { 3. tangent } A & =\frac{1}{\text { cotangent } A}
\end{aligned}
$$

F. Pythagorean relations

$$
\begin{aligned}
& \text { 1. } \sin ^{2} A+\cos ^{2} A=I \\
& \text { 2. } \sec ^{2} A-\tan ^{2} A=I \\
& \text { 3. } \csc ^{2} A-\cot 2 A=1
\end{aligned}
$$

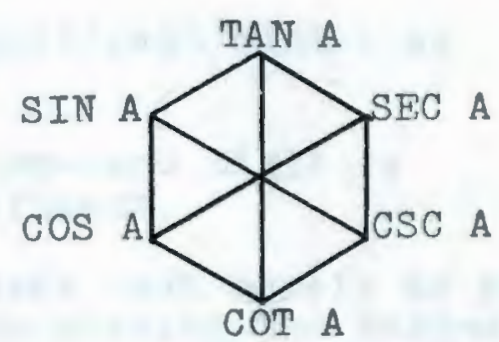

a. Show that the functions at the ond of any central diagonal are reciprocals of each other.

$$
\text { e.8. } \tan A \neq \frac{1}{\cot A}
$$

b. Any function is the product of the two functions between which it lies on the hexagon.

$$
\text { e.8. } \tan A=\sin A \sec A
$$

c. Any function may be expressed as a fraction in which the numerator is either of the two functions next to it on the hexagon, and the denominator 1s the one next beyond.

$$
\text { e.g. } \tan A=\frac{\sin A}{\cos A}
$$

d. The product of the functions at any three alternate vertices of the hexagon is 1 .

$$
\text { e.g. } \tan A \cos A \csc A=1
$$

TOPIC II--SOLUTION OF RIGHT TRIANGLE

Content

A. Exact and approximate numbers

B. polving the right triangle with the natural functions

\section{Teaching suggestions}

It is well to review here approximate numbers and extend the concepts involved.

Point out that all measurements are approximate, and that an exact number is obtained by the process of counting. 
Define significant digits as follows :

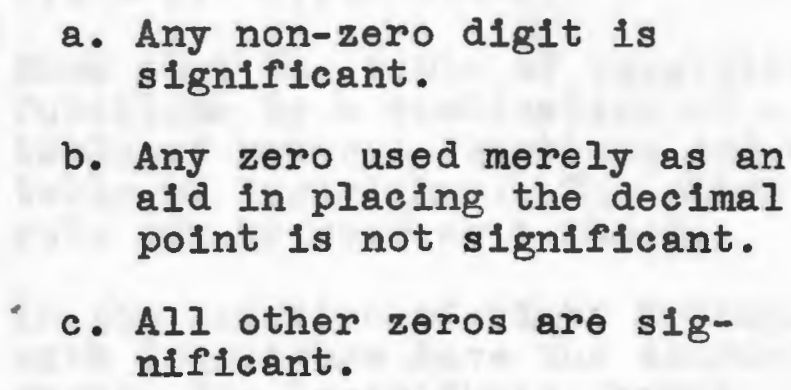

a. Any non-zero digit is significant.

b. Any zero used merely as an ald in placing the decimal point is not significant.

- c. All other zeros are significant.

Show what is meant, by precision and accuracy.

Have students round off answers to the degree of precision of the given data.

Emphasize the fact that accuracy of measurement cannot be improved by computation.

Use the natural functions to solve right triangles.

Let the given sides contain not more than three digits, and postpone interpolation by using the next smaller number of degrees and minutes.

TOPIC III--USE OF TABLES AND INTERPOLATION--SOLVING RIGHT TRIANGLES BY LOGARITHMS

Content

A. squares and square root

B. Natural trigonometric functions

C. Iogarithms

D. Iogarithms of trigonometric functions

\section{Teaching suggestions}

Review the use of logarithms here as they have been taught previously. Renew the basic concepts of logarithms stressing the idea that logarithms are exponents.

Drill pupils on interpolation with each of the tables. Emphasize the fact that interpolations are at best approximations. 
B. Solution of right triangles using logarithms
Show class that the idea of interpolation is based upon the principle of "proportion."

Show that the table of logarithmic functions is a combination of a table of natural functions and a table of logarithms. The slide rule may be used as a check.

In the solution of right triangles with logarithms have the students derive the logarithmic formula from the natural formula and then proceed to the computation.

Insist that the work be orderly and neatly arranged in columns.

Show the advantage of setting up the "frame work" for the logarithms before turning to the tables.

A wide varlety of practical problems arising in surreying, navigation, and field work should be used.

TOPIC IV--MEASUREMENT OF ANGLES

Content

A. Generating an angle

1. The positive angle

2. The negative angle

B. The measurement of angles

1. The degreeminute-second system

2. The radian system

\section{Teaching suggestions}

Rotate a line about a fixed point. If the direction of rotation is counter-clockwise, the angle is positive; if the rotation is clockwise, the angle is negative. The first position of the rotating line is called the initial side; the final position is called the terminal side of the angle. Illustrate by the use of the hands of the clock.

Review the tables for trigonometric functions; emphasize $300,45^{\circ}, 600$, and $90^{\circ}$ angles. Students should be able to sketch these special angles with fair precision. 
3. The mil
The student should be able to convert seconds to the decimal part of a minute. He should also be able to convert minutes and seconds to the decimal part of a degree. The decimal form is preferred today in such work as land surveying.

\section{Illustration:}

$$
40033^{\prime} 18^{\prime \prime}=40033.3^{\prime}=40.555^{\prime}
$$

Pupils should be able to express any angle in any of these three forms.

Define the radian.

The Armed Forces make much use of the mil for measuring angles. The students should learn and convert from mils to degrees and from degrees to a mil.

Define a mil as $1 / 6400$ of a revolution. Thus, $1600 \mathrm{mils}=900$

To give a pupil a general concept of the size of a radian, draw in a circle a central angle of $60^{\circ}$. This will have a chord equal to the radius. Since the arc subtended by one radian must be equal to the radius, imagine the chord to be pli$a b l e$ and fitted to the arc. The student should see that this would have the effect of slightly lessening the angle. The student should conclude, therefore, that one radian is slightly less than $60^{\circ}$.

TOPIC V--GENERAL PROPERTIES OF TRIGONOMETRIC FUNCTIONS

\section{Content}

A. Igonometric functions the general angle

1. Reduction of the function of any

\section{Teaching suggestions}

Show how the functions vary in sign as the angle rotates from 00 to 3600. Show that each function is negative in two quadrants and positive in two quadrants. 
general angle to the function of an acute angle

2. Change the sign of the function as the angle rotates from $0^{\circ}$ to $360^{\circ}$.

3. Functions of useful special angles

1. First quadrant angle of $30^{\circ}, 45^{\circ}$, and $60^{\circ}$.

2. Second quadrant angles of $120^{\circ}$ $135^{\circ}$, and $150^{\circ}$.

3. Third quadrant angles of $210^{\circ}$ $225^{\circ}$, and $240^{\circ}$.

4. Fourth quadrant angles of $300^{\circ}$ $315^{\circ}$, and $330^{\circ}$.

c. Iransformation formulas

1. Functions of $90^{\circ} \pm A$

2. Functions of $180^{\circ} \pm \mathrm{A}$

3. Functions of $270^{\circ} \pm A$

4. Functions of $360^{\circ} \pm A$

5. Functions of $n \cdot 90^{\circ} \pm 1$
The student should be able to reduce the function of any angle in terms of the function of an acute angle.

Show that quadrantal or boundary angles are $00,90^{\circ}, 180^{\circ}, 270^{\circ}$ and $360^{\circ}$. In the first quadrant the special angles are $30^{\circ}, 45^{\circ}$, and $60^{\circ}$.

Teach pupils to apply the tables to angles of any quadrant, or to use the general angle.

Find functions of $90^{\circ} \pm A, 180^{\circ} \pm A$,
$270^{\circ} \pm$. To show the derivation of the formula $\sin \left(90^{\circ}+A\right)=\cos A$, select the angle $\mathrm{A}$ about $20^{\circ}$ and locate the angle $\left(90^{\circ}+\mathrm{A}\right)$; on the terminal sides of these angles, locate points, $P$ and $Q$, equidistant from the origin 0 , for convenience. Draw the ordinates of these points RP and SQ; place signs on the coordinates; apply the definition of the sine of $(900+$ A) to the figure and, using the principle of equal parts of congruent triangles, show that,

$$
\sin \left(90^{\circ}+A\right)=\frac{S Q}{O Q}=\frac{O R}{O P}=\cos A
$$

The other functions are derived in like manner. By the use of other such figures the functions of the other angles are converted into functions of $A$.

In the various texts the teacher may find such surmarizing formulas as the following. These will be very helpful to students in remembering the relationships of the functions of the general angle.

$$
\begin{aligned}
& f\left(180^{\circ} \pm A\right) \text { or } f\left(360^{\circ} \pm A\right)=f(A) \\
& \text { with the proper sign. }
\end{aligned}
$$


In every case the sign of $f\left(n 90^{\circ} \pm A\right.$ ) is determined by the quadrant in which the terminal line lies. Give many exercises to fix these principles.

After the student understands the method of determining the sign of any function in any quadrant, the following device may prove helpful in quickly determining the sign of any function:

By placing the letters of the word CAST in ther four quadrants, beginning with the fourth and going counterclockwise, the letter In the appropriate quadrant represents the function, and its reciprocal function, which is positive in that quadrant.

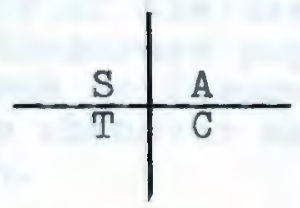

Observe that:

In Quadrant I, ALI functions are positive;

In quadrant II, SINE and its reciprocal, cosecant are positive; In quadrant III, TANGENT and cotangent are positive; In Quadrant IV, COSINE and secant are positive;

All other functions are negative.

Make a distinct figure for each ang le with the initial side always on the $x$-axis.

Mark a point, $P$, on the terminal side of the angle and select convenient coordinates for $P$.

When a $30^{\circ}-60^{\circ}-90^{\circ}$ triangle appears, show that convenient coordinates are $\sqrt{3}, 1$, and 2 , placed in agreement with the theorem "The greater side lies opposite the greater angle, and conversely." When a $45^{\circ}-45^{\circ}-900$ 
triangle appears, 1,1 , and $\sqrt{2}$ are convenient. It may be necessary to review the underlying geometry.

Make figures showing the second quadrant special angles. Be careful in placing the proper signs on the coordinates and explain that the radius is positive always because it is regarded as the principle square root of the sum of the squares of the other two sides of the triangle.

In the same way, show the special angles of the third and fourth quadrants.

Emphasize that the definitions apply to the functions of every angle.

Drill until the pupils are able to give rather quickly a desired funetion of any of the useful special angles. Encourage pupils to turn to a diagram to figure out a relationship whenever memory leares a question.

Summary of the method of finding the trigonometric functions of any angle $A$ :

a. Place $A$ in standard position. Take a point $P$ on the terminal side, and complete the triangle of reference DOP, marking each side with its proper algebraic sign.

b. From the given value of $A$ determine the value of the related angle DOP, by finding the positive difference betwoen the numerical value of $A$ and the nearest multiple of $180^{\circ}$. This value should always Ile between 00 and $90^{\circ}$.

c. Find the numerical value of any function of $A$ by using the table to determine the numerical value of the corresponding function of the related angle of $A$. 
d. The algebraic sign of the function of A will then be determined by the definition of the function and the signs of the sides of the triangle of reference. The result will be the signed value of the required functions of $A$.

TOPIC VI--GRAPHS OF TRIGONOMETRIC FUNCTIONS--INVERSE FUNCTIONS

Content

A. The graphs of the functions

1. with intervals of

2. with intervals of $10^{\circ}$

3. periodicity

4. maximum and minimum values

5. use of graphs of trigonometric functions in wave motion

B. Inverse functions

1. Terminology

a. Inverse sine $x$

b. ant1-sine $x$

c.arc $\operatorname{sine} x$

d. $\sin ^{-1} x$

2. Change inverse functions to direct functions

3. Multiple values of any function

\section{Teaching suggestions}

Graphing of the trigonometric function is applicable at any time during the course.

This topic gives good opportunity to study the ways in which the change in an angle's size produces corresponding changes in its trigonometric functions.

It is well to use the same scale for ordinates and abscissas. The curves may be plotted using points at intervals of $30^{\circ}$. This serves as a drill on the functions of the special angles.

A second method makes use of points at intervals of $10^{\circ}$, with the aid of a table of natural functions. This locates more points and thus leads to more accurate curves.

A third method is purely geometric and makes use of a unit circle and the line representations of the functions. To do this quickly and skillfully, a drawing board and a T-square are helpful.

Use the graphs of the functions to teach the changes of value of the functions, periodicity, and their maximum and minimum values in each of the quadrants.

Use the graph to point out related 
c. Polar coordinates and equivalent functions. The sine and cosine curves indicate clearly the usefulness of these functions in the mathematics of wave motion.

The Inverse functions may not be advisable for all pupils. The students who will continue the study of mathematics or the physical sciences in college will need a complete understanding of the symbolism at least.

Use familiar 1llustrations (radian or degrees) to impress firmly the inverse notation with reference to the common direct notation:

For example, the direct function $\sin \frac{p}{6}=\frac{1}{2}$ is writton as $\sin ^{-1} \frac{1}{2}=\frac{p t}{6}$

in the inverse function.

Point out clearly that while the direct trigonometrio functions are single-valued, the inverse functions are multi-valued. The smallest possible value is called the principal value.

Show class how to find as many multiple values of any function as may be desired from the principal value of that function. Such formulas are called general values. Thus, if $\tan k=m$, then arc tan $m=k+$ $\mathrm{n}$ p1, when $\mathrm{n}$ is an integer, pos1tive, negative, or zero.

Polar coordinates may be studied as enrichment material.

The origin of the peculiar inverse symbolism may create interest and at the same time clarify the important distinction between trigonometric and algebraic functions.

Although exponential notation of algebraic equations and the inverse notation of trigonometric equations 
seem similar, the pupil must recognize that they are not mathematically equivalent. For example,

Algebra

$$
\begin{aligned}
& \text { If } s: x=k \text { then } x=s^{-I_{k}} \\
& \text { Again, } s \cdot s^{-1} x=x \\
& \text { But while } s^{-1}=\frac{1}{s} \\
& \text { And while } s=\frac{I}{s}-1 \\
& \text { Trigonometry } \\
& \text { If sin } x=k \text { then } x=\sin ^{-1} k \text {; } \\
& \text { Also, } \sin \left(\sin ^{-1} x\right)=x \text {. } \\
& \text { Note that } \sin ^{-1} x \pm \frac{1}{\sin ^{\prime}} \\
& \text { Note that } \sin ^{x} \pm \frac{1}{\sin ^{-1} x}
\end{aligned}
$$

TOPIC VII--IDENTITIES AND EQUATIONS

Content

A. Fundamental identities

1. $\sin ^{2} \mathrm{~A}+\cos ^{2} \mathrm{~A}=1$

2. $\sec ^{2} A-\tan ^{2} A=1$

3. $\csc ^{2} A-\cot ^{2} A=1$

4. $\tan A=\frac{\sin A}{\cos A}$

5. $\cot A=\frac{\cos A}{\sin A}$

6. $\tan A=\frac{1}{\cot A}$
Teaching suggestions

Students should have a solid understanding of the fundamental trigonometric relationships before identities are introduced.

Establish difference between a trigonometric equation" and a "trigonometric identity."

When selecting identities, keop in mind that there are three chief values of their derivation or proof:

a. To attain skill in the algobraic manipulation of the trigonometric formulas; 


$$
\begin{aligned}
& \text { 7. } \sec A=\frac{1}{\cos A} \\
& \text { 8. } \csc A=\frac{1}{\sin A}
\end{aligned}
$$

B. Miscellaneous 1dentities

c. Functions of special angle relationships

1. sum or difference
of two angles

2. twice an angle

3. half an angle

D. Irigonometric equations b. to be able to reduce a trigonometric expression from a given form to an identical one whlch is more convenient;

c. to derelop the ability to handle the identities of advanced mathematics.

When both sides have been reduced to the same expression, the identity is proved. There are two accepted ways for accomplishing this:

a. Reduce e1ther.'side to the 1dentical form of the other.

b. Reduce each side independently to a third identical term.

When solving trigonometric equations it is best to transform every function in terms of one trigonometric function. After the algebraic solution is obtained, a cheok should be made to find valid angles and discard impossible results.

When study of identities and trigonometric equations has been completed, the student should be able to 1 dentify an identity and a trigonometric equation from a group containing both.

The geometric method is preferred by most pupils:

Draw a right triangle with one of its sides unity, according to the function in terms of which the other functions are to be derived. When other functions are expressed in terms of the sine or of the cosine, the hypotenuse, or distance, is unity; in terms of the tangent or of the secant, the adjacent side or the abscissa is unity; in terms of the cotangent or of the cosecant, the ordinate or the opposite is unity. The other sides of the right triangle, or the other co- 
ordinates are easily placed in terms of the desired function. By applying the fundamental def1nitions, the desired functions come diretly from the figure.

The algebraic method consists of a series of transformations by means of $s$ ome of the standard identities. Pupils who are skillful in such transformations in algebra will experience little difficulty in the trigonometric set-up.

TOPIC VIII--SOLUTION OF THE GENERAL TRIANGLE

Content

A. The law of sines

B. The law of cosines

c. Formulas for functions of sum and difference of two angles

1. $\sin (x \pm y)$

2. $\cos (x \pm y)$

3. $\tan (x \pm y)$

4. $\cot (x \pm y)$

D. The double angle formulas

B. The half angle formulas

F. Formulas for the sum and difference of the functions of two angles
1. $\sin x \pm \sin y$
2. $\cos x \pm \cos y$

Teaching suggestions

All formulas in this unit are used to solve the oblique triangle. The teacher should take considerable time in the derivation of the formulas and should provide many practical applications.

The law of sines is used to solve a triangle with: (a) two given angles and any side and (b) two sides and the angle opposite one of them. The teacher should take care to avold giving values which lead to the ambiguous case in (b).

An additional use for the law of sines comes later. This occurs when two sides and the included angle are given and the third side is to be found by logarithmic solution. The two angles not given are previously computed from the law of tangents.

The law of cosines is easily derived by drawing an altitude to one of the sides. The Pythagorean theorem is then applied. Simple algebraic and trigonometric transformations and reductions give the law of cosines, 
3. $\tan x \pm \tan y$

4. $\cot x \pm \cot y$

5. Identities involving the sum and differences of the functions of two ang les

\section{An identity useful in checking tri- angles}

G. The law of tangents

H. The functions of the half angles of a triangle

1. $\sin \frac{1}{2} A=\frac{(s-b)(s-c)}{b c}$

2. $\cos \frac{1}{2} A=\frac{(s)(s-a)}{b c}$

3. $\tan \frac{1}{2} A=\frac{r}{s-a}$

I. The computation of the angles of a triangle when the three sides are given

J. The area formulas

$$
a^{2}=b^{2}+c^{2}-2 b c \cos A
$$

As can be seen, the law of cosines is not adapted to logarithms. AIl the problems to be solved by 1t, therefore, should be confined to triangles whose given sides are expressed by one or two digits; otherwise, laborlous multiplications will be necessary.

The law of cosines is used to solve a triangle with: (a) two given sides and the included angle to find the third side and (b) three given sides to find the angles! of the triangle.

Trlangles whose sides are one- or two-digit numbers solved by the law of cosines give much satisfaction to students and are thoroughly worthwhile, even though the logarithmic method using the functions of half angles is taught later. This case is easily checked by the relation,

$$
A+B+C=180^{\circ}
$$

For convenience, it is suggested that $x+y$ lie in the first quadrant when deriving the formulas for the function of the sum and difference of two angles. The generalized proof should not necessarily be required of all pupils.

The chief objective in the study of the formulas for the sum and difference of the functions of two angles is to attain skill in the application of standard formulas to transformations and reductions. Thus, to prove

$$
\frac{\tan x+\tan y}{\cot x+\cot y}=\tan x \tan y
$$

Simply convert cotangents into tangents and the left member is easily transformed into the right member. Exercises which merely transform one complication into another are generally valueless. 
The formula, a sin $\frac{1}{2}(B-C)=(b-c)$ cos $\frac{7}{\mathrm{i} A}$, contains all six parts of a triangle. It is easily applied logarithmically and makes an excellent check to any set of computed parts.

The analytic derivation of the law of tangents is generally preferred to the geometric derivations.

When two sides and the included angle of a triangle are given, the law of tangents is usually employed, logarithmically, to find the required angles. It is advisable to avoid negatives by placing the larger parts before the smaller parts. After the two angles are thus computed, the law of sines is used to find the third side.

To find the formula, $\sin \frac{1}{2} A$, the transformed law of cosines,

$$
\cos A=\frac{b^{2} \neq c^{2}-a^{2}}{2 b c}
$$

is substituted into the formula,

$$
2 \sin ^{2} \frac{1}{2} \mathrm{~A}=1-\cos \mathrm{A}
$$

Algebraic transformation followed by the substitution, $a+b+c=$ $2 s$, readily produces the formula desired. For the formula for cos i $A$, start with the formula $2 \cos ^{2}$ $\frac{1}{2} A=1+\cos A$. The derivation proceeds similar to that above.

To derive the formula for $\tan \frac{1}{2} A$, divide $\sin \frac{1}{2} A$ by $\cos \frac{1}{2} A$ and $\tan$ $\frac{2}{2} A$ is obtained. The formula is then made homogeneous and takes the form,

$$
\tan \frac{1}{2} A=\frac{r}{s-a}
$$

when

$$
r=\sqrt{\frac{(s-a)(s-b)(s-c)}{s}}
$$


The students will perhaps be interested in the geometric meaning of $(s-a),(s-b),(s-c), s$, and $r$ and their derivation from the triangle with its inscribed circle and the related circle.

The law of cosines gives an easy solution by natural functions when the sides are all one- or two-digit numbers. The convenient logarithmic solution comes from the half angle formulas. The formulas for the tangents of the half angles are easler to remember and are generally preferred.

All of these formulas are derived by using the well known principle that the area of a triangle is equal to half the product of 1 ts base and its altitude. The altitude is found easily from the formula,

$$
h=b \sin A \text { or } a \sin B
$$

The base, if not given, is quickly computed. Hence, it is not necessary to derive special formula for the area. Hero's formula is well known. 


\section{SOLID GEOMETRY}

\section{INTRODUCTION}

This course in solid geometry introduces the pupil to spatial relations and the geometry of three dimensions by means of experiment and perspective drawing. Models should be used to introduce and help the pupll in analyzing the theorems found in these toples:

$\begin{array}{ll}\text { I. } & \text { Introduction } \\ \text { II. } & \text { Lines and Planes in Space } \\ \text { III. } & \text { Dihedral and Polyhedral Angles } \\ \text { IV. } & \text { Locus } \\ \text { V. } & \text { Polyhedrons } \\ \text { VI. Cylinders and Cones } \\ \text { VII. The Sphere } \\ \text { VIII. Enrichment Topics }\end{array}$

Thphasis is placed on spatial relations and their importance in science, industry, and art. The derivation and application of the mensuration formulas provide an opportunity to develop real mastery in the arithmetic and algebraic skills used in the solution of practical problems. Supplementary topics are suggested to stimulate the superior pupil to do research in his field of interest.

\section{TOPIC I--INTRODUCTION}

\section{Content}

\section{Teaching suggestions}

A. Relationship of plane and solid geometry

B. Basic terms: point, line, plane, solid

C. Constructions and perspective
Bring out fact that plane geometry consists of points and Iines which lie in the same plane, while in solid geometry the points and lines may lie in different planes.

Also, show that plane geometry is two-dimensional and deals with the 
D. Locus of points, Iines, planes

E. Intersections of: Iines with lines, Iines with planes, planes with planes

F. Review of nature of geometric proof

1. Nature of axioms, postulates, theorems

G. Origin and history

H. Fields of work using solid goometry measurement of flat surfaces, while solid geometry deals in the measurement of three-dimensional objects. Plane geometry is the surface on the board; solid geometry is the room itself.

Use a weight on the end of a string to show that a point moving in a fixed direction generates a line; a line moving in a fixed direction generates a plane. Then have the pupils move the various figures of plane geometry in a fixed direction to show that a moving plane generates the solids of space.

Have pupils visualize in space the moving center of some circular object such as an embroidery hoop to demonstrate that a point has position only.

Have some modeling clay in a shallow box and with the use of wire or tooth plcks demonstrate the four ways planes are determined.

Cut out a cardboard triangle, locate the center of gravity by drawing the throe medians. Balance this triangle on a pencil point or a straight wire. Then have the pupils answer these questions :
a. Is the pencil perpendicular to the three medians?
b. Will it be perpendicular to all the lines passing through the point?
c. When is a line perpendicular to a plane?

Locate pictures on post cards or in magazines which illustrate differences in perspective. Paste them on $7^{\prime \prime} \times 10^{\prime \prime}$ cardboards. Project them on a screen with an opaque projector. Ask the following questions: 
a. Are parallel lines actually parallel in the pictures?

b. How are right angles and circles portrayed?

c. What appears to happen to parallel lines as they recede from the observer?

d. How is depth in pictures achleved?

e. How are vertical lines represented?

Bring out the fact that pictures of buildings are made so that the side of the bullding appears about onehalf the length of front.

Discuss the perspective of various pictures shown on a screen.

Teach pupils to draw cubes and other geometric figures in a horizontal plane. Be sure that they observe these rules: Use vertical lines to represent vertical lines of the figure. Use slanting lines to indicate lines that recede from the observer. Use dotted lines to indicate Iines which cannot be seen. Use shorter lines to indicate receding edges or lines of the figure. Use oblique or acute angles for right angles when drawing horlzontal planes. Use heavier ines to indicate lines near the observer. Make horlzontal line at right angles to the line of vision appear parallel.

Have pupils make drawings of the text-book theorems and originals on the relationship of lines and planes on $7^{n} \times 10^{n}$ cardboard.

Again, select the best of these drawings to project on the screen with an opaque projector during the study of Iines and planes. State the theorem on some of these cards 
and have the pupil give the hypothesis and conclusion to the lettered figure on the screen and discuss how to prove the theorems. On others give the hypothesis and have the pupils see what conclusion can be drawn.

For enrichment the pupils could study and read blueprints to develop the ability to visualize three-dimensional objects when represented in a plane drawing.

A project might be, to have some of the pupils report on the origin and history of solid geometry along with its early contributions.

Usually pupils who take solid geometry in high school are a group with special vocational interests. Thus, it will help to motivate the study of the subject to show the use of solid geometry in these vocations.

TOPIC II--LINES AND PLANES IN SPACE

Content

\section{A. Perpendicular lines and planes}

1. Conditions under which lines are perpendicular to planes

2. Conditions under which planes are perpendicular to ines

3. Relationship between oblique and perpendicular lines to a plane

\section{Teaching suggestions}

It is very important that pupils not learn the theorems of solid geometry es independent 1 tems. Rather the teacher should help them seo relationships among several theorems. These relationships help to add meaning and to ald learning. The outline of content is intended to suggest some headings around which theorems may be grouped to emphasize relationships.

After pupils develop the proof for such a theorem as: "If a ine is perpendicular to each of two intersecting lines at their point of intersection, it is perpendicular to the plane of two lines." They 
B. Parallel lines and planes

1. Lines parallel to planes

2. Perpendiculars forming parallels

may discuss such applications as how buildings and posts or poles are made upright.

Establish the logical dependencies of the proof of this theorem and other theorems on the theorems of plane geometry.

Have puplls write the formal proof for the plane geometry theorem, "If two points are each equidistant from the ends of a segment, they determine the perpendicular-bisector of the segment.".

Call attention to the fact that the same type of logical reasoning is used in proving the solid geometry theorems.

Stress the fact that axioms, postulates, and theorems in plane geometry may be used as the basis of proof in solid geometry.

As pupils progress in the study of theorems on lines and planes, have them make a table showing the analogous theorems of plane geometry thus :

PLANE GEOMETRY

Two straight

lines can intersect in only one point.

There can be one and only one perpendicular to a line at a point on the line.
SOLID GEOMETRY

Two planes can intersect in only one line.

Through a given point in a plane there can be drawn one line, and only one, perpendicular to the plane.

After pupils have developed the proof for the theorem, "If two straight lines are cut by three parallel planes, their corresponding segments are proportional," have them solve numerical problems, such 
as $\frac{x}{6}=\frac{2}{8}$ to maintain skill in

algebra.

Relate the use earpenters, surveyors, and engineers make of the theorems and corollaries of solid geometry.

Have simple examples of the application of these theorems.

Review theorems and exercises using the opaque projector with the drawings the pupils made during the study of perspective.

Stress the importance of clear definitions and good descriptions. Revlew the elements of a good definition and develop definitions of key words inductively.

Have pupils define oblique, parallel, perpendicular, plumb line, carpenter's level, carpenter's square, analogous, duality, distance, skew lines, coplanar, dimension, collinear, coincide, concurrent, determine, surface, and plane.

Have pupils prepare a list of groups of theorems proving two lines parallel, two planes parallel, a line perpendicular to a plane, a line parallel to a plane, and two line segments equal.

Allow pupils to work in groups to review the proofs and discuss and state examples of practical applications of these principles in their environment.

TOPIC III--DIHEDRAL AND POLYHEDRAL ANGLES

Content

A. Dihodral angles

1. Nature
Teaching suggestions

Models of varlous types may be used with great profit in teaching solid geometry. A pupil is well along 
2. Plane angles of dihedral angles

3. Classes

a. Complimentary, supplementary, right, acute, obtuse, vertical

4. Congruency

5. Related theorems

B. Polyhedral angles

1. Nature

2. Classes

a. Trihedral, tetrahedral, etc., 1sosceles, convex

3. Relationships among face angles of polyhedral angles

4. Related theorems toward the proof of a theorem when he has clearly seen the relationships involved through handling or observing a model. Several suggestions will be given in this guide for such models.

Point out examples of dihedral angles in the classroom.

Illustrate and classify the different kinds of angles formed by folding and unfolding a plece of ruled paper. Fold so that the crease of the fold is perpendicular to the lines of the paper.

Use plastic straws strung together with elastic thread or cardboard to develop an informal proof for the theorems, "The sum of the face angles of a polyhedral angle is less than 360 degrees, "and "The sum of any two face angles of a trihedral angle is greater than the third."

Explain the nomenclature and terms, such as similar and congruent polyhedral angles, faces, vertical polyhedral angles, etc.

Point out that the edges and faces of polyhedral angles are unlimited in extent.

\section{Teaching suggestions}

This might be regarded as an optional topic. It is recommended, however, because it is usually interesting to pupils and is a basic aspect of some of the mathematics which a pupil will encounter if he continues his study of mathematics beyond high school.

The study should be initiated with simple examples of loci in planes and develop visualization to threedimensional figures, for example, 
"The perpendicular bisector of a segment is the locus of points equidistant from the end points." Then, by analogy develop the corresponding solld geometry concept.

Have the pupils make a table similar to the following showing the corresponding loci of plane and solld geomotry:

CONDITION PLANE SOLID

At a given A circle A sphere
distance
from a
fixed
point

\begin{tabular}{|c|c|c|}
\hline $\begin{array}{l}\text { Equidis- } \\
\text { tant from } \\
\text { two points }\end{array}$ & $\begin{array}{l}\text { A line, } \\
\text { perpen- } \\
\text { dicular } \\
\text { bisector } \\
\text { of the } \\
\text { line seg- } \\
\text { ment join- } \\
\text { ing the } \\
\text { two points }\end{array}$ & $\begin{array}{l}\text { A plane per- } \\
\text { pendlcular } \\
\text { to the line } \\
\text { segment } \\
\text { joining the } \\
\text { two points } \\
\text { at its mid- } \\
\text { point }\end{array}$ \\
\hline $\begin{array}{l}\text { Equidis- } \\
\text { tant from } \\
\text { two paral- } \\
\text { lel lines }\end{array}$ & $\begin{array}{l}\text { A line bi- } \\
\text { secting the } \\
\text { plane of } \\
\text { the two } \\
\text { lines and } \\
\text { parallel to } \\
\text { them. }\end{array}$ & $\begin{array}{l}\text { A plane per- } \\
\text { pendicular } \\
\text { to and bi- } \\
\text { secting the } \\
\text { plane of } \\
\text { the two } \\
\text { lines. }\end{array}$ \\
\hline $\begin{array}{l}\text { Equidis- } \\
\text { tant from } \\
\text { two inter- } \\
\text { secting } \\
\text { lines }\end{array}$ & $\begin{array}{l}\text { Two lines } \\
\text { bisecting } \\
\text { the verti- } \\
\text { cal angles } \\
\text { formed by } \\
\text { the Iines }\end{array}$ & $\begin{array}{l}\text { Two planes } \\
\text { blsecting } \\
\text { the angles } \\
\text { formed by } \\
\text { the lines } \\
\text { and perpen- } \\
\text { dicular to } \\
\text { their plane }\end{array}$ \\
\hline
\end{tabular}

Continue the table to show that the point-line relationship in the plane becomes the line-plane relationship in space. 
PLANE GEOMETRY

\section{CONDITION}

Locus of points at given distance from a line.
LOCUS

Two lines equidistant from the given line and parallel to 1 t.

\section{SOLID GEOMETRY}

\section{CONDITION}

Locus of points at given distance from a given plane.

\section{LOCUS}

- Two planes equidistant from the given plane and parallel to 1 t.

Treat this topic in an informal way and plan to develop visualization by the use of objects and by discussion of locus problems and exercises.

Stress loc1 in everyday situations through the study of aerial maps, photographs, etc. Have the pupils bring into the classroom such projections.

Develop the meaning of projection by means of wire, string, etc.

Explain the projections of pictures on a screen.

TOPIC V--POLYHEDRONS

\section{Content}

4. Parts of polyhedrons

1. Faces

2. Edges

3. Vertices

4. Diagonals

\section{Teaching suggestions}

Copy and enlarge the patterns of the five regular polyhedrons to be found in many textbooks and make models from them.

Demonstrate how the solids are generated by a moving line and a geometric figure. 
B. Names by number of faces

C. Regular polyhedrons

D. Prisms

E. Parallelepipeds

F. Rectangular solids

G. Surface area of polyhedrons

H. Volume of polyhedrons

I. Pyramids

J. Truncated solids

K. Similar polyhedrons
Make flattened out versions of the prisms, the cube, and the rectangular solids. Identify the plane geometry figures and review the area formula for each figure.

Use these models to illustrate the meaning of the definitions and to show why there can be only five regular polyhedrons.

Have pupils solve problems using these formulas.

Review the common mensuration formulas on length, area, and volume.

Help pupils develop formulas for the lateral area of the flattened out solids.

Have pupils write out a formal proof for these theorems and solve the examples in the text.

Make models from the flattened out patterns and develop volume formulas on each.

Have pupils solve many problems involving the application of these formulas. These problems should be selected so as to give practice in solving the fractional and literal equations and in simplifying radicals. Pupils may leave their answers in the simplest radical form.

Solve problems applying principles of construction, to ongineering, architecture, science, etc.

Teach pupils to analyze complicated figures, take them apart and draw important parts, such as the base, a lateral face, a right section parallel to the base, etc., again in their correct proportions as though they were in the plane of the paper. 
Develop the basic formulas by Cavalieri's theorem and the Prismatoid formula.

TOPIC VI--CYLINDERS AND CONES

Content

A. Cylinders

1. Classes

2. Area

3. Prisms inscribed in and circumscribod about cylinders

4. Volume

5. Similar cylinders

B. Cones

1. Parts

2. Classes

3. Properties of sections

4. Area

5. Volume

C. Conic sections (optional)

\section{Teaching suggestions}

Relate the formulas for the lateral area and volume of the cylinder to the respective formulas of the prism by means of flattened out figures and the three-dimensional models.

Show how the lateral area and volume of a cone may be developed from those of the pyramid.

Carefully present definitions of new terms such as axis, conical surface, cylindrical surface, directrix, generatrix, slant helght, and right cylinder.

Have pupils solve numerical problems to show that the lateral area of a cone is the limit which the lateral areas of regular inscribed and circumscrlbed pyramids approach when the number of their lateral faces is indefinitely increased and the volume of the cone is the limit of the volume of these pyramids.

Make a pattern of a right circular cone which has a slant height of 6 in. and a base radius of 2 in.

Tabulate the results and stress the fact that in similar figures areas are to each other as the squares of corresponding lines; volumes are to each other as the cube of corresponding lines.

Use models to identify and explain the conic sections. 
Have pupils report on the uses of the conic sections.

Review the equations of the conic sections. Thus:

EQUATIONS

$x^{2}+y^{2}=r^{2}$

$\frac{x^{2}}{a^{2}}+\frac{y^{2}}{b^{2}}=1$

$y=a x^{2}+b x+c, \quad$ Parabola

$\frac{x^{2}}{a^{2}}-\frac{y^{2}}{b^{2}}=1$
CONIC SECTION

Circle

Ellipse

Hyperbola
TOPIC VII--THE SPHERE

\section{Content}

A. Parts of a sphere

B. Sections

C. Circles of a sphere

D. Polar distance

E. Tangents of a sphere

F. Spheres inscribed in and circumscribed about polyhedrons

G. Related theorems and applications

H. Area

I. Volume

\section{Teaching suggestions}

Associate the definitions of the properties of a sphere with those of the circle.

Ask why aviators fly the ares of great circles when flying from New York to Paris. Use a globe to explain the answer.

Place on exhibit in the classroom a globe, a map showing the air routes around the world, a map showing the time belts on the earth's surface, and other 1llustrations of the application of the geometry of the sphere to the many flelds of learning.

Develop the definitions of great circles, lune, zone, etc., and call attention to their use as latitude, meridians, and other measuring devices used in various phases of life such as: sclence, engineoring, architecture, navigation, and aeronautics. 
Have pupils read the proofs and understand the logical sequence of the theorems, but emphasize the numerical and algebraic application of them.

Use the globe to explain the polar distance. Have pupils work in groups and prove the theorems.

Stress the fact that the sides and angles of a spherical polygon are equal respectively in degrees to the face angles and dihedral angle formed at the center of the sphere.

Emphasize difference between congruent and symmetrical triangles.

Assist students in developing the formulas for the area of a sphere, the area of a lune, and a zone. Have them solve many problems using same.

Have pupils construct from cardboard a cone and a cylinder with the height and diameter of each equal to the diameter of a ball. Show that the cylinder requires three fillings of the cone with water to fill 1t. Empty the water, place the ball in the cylinder and show that it now requires only one filling of the cone to fill it. Have the pupils state the conclusions which they draw from this experiment.

In such an experiment, always emphasize that a conclusion has not been logically reached. However, this type of experimentation is excellent as a stimulation of pupil interest and as a means of clarifying understandings of the relationships discovered. Pupils must, however, be taught to see the need for a deductive proof before the conclusion can be held as a universal one. 
TOPIC VIII--ENRICHMENT TOPICS

\section{Content}

A. Photogrammetry

1. Definition

2. Application

B. Slide rule

C. Sundial

\section{Teaching suggestions}

Have pupils report on topographic mapping with aerial photographs, the geometry of a vertical photograph, the use of tilted oblique photographs in making world aeronautical charts, how horizontal positions of objects are determined graphically from aerial photographs when the position of a few objects is known, how the sensation of depth is achieved, the use of photogrammetry in medicine, in traffic accident investigations, and in the reconstruction of historic buildings.

Have class construct a simple slide rule and apply the rules for multiplying and dividing with logarithms.

Have pupils construct a scale to find square roots and square numbers by applying the rules used in the work with logarithms.

Study the mathematics of the sundial and construct one on the school ground. 
CHAPTER IV

\section{DISCUSSION}

It is quite evident that the outline form used in this thesis is incomplete. The omission or absence of any suggestion does not, however, constitute a deficiency. Proper references and suggestions can be added after they, too, have been in actual classroom use. Because of the many diverse conditions encountered in teaching, each teacher might experiment, and, over a period of several years, develop her own file of aids and references, suitable to her own manner of teaching and appropriate to the particular method she uses or to the unit which she may have chosen.

However, the present manual is a foundation. Teachers may use any part of it as a basis for building their own finished lessons or units. It would grow through the teachers' own initiative. It could conceivably take much time to build a good manual based on the present phllosophy and objectives. If one is to be consistent, changes in both philosophy as well as content should be anticipated. It is not beyond reason and expectation, that, through constant revision and in the light of new experiences, this manual will eventually be outmoded and replaced.

To say that a manual, such as this one, is complote 
and final would be inconsistent with the policy of encouraging teacher experimentation. The unfinished manual is needed. As a result, a project to motivate the cooperative effort of teachers as a professional group, stimulating professional inquiry and employing professional interests, attitudes, and skills, is introduced. The unfinished manual should be considered then in a natural jet desirable state.

A subject of paramount importance in the North Kingstown schools should be the possibility, in the very near future, of forming a curriculum study committee embracing all twelve grades. Certainly then, if not sooner, all teachers of mathematics in the system would be working to add their individual aids and suggestions to the present manual which might, in turn, serve as a nucleus for such new ideas. Thus, there might be a question in the minds of many teachers concerning the accuracy and usefulness of any suggestions added at this time. It is herewith suggested that these be added by individual teachers according to their own experience and only after their value has been proven. However, in so doing, it is posible jet dangerous to its usefulness since the manual may become too awkward and cumbersome. Thus, it has been the thought in the mind of the writer to add only those references for which previous experience has been made for their certainty.

Another deficiency in the manual, if it can be called such, is the fact that tradition and the opinions of textbooks have determined its content material and the sequence in which 
the material is presented. Research should determine any deviation for anything as important as this in the fleld of education. This has not been done, however, since education is sometimes referred to as an inexact science. It is still largely a matter of hope and faith.

It goes without doubt that this manual will be revised and added to during its first year of operation. With this

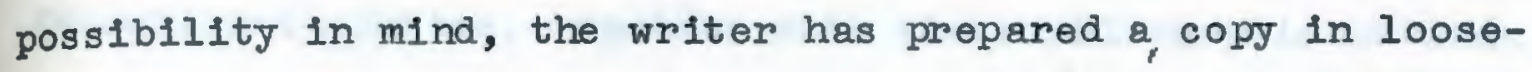
leaf form. Certainly revisions and additions to such a manual would be greatly facilitated by such a plan. If each teacher, experienced as well as inexperienced, In the mathematics department of North Kingstown's Junior and Senior High Schools were presented such a booklet, It would be sincerely hoped that the teaching standards in said schools would be substantially raised.

While there was no curriculum study group in operation on this work, there are certain suggestions for the same which can be seen by the writer as being most profitable. Failure to recognize these could result unless certain suggestions for informal meetings of such a group are adhered to. Teachers tend to avoid attending formal meetings after school hours for curriculum study. Even if this seems to be a lack of professional attitude, it cannot be considered entirely the fault of the teachers. Truly, the majority of teachers are exhausted at the end of a school day. Special attention should be given to 
group dynamics in planning any activity of this type.l Many teachers have been discouraged from participating in any such work for two main reasons: first, the meetings have been too long and have been a real imposition upon teachers; and second, many teachers have been turned away from curriculum work by reading many of the heavy and dull volumes written by theorists who themselves have been away from the classroom much too long. Educational studies, together with their philosophic methods of research are often explained in such a vague manner that teachers consider the study of such beyond their capabilities-something to be left to the experts.

Keep group meetings small in number, for then teachers feel more relaxed and free to talk casually. Then, there is a feeling that they are free to say exactly what they think. With such points in mind, meetings with teachers should be very informal and brief. Therefore, for such meetings to be productive, the leader must plan carefully the points he wishes to bring up for discussion. Also, it is important that he be a good conversationalist with the ability to direct the discussion In a general manner to the topics he wishes. Then, and only then, are teachers more apt to say what they really think rather than what they think is expected of them. After much time and study had been spent on the preIiminary outline of the philosophy, objectives, and subject

IE. A. Krug, Curriculum Planning. (New York: Harper and Brothers, 1950 ) p.224. 
matter material, the writer concluded that the most essential part of any such manual is its statement of philosophy and its objectives. However, working out and evaluating each phase of the work brought out two things: first, it made clear what was expected of teachers in teaching mathematics, and second, the need for definite aids and suggestions of methods to be used. Such suggestions could be considered as starting points, as something to be evaluated and as a basis for experimentation. Teachers, especially new ones, often feel insecure when they do not know what is expected of them. They often do not have enough confidence in their own conclusions about teaching methods or content material. When teaching, they look for those things which are clearest to them and which are most easily understood by anyone who might have criticized them.

New or inexperienced teachers are sometimes timid about being left alone to teach in any manner they deem proper to bring about the desired objectives. Realizing the importance of their task they like to have assurance that what they do has the approval of fellow teachers and supervisors. Getting something down in black and white, something they can turn to for help, seems to be a symbol of security to them as well as creating the atmosphere for some experimentation of their own. Thus, it can be plainly seen that the writer feels that there is a definite need for such a manual in the secondary schools of North Kingstown. However, the intent used in the building and composing of this work in mathematics has not been to limit 1ts 1deas and suggestions to this one school system, 
but rather, to allow it be an incentive to other mathematics teachers who might find now ideas and aids within its pages. 


\section{CHAPTER V}

\section{RECOMMENDATIONS FOR THE PREPARATION OF A MANUAL}

1. Philosophy, objectives, and suggestions are necessary in a mathematics manual. Only after a philosophy for the task has been formed can specific objectives for any part of the curriculum be stated. The most skilled and experienced teachers usually need only an understanding of these objectives and the accompanying philosophy in order to carry out their teaching assignment successfully. Inexperienced teachers or those unfamiliar with the objectives usually feel strongly a need for suggestions which will help them achieve these very objectives. A sense of insecurity or anxiety is often common among younger or newer teachers who are left to teach by themselves with only an occasional visit from a supervisor. Many teachers have stated that a curriculum manual, whatever the fleld may be, gives them the assurance which they need that they are teaching the requirements. When experience has brought confidence into a new teacher's personality, she seldom needs to consult the manual to any extent. Also, many older, more experienced teachers have often wondered whether or not they were on the right track. Doubtless, a complete guide with teaching suggestions such as are included here would have been of great help. As a result, it is recommended 
that a manual should not be merely a short outline of philosophy or objectives. It should contain all the alds and suggestions that teachers think worthy of inclusion in the manual.

2. There is no preferred sequence in which the curriculum material is presented. Today, when the mathematics of our secondary schools is in such a questionable state, it is rather difficult to agree upon the grade level at which most content material should be presented. There are so man variables encountered in each course to say that it would be ready for any previously selected experience unit. In conclusion, teachers should be left free to select the units or topics which they consider best. to meet the needs of the class at any particular point in its progress. However, the material selected by the teacher should have the same objectives and be consistent with the accepted philosophy of teaching.

3. Curriculum study, construction, and revision should be continuous. When a manual is considered finished, it ages quickly. To say that it is finished is to encourage complacency and discourage future investigation and study. Only by leaving it open to further inquiry and investigation as well as amendment can it be kept at the highest level of development and remain useful. There is always new material coming forth and this and more promising material should constantly replace older, less useful, out-of-date material, if curriculum development is to keep abreast of soclal development and the times. True, philosophy, objectives, and content are largely determined 
by the opinions of those engaged in curriculum construction. Consequently, it is necessary to recommend frequent investigations and inquiries into the state of opinions because points of view change rapidly.

4. Changes in method and content should be gradual. Conservative teachers often look with suspicion upon any recommendations for a change in method or content which may, in turn, be considered minor. Then, too, they often feject entirely big changes. Such a condition is no doubt brought on by the loss of security felt by the experienced teachers when familiar skills and knowledges are suddenly no longer of use to them. It means a reformation to them; they must start over in much the same manner that a beginning teacher does.

Therefore, the desired level of teaching should be compromised with that presently accepted. There are two answers here: the first is to make all changes gradually and, if possible, as a result of suggestions by teachers themselves; and the second is to promote in the teachers a sense of confidence in their supervisor and principal. It can help prevent any loss of security on their part if they know that purposeful experimentation will meet with praise, and that they will be considered capable teachers regardless of methods used.

5. Constant attention should be given to the orientation of the child. Children are naturally most concerned with their immediate surroundings, environment, and present needs. They need help in discovering the contributions that they themselves can make now to the welfare of the groups of 
which they, as individuals, are members. They need and want to achieve recognition as they are now, at their present state of physical and mental development. Youth can make real contributions to the welfare and success of their respective families, classes, or other groups. They are often serlous about their delegated objective. Teachers and parents should reciprocate in these attitudes and the role their children or students play in family or school life.

6. Cooperative planning in the preparation of such a manual is necessary. While such activity was not utilized to any great extent in this manual, opinions and suggestions have been sought at various times from members of the department. They have often been reflected in the body of the subject matter. Very little cooperative planning was used due to the pressure of time. However, with the possibility of a curriculum study group being organized at North Kingstown, it is suggested and anticipated by the writer that this present manual serve as a nucleus for future study and expansion of ldeas by a larger group. Oftentimes, a manual passed on by a supervisor or administrator to a new teacher is difficult to accept and use. Many teachers are willing to do so, but as a result, their teaching is very mechanical and subject-matter centered. Then, too, some teachers are devoted to method. They lose sight of valid objectives. It is felt that if teachers were to have worked on the manual's preparation they would necessarily consider both objectives and content.

If teachers share in the manual's preparation, they 
share the responsibility for its success. They find themselves in a position of defending themselves as well as their philosophy of teaching. Personal contributions make the added work and time spent in its preparation more worthwhile. Good teachers also contribute their personalities which often serve to inspire others, to stimulate critical thinking, and to promote friendly cooperation.

7. Should the teaching of any item of subject matter or the use of any special method of teaching be identified with the attalnment of any of the objectives of mathematics, the construction of a manual would be greatly simplified. It would still be necessary to state a philosophy and to determine obfectives. Howerer, the attainment of these objectives would become a more exacting sclence. The acquisition of certain skills and knowledges is already provided for by the inclusion of a certain amount of drill and the proper topics in the curriculum. Certainly necessary are surer, more positive and concrete methods of teaching certain attitudes, appreciations, and skills--both social as well as mathematical. 


\section{ACKNOWLEDGMENTS}

Without the encouragement, assistance and perseverance of Dr. Frank M. Pelton this study would never have been completed. It was also a result of his counsel and guidance that the program of graduate study was undertaken and followed through to completion. Many thanks and much appreciation are due him in particular and to the mathematics teachers of North Kingstown High who contributed in no small degree to the thoughts and 1deas behind the scenes of this manual.

Acknowledgment must also be made to the valuable assistance of my wife, who made me continue on, as well as state clearly every part of the thesis. Without her patience, assistance, and endurance it is difficult to see how this study could have been completed. 


\section{BIBLIOGRAPHY}

\section{General Reference Books}

American Association of School Administrators, Education for Family Life. 19th Yearbook, Washington, D. C.:National Education As sociation, 1941.

Amerioan School Curriculum. 3lst Yearbook, Washington, D. C. : National Education Assoclation, 1953.

Association for Supervision and Curriculum Development, Group Planning in Education. Yearbook, Washington, D. C.: National Education Association, 1945. , Leadership Through Supervision. Yearbook, Washington, D. C.: National Education Association, 1946. , Toward Better Teaching, Yearbook, Washington, D. C.: National Education Association, 1949. , What Shall the High Schools Teach? 1956 Yearbook, Washington, D. C.: National Education Ass oc iation, 1956.

Barr, A. S., Burton, William H., and Brueckner, Leo J., Supervision. New York: D. Appleton-Century, 1947

Breed, Frederick S., Education and the New Realism. New York: Charles Scribner's Sons, 1932.

Burton, William H., The Guidance of Hearing Activities. New York: D. Appleton-Century Co., 1944. Guidance of Major Specialized Learning Activity Within the Total Learning Activity. Cambridge: Harvard University Press, 1944.

Carr, E. R., Wesley, E. B., and Murra, W. F., "Social Studies," Encyclopedia of Educational Research. Walter S. Munroe (ed.). New York: The Macmilian Co., 1950.

Caswell, Hollis and Campbell, Doak S., Curriculum Development. New York: American Book Co., 1935.

Cox, P. W. L., Duff, J. C., and MeNamara, M. Basic Principles of Guidance. New York: Prentice-Hall, Inc., 1949. 
Cremin, L. A., and Borrowman, M. L., Public Schools in Our Democracy. New York: The Macmilian Co., 1956

Dewey, John. Democracy and Education. New York: Macmillan Co., 1917. ig $\frac{\operatorname{Exp}}{16}$

Educational Policies Commission. Education for All American Children. Washington 6, D. C.,: National Education Association, 1948.

The Purposes of Education in American Democracy. Washington 6, D. C.: National Education Association, 1938.

, Learning the Ways of Democracy: A Casebook of Civic Education. Washington 6, D. C.: NationaI Education Association, 1940.

Featherstone, William B. A Functional Curriculum for Youth. New York: American Book Co., 1950.

Fine, Benjamin. Democratic Education. New York: Crowell, 1946. Highet, Gilbert. The Art of Teaching. New York: Alfred A. Knopf, 1954.

Koopman, C. Robert, Miel, Alice, and Misner, Paul J., Democracy in School Administration. New York: D. Appleton-Century Co., 1943 .

Krug, Edward A., Curriculum Planning. New York: Harper and Brothers, 1950.

Lane, Howard and Beauchamp, Mary, Human Relations in Teaching. Englewood Cliffs, N. J.: Prentice-Hall, Inc., 1956.

Lee, Jonathan Murray and Lee, Doris May, Child and H1s Curriculum. 2nd ed. revised. New York: Appleton-Century-Crofts, 1950.

Olsen, Edward G., School and Community. New York: Prentice-Hall, 1945.

Spears, Harold, Curriculum Planning Through In-Service Prograns. Englewood Cliffs, N. J.: Prentice-Hall, Inc., 1957.

Wiles, Kimball. Supervision for Better Schools. New York: Prentice-Hali, Inc., 1950. 


\section{Instructional Materials, and Manuals}

GENERAL MATHEIMATICS

Buswell, G. T., Brownell, W. A., and John, L., Living Arithmetic, Grade 1. New York: Ginn and Co., 1943. $314 \mathrm{pp}$. Living Arithmetic, Grade 8. New York: Ginn and Co., 1943. $314 \mathrm{pp}$.

Clark, J. R., Schorling, R., and Smith, R. R., Arithmetic for Young America, Grade 7. revised edition. New York:

World Book Co., 1949.

- Arithmetic for Young America, Grade 8, revised edition, New York: World Book Co., 1949. $402 \mathrm{pp}$.

Grossnickle, F. E., General Mathematics. Philadelphia: The John c. Winston co., 1949. 362 pp.

Lasley, S. J., and Mudd, M. F., The New Applied Mathematics, 3rd. ed. New York: Prentice-Hali, Inc., 1945, $431 \mathrm{pp}$.

Nelson, G. D., and Grime, H. E., Making Mathematics Work. New York: Houghton Miffiln Co., $1950.630 \mathrm{pp}$.

Stein, E. I., Refresher Arithmetic. New York: Allyn and Bacon, 1951. $388 \mathrm{pp}$.

Upton, C. B., and Fuller, K. G., Arithmetic, Grade 1. New York: American Book Co., 1951. $328 \mathrm{pp}$.

, Arithmetic, Grade 8. New York: American Book Co., 1951. $360 \mathrm{pp}$.

FIRST COURSE ALGEBRA

Aiken, D. J., and Henderson, K. S., Algebra - Its Big Ideas and Basic Sk1l1s. New York: Harper and Brothers, 1950. $\overline{409}$ pp.

Hart, W. W., A First Course in Algebra. Boston: D. C. Heath and $\mathrm{Co} ., 1947.389 \mathrm{pp}$.

Lennes, N. J., and Maucker, J. W., A First Course in Algebra. 2nd. ed. New York: The Macmilian Co., 1949.561 pp.

Stein, E. I., Algebra in Easy Steps, enlarged ed. New York: News om and Co., 1949. $282 \mathrm{pp}$. 
Welchons, A. M., and Krickenberger, W. R., Algebra-Book One. Boston: Ginn and Co., 1953. $518 \mathrm{pp}$.

White, M. R., Elementary Algebra. New York: Allyn and Bacon, Inc., 1957. $460 \mathrm{pp}$.

PLANE GEOMETRY

Avery, Royal A., Plane Geometry. New York: Allyn and Bacon, Inc., $1950.460 \mathrm{pp}$.

Hart, Walter W. Pl Plane Geometry. Boston: D. C. Heath and Co., 1950. $382 \mathrm{pp}$.

Herberg, Theodore, and Orleans, Joseph B., A New Geometry. Boston: D. C. Heath and Co., 1940. 402 pp.

Morgan, F. M., Foberg, J. A., and Breckenridge, W. E., Plane Geometry. Boston: Houghton Mifflin Co., 1943. $4 \sqrt{45} \mathrm{pp}$.

Schorling, R. C., Clark, J. R., and Smith, R. R., Modern School Geometry. Yonkers-on-Hudson, New York: World Book Co., 1948. $436 \mathrm{pp}$.

Shute, W. G., Shirk, W. W., and Porter, G. F., Plane Geometry. New York: American Book Co., 1953. 407 pp.

Welchons, A. M., and Krickenberger, W. R., New Plane Geometry. Boston: Ginn and Co., 1952. 568 pp.

SECOND COURSE ALGEBRA

Aiken, D. J., and Henderson, K. B., Algebra - Its Big Ideas and Basic Skills. New York: Harper and Bros., 1950 409 pp.

Edgerton, E. I., and Carpenter, P. A., Intermediate Algebra. Boston: Allyn and Bacon, Inc., $1957.460 \mathrm{pp}$.

Hart, W. W., A Second Course in Algebra. Boston: D. C. Heath Co., 1947. $373 \mathrm{pp}$.

Lennes, N. J., and Maucker, J. W., A Second Course in Algebra. 2nd. ed. revi sed. New York: The Macmillan c0., 1950. $522 \mathrm{pp}$.

Stein, E. I., Algebra in Easy Steps, enlarged ed. New York: News om and Co., 1949. $282 \mathrm{pp}$.

Welchons, A. M., and Krickenberger, W. R., Algebra, Book Two. Boston: Ginn and Co., 1953. $518 \mathrm{pp}$. 
TRIGONOMETRY

Butler, C. H., and Wren, F. L., Trigonometry for Secondary Schools. New York: D. C. Heath and Co., 1948. $360 \mathrm{pp}$.

Mallory, V. S., New Trigonometry. Chicago: Benjamin H. Sanborn and Co., 1947. $264 \mathrm{pp}$.

Mills, C. N., and Atkin, E. I., and Flagg, E. B., Plane Prigonometry. New York: Scott, Foresman, and Co., 1937. $170 \mathrm{pp}$.

Sparks, F. W., and Rees, P. K., Plane Trigonometry. New York: Prentice-Hall, Inc., 1946. $179 \mathrm{pp}$.

Welchons, A. M., and Krickenberger, W. R. ' Trigonometry with Tables. Boston: Ginn and Co., 1957. $337 \mathrm{pp}$.

SOLID GEOMETRY

Avery, R. A., Solid Geometry. Boston: Allyn and Bacon, 1943. $212 \mathrm{pp}$.

Schorling, R., Clark, J. R., and Smith, R. R., Modern School Solld Geometry. Yonkers-on-Hudson, New York: World Book c0., 1949. 256 pp.

Shute, W. G., Shirk, W. W., and Porter, G. F., Solid Geometry. New York: American Book Co., 1953. 276 pp.

Welchons, A. M., and Krickenberger, W. R., Solid Geometry. Boston: Ginn and Co., 1952. $272 \mathrm{pp}$.

\section{Perlodicals}

Bruns, R. F., and Frazier, A., "Sequence and Range of High School Mathematics," Mathematics Teacher, I (December 1957), 562-566.

Bush, L. E., "Teacher Education in Mathematics," School Science and Mathematics, LVIII (January 1958), 32-34.

Cogan, E. J., "New Approach to High School Mathematics," Mathematics Teacher, I (May 1957), 347-349.

Edwards, P. D., "Teacher Education in Mathematics," School Science and Mathematics, LVIII (January 1958), 31-32.

Fawcett, H. P., "Better Mathematics Teaching, Where?", Mathematics Teacher, L (May 1957), 90-91. 
Hartung, M. L., "Trends in Secondary School Mathematics," School Science and Mathematics, LVIII (January 1958), 25-26.

Read, C. B., "What's Wrong with Mathematics?" School Science and Mathematics, IVIII (March 1958), 181-186.

Rourke, R. E. K., "Some Implications of Twentieth Century Mathematics for High Schools," Mathematics Teacher, LI (February 1958), 74-86.

4. Reports

College Entrance Examination Board. Program for College Preparatory Mathematics. A Report of the Commission on Mathematics. New York, 1959.

National Council of Teachers of Mathematics. Mathematics for the Academically Talented Student. A Report sponsored jointly by the N. E.A.Project on the Academically Talented Student and the National Council of Teachers of Mathematics. Washington 6, D. C. 1959.

Snader, D. W., Functional Mathematics. An Integrated Program for Grades Seven through Twelve. Prepared by Charles Scribner's Sons, Education Department. New York, 1959.

Brown, Kenneth E., Curriculum Materials in High-School Mathematics. Bulletin 1954, No.9, U. S. Department of Health, Education, and Welfare, Washington D. C. , Offerings and Enrollments in Science and Mathomatics in Public High Schools. J. S. Department of Health, Education, and Welfare, Washington D. C., 1956. Analysis of Research in the Teaching of Mathematics 1955 and 1956 . U. S. Department of Health, Education, and Welfare, Washington D. C., 1956.

U. S. Office of Education. Mathematics and Science Education in Public Schools. Circular No. 533. U. S. Department of Health, Education, and Welfare, Washington D. C., 1958. 